\title{
Unidad Didáctica: Who wants fracking in town?
}
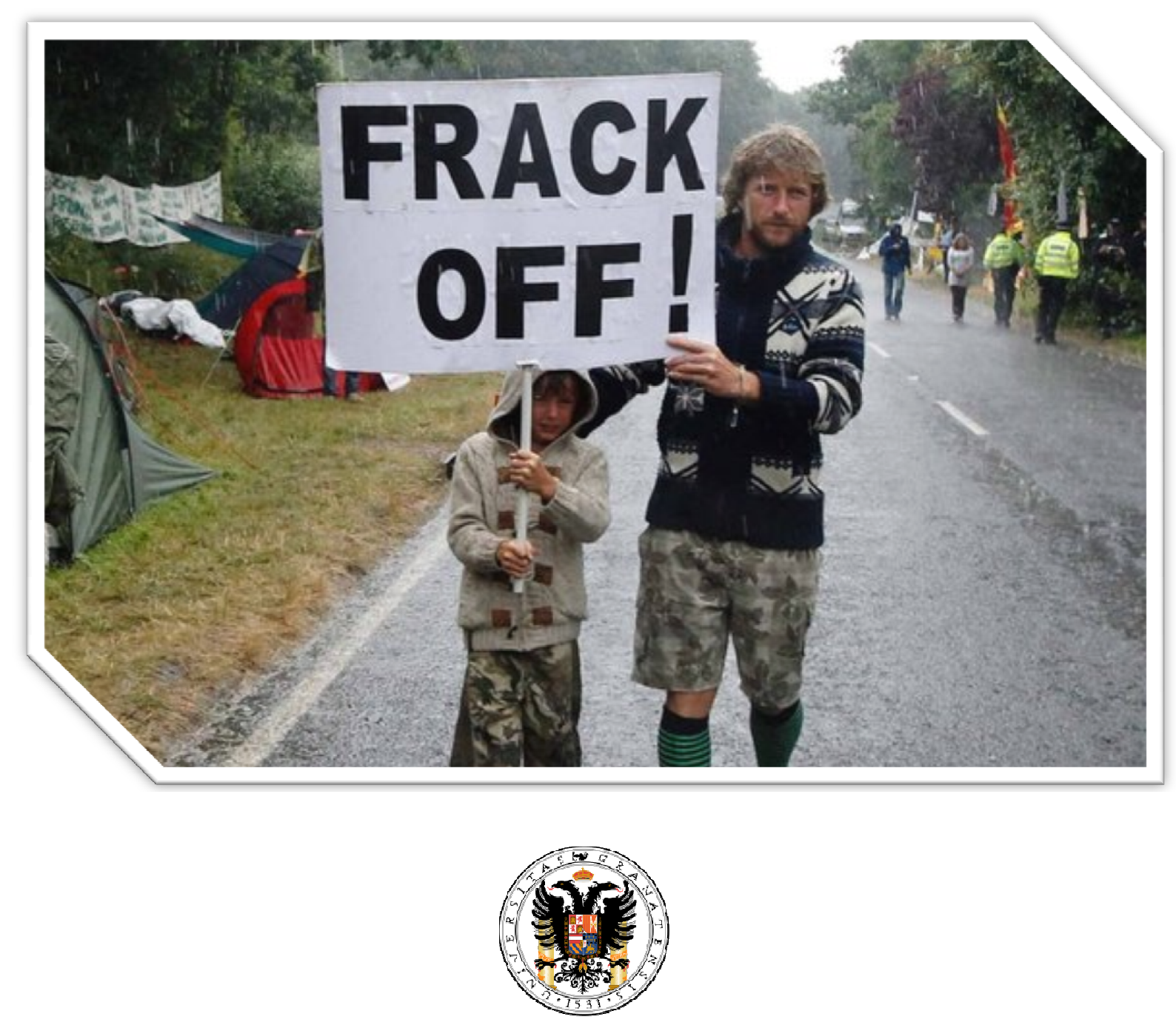

Universidad de Granada

Autor: Miguel Parra Sierra

Dirigido por: Javier Carrillo y David Gallego 
Unidad Didáctica: Who wants fracking in town? 2015 
RESUMEN: El presente documento consiste en una unidad didáctica diseñada para trabajar temas como los problemas medio ambientales, los ciclos de la materia y las herramientas de gestión ambiental para $2^{\circ}$ de Bachillerato de la materia de Ciencias de la Tierra y del Medioambiente. La metodología propuesta combina aspectos del enfoque Ciencia-Tecnología-Sociedad(-Ambiente) y de aprendizaje cooperativo con lo que se pretende despertar un espíritu crítico en el alumnado, al mismo tiempo que se promueve la cooperación. Así, a lo largo de la unidad didáctica se utiliza como hilo conductor el fenómeno del fracking, un tema de actualidad y controvertido que sirve para ilustrar los conflictos de interes existentes alrededor de muchos problemas ambientales. Además, está diseñada para su aplicación en centros bilingües (o plurilingües) en los que, a través de un enfoque Aprendizaje Integrado de Contenidos y Lenguas Extranjeras" (AICLE), se prepare al alumnado para un mundo cada vez más global, en el que manejar con soltura alguna lengua extrangera se torna algo fundamental.

PALABRAS CLAVE: Unidad Didáctica; Fracking; Fracktura Hidráulica; Ciencia, Tecnología, Sociedad y Medioambiente (CTSA); Aprendizaje Cooperativo; Aprendizaje Integrado de Contenidos y Lenguas Extranjeras (AICLE).

ABSTRACT: The present document consits in a teaching unit designed to work on subjects such as environmental problems, the cycles of matter and Environmental Management Tools for $2^{\text {nd }}$ year of Bachillerato on the subject of Sciences of the earth and the environment. The proposed methodology combine aspects of Science-Technology-Society and cooperative learning, in order to awaken critical thinking in students, while cooperation is promoted. Thus, along this teaching unit the phenomenon of fracking is used as a common thread, a controversial and topical issue that is usefull for illustrate the conflicts of interest that exist around many environmental problems. Besides, it is designed to be applied in bilingual (or multilingual) centers where, through CLIL approaches, students will be prepared for an increasingly global world, in which handle with some foreign language becomes something essential.

KEY WORDS: Teaching unit; Fracking; Hydraulic fracturing; Science, Technology and Society (STS); Cooperative learing; Content and Language Integrated Learning (CLIL). 
Unidad Didáctica: Who wants fracking in town? 2015 


\section{ÍNDICE}

$\begin{array}{ll}\text { 1. Introducción } & 7\end{array}$

2. Fundamentación Teórica $\quad 8$

$\begin{array}{ll}\text { 2.1 Fundamentación Científica } & 8\end{array}$

2.1.1 El Ciclo del Carbono 9

2.1.2 Extracción de hidrocarburos por fracturación hidráulica 15

$\begin{array}{ll}\text { 2.2 Fundamentación Didáctico-pedagógica } & 19\end{array}$

$\begin{array}{ll}\text { 2.2.1 CLIL } & 19\end{array}$

2.2.2 Alfabetización Científica y CTSA 23

$\begin{array}{ll}\text { 2.2.3 Aprendizaje Cooperativo } & 27\end{array}$

3 Marco Legislativo $\quad 29$

4 Contextualización $\quad 31$

$\begin{array}{ll}4.1 \text { Curso } & 31\end{array}$

$\begin{array}{ll}\text { 4.2 Características del Centro } & 31\end{array}$

$\begin{array}{ll}\text { 4.3 Características del Alumnado } & 31\end{array}$

4.4 Ubicación en la Programación 34

4.5 Temporalización 35

5 Objetivos $\quad 36$

6 Competencias $\quad 37$

7 Contenidos $\quad 38$

$\begin{array}{ll}\text { 7.1 Big Ideas } & 39\end{array}$

7.2 Ideas Previas $\quad 40$

7.3 Contenido Transversal 42

8 Metodología $\quad 44$

8.1 Modelos Didácticos 44

8.2 Orientaciones metodológicas 45 
8.2.1 CTSA

8.2.2 Aprendizaje Cooperativo

8.2.3 CLIL

8.3 Recursos

8.4 Atención a la Diversidad

8.5 Actividades

8.5.1 Fase 0

8.5.2 Fase 1.1

8.5.3 Fase 2

8.5.4 Fase 1.2

8.5.5 Fase 3

8.5.6 Fase 4

8.6 Evaluación

8.6.1 Evaluación Inicial

8.6.2 Evaluación Formativa

8.6.3 Evaluación Sumativa

8.6.4 Heteroevaluación

8.6.5 Autoevaluación

8.6.6 Coevaluación

8.6.7 Criterios de Evaluación

8.6.8 Procedimientos e Instrumentos de Evaluación

8.6.9 Criterios de Calificación

8.7 Relación entre los Elementos de la Unidad Didáctica

9 Bibliografía

9.1 Páginas Web
46

48

49

51

52

53

54

56

61

62

63

64

65

65

66

66

66

67

67

67

69

70

72

73

80

83

10 Anexos 


\section{INTRODUCCIÓN}

Este TFM consiste en una Unidad Didáctica para la materia de Ciencias de la Tierra y del Medioambiente de $2^{\circ}$ curso de Bachillerato, en el marco legislativo de la LOE (Referencia). El eje vertebrador de esta unidad didáctica es el estudio de la fracturación hidráulica, comúnmente conocida como Fracking. Esta actividad está de actualidad debido a su incipiente aplicación en nuestro país, aunque lleva décadas aplicándose en otros países como Estados Unidos. Además, viene rodeada de una fuerte polémica que pone de manifiesto los conflictos de intereses que existen en torno a los problemas ambientales, al plantearse una disyuntiva (a menudo engañosa) entre progreso económico y protección del medio ambiente.

Este hilo conductor sirve de ejemplo para tratar distintos contenidos: los impactos ambientales, los ciclos de la materia, la sostenibilidad, las legislaciones ambientales, evaluaciones de impacto ambiental y ordenación del territorio. Con la ventaja de que son abordados desde la aplicación a un contexto actual de relevancia, que permita al alumnado ${ }^{1}$ establecer una conexión entre los temas tratados en el aula y el entorno en el que viven.

Esta unidad didáctica pretende ser de utilidad para el alumnado, dotándole de herramientas que le permitan desenvolverse en la sociedad contemporánea. En este sentido, se trabaja con un enfoque de Ciencia-Tecnología-Sociedad(Ambiente) (CTSA), que favorece el desarrollo de un pensamiento crítico, a la vez que permite abordar los conocimientos teóricos aplicándolos al mundo real. Otro aspecto importante es la puesta en valor de la cooperación, como forma de contrarrestar la competitividad y aislamiento del individuo imperantes, fomentado mediante la aplicación de técnicas de aprendizaje cooperativo. Por último, en un mundo globalizado es fundamental el manejo de varios idiomas, tanto para comunicarse en el campo de lo personal, como para tener acceso a una mayor variedad de información (y por tanto de perspectivas). El idioma internacional más extendido en occidente es el inglés, por lo que la perspectiva Aprendizaje Integrado de Contenidos y Lenguas Extranjeras (AICLE ${ }^{2}$, en inglés, corresponde con el quizás más popularizado "Content and Language Integrated Learning" CLIL) aquí utilizada, es un valor añadido a la formación de los ciudadanos del mañana, que serán necesariamente más globales.

\footnotetext{
${ }^{1}$ A lo largo del TFM se hace uso, en la medida de lo posible, de términos de género neutro (alumnado). No obstante, con el fin de evitar repeticiones o ralentizar la lectura, se intenta huir del desdoblamiento del lenguaje (alumnos/alumnas), recurriendo en estos casos al masculino genérico (alumnos). Esta práctica no está considerada como un uso sexista del lenguaje (Bosque, 2012), y considero que su aportación a la invisibilización de la mujer es mínimo.

${ }^{2}$ En adelante nos referiremos a esta perspectiva por sus siglas en inglés: CLIL.
} 


\section{FUNDAMENTACIÓN TEÓRICA}

\subsection{Fundamentación Científica}

Actualmente, tanto el calentamiento global, como el cambio climático que éste supone, son fenómenos innegables. Desde mediados del siglo XX se observan cambios sin precedentes que lo evidencian, como son el calentamiento de la atmósfera y los océanos, la disminución de la superficie cubierta de hielo y nieve en el globo, y el aumento del nivel del mar (Pachauri et al., 2014). Este cambio del clima a nivel global se debe, en gran medida, al aumento de la concentración de gases de efecto invernadero (GHG), principalmente el dióxido de carbono $\left(\mathrm{CO}_{2}\right)$, el metano $\left(\mathrm{CH}_{4}\right)$ y el óxido nitroso $\left(\mathrm{N}_{2} \mathrm{O}\right)$ en la atmósfera terrestre. La concentración de estos gases ha aumentado significativamente desde el inicio de la Era Industrial, cuyo inicio está establecido en 1750, debido al gran crecimiento tanto económico como poblacional que se ha tenido lugar desde entonces (Ciais et al., 2014).

Según indica el último informe del Panel Intergubernamental sobre el Cambio Climático (IPCC) con fecha 2013, la emisión antropogénica de estos gases sigue siendo la principal causa del cambio climático, ya que juntos suman el $80 \%$ del forzamiento radiativo (balance entre la radiación incidente y la expulsada de la atmósfera) que produce el conjunto de todos los GHG (Ciais et al., 2014). A escala global, estos cambios son consecuencia de las emisiones asociadas al uso de la energía (especialmente los combustibles fósiles), mientras que a nivel regional y local, la urbanización y el cambio en los usos del suelo son los motivos más importantes (Karl y Trenberth, 2003). Sin embargo, las variaciones de $\mathrm{CO}_{2}$ registradas desde entonces responden, no solo a las actividades humanas, sino también a procesos biogeoquímicos y climatológicos y sus interacciones con el ciclo del carbono (Falkowski et al, 2000). Así, el cambio observado en las concentraciones atmosféricas de $\mathrm{CO}_{2}, \mathrm{CH}_{4}$ y $\mathrm{N}_{2} \mathrm{O}$ resulta del balance entre las emisiones antropogénicas, y la perturbación de los procesos naturales que producen la eliminación parcial de estos gases de la atmósfera (Ciais et al., 2014).

En las últimas décadas estamos presenciando los impactos que el cambio climático tiene sobre los sistemas naturales y humanos. Desde 1950 se vienen observando cambios en los fenómenos climáticos extremos, como el aumento de las máximas y descenso de las mínimas temperaturas, aumento del nivel máximo del mar, un incremento en el número de fuertes precipitaciones en numerosas regiones, entre otras (Pachauri et al., 2014) 


\section{Unidad Didáctica: Who wants fracking in town? 2015}

Dada la actual tendencia en materia de demanda energética, las amplias reservas de combustibles fósiles, la falta de conciencia global para un cambio de modelo energético, y las predicciones de crecimiento de la población humana, las concentraciones de GHG parecen abocadas a aumentar durante los próximos siglos (Falkowski et al, 2000). Existen numerosas evidencias de que, en caso de continuar estas emisiones, aumentarán las posibilidades de un impacto irreversible y severo sobre los ecosistemas y las personas (Pachauri et al., 2014). Estos impactos producirán un mayor calentamiento global, así como cambios duraderos en todos los componentes del sistema climático (incluido el ciclo del carbono), que darán lugar a un mayor aumento de las temperaturas y precipitaciones extremas, disminución del hielo y la nieve estacional y polar, aumento del nivel del mar, entre otros. (Karl y Trenberth, 2003).

A pesar de los progresos en materia de monitorización y comprensión del cambio climático, todavía existen muchos impedimentos científicos, técnicos e institucionales a la hora de planificar las medidas de adaptación y mitigación de los efectos del cambio climático (Karl y Trenberth, 2003). En este escenario, es fundamental entender las causas y consecuencias de estos problemas ambientales para tomar medidas que afectarán a nuestra civilización durante generaciones (Falkowski et al, 2000).

En vista de la situación planteada hasta ahora, se hace evidente la importancia del problema del cambio climático, así como la necesidad de concienciar a todos los estratos de la población al respecto. De este modo, uno de los principales propósitos de este TFM es transmitir estas ideas al alumnado de bachillerato, que además de ciudadanos, serán los científicos, técnicos y gestores del futuro. En la presente unidad didáctica nos centraremos en el ciclo del carbono, dentro del cual se considera tanto el dióxido de carbono como el metano, puesto que estos son los GHG más relevantes desde un punto de vista tanto cuantitativo como cualitativo.

\subsubsection{El ciclo del carbono}

Los GHG representan la fase gaseosa de diversos ciclos biogeoquímicos globales, los cuales controlan los flujos y las transformaciones de los elementos $(C, N, P$, etc.) entre los distintos compartimentos del Sistema Terrestre (atmósfera, biosfera, océanos, y suelos y litosfera), producidos por procesos bióticos y abióticos. Dado que estos procesos están ligados al medio ambiente, los cambios en el clima y el impacto del ser humano en los 
ecosistemas (por ejemplo el uso del suelo o los cambios en el uso de las tierras) modifican la concentración atmosférica de los GHG. Por tanto, podemos concluir que los procesos climáticos y el ciclo biogeoquímico de elementos como el carbono están íntimamente relacionadas (Ciais et al., 2014). La Figura 2.1 muestra un esquema del ciclo del carbono:

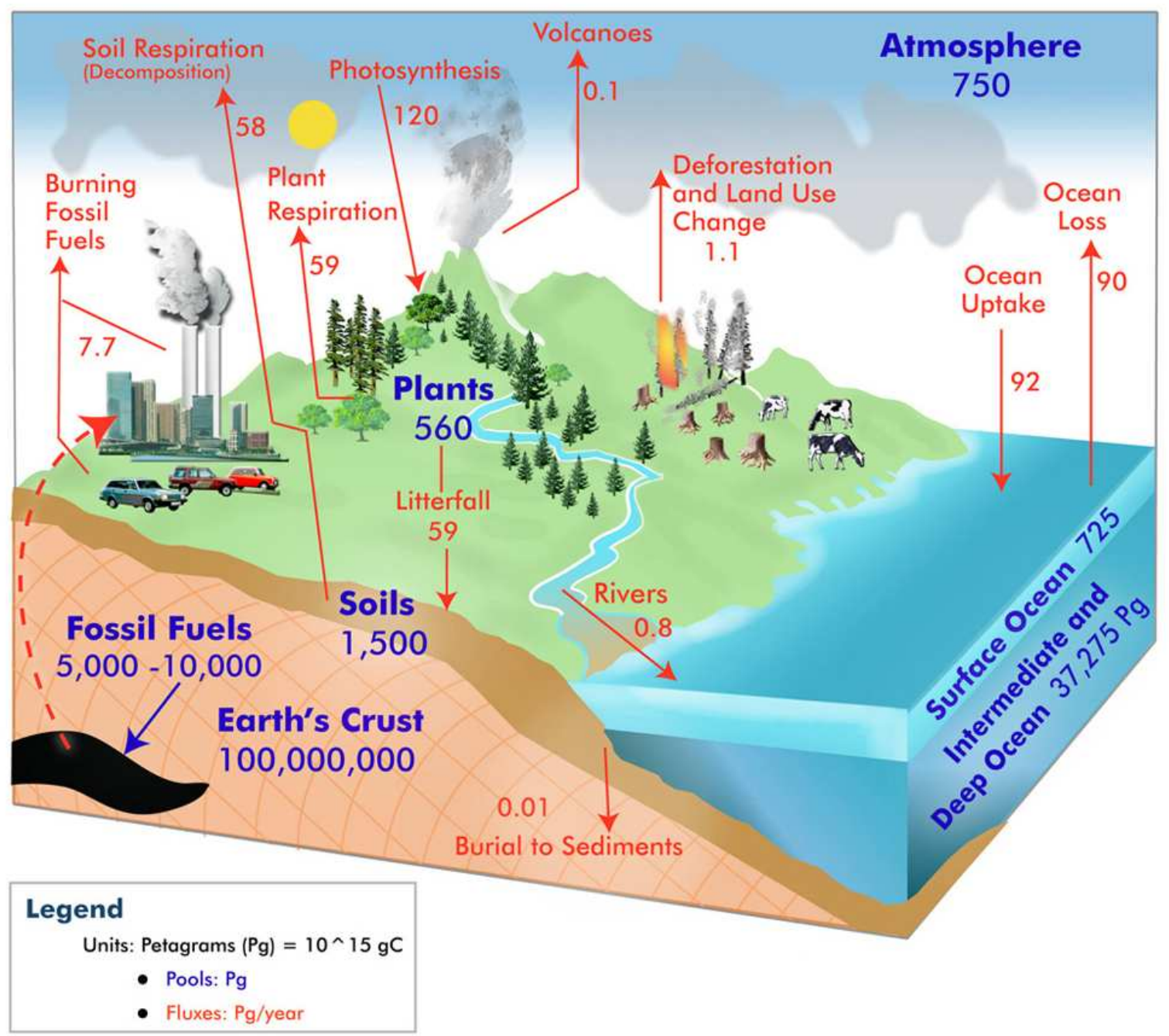

Copyright 2010 GLOBE Carbon Cycle Project, a collaborative project between the University of New Hampshire, Charles University and the GLOBE Program Office. Data Sources: Adapted from Houghton, R.A. Balancing the Global Carbon Budget. Annu. Rev. Earth Planet. Sci. 007.35:313-347, updated emissions values are from the Global Carbon Project: Carbon Budget 2009. Figura 2.1. Esquema del ciclo de carbono. En azul se presentan los reservorios de carbono $(\mathrm{PgC})$ y en rojo los flujos (Las unidades se expresan en $\mathrm{PgC} / \mathrm{año}$ ). 1 Petagramo $(\mathrm{PgC})=10^{15} \mathrm{gC}$. [1]

Durante los 7.000 años anteriores a 1750, las concentraciones tanto de $\mathrm{CO}_{2}$ como de $\mathrm{CH}_{4}$ reveladas por los testigos de hielo muestran un incremento muy lento (de 260 a 280 ppm para el $\mathrm{CO}_{2}$ ), en contraste con el incremento de estos gases causado por el ser humano a partir de la era preindustrial. La contribución de los cambios del uso de la tierra en las primeras etapas de la humanidad es insuficiente para explicar este incremento anterior a 1750. Retrocediendo aún más en el tiempo, durante los 800.000 años anteriores a 1750, la mayor variación de concentración en $\mathrm{CO}_{2}$ atmosférico registrada fluctúa entre 180 ppm 


\section{Unidad Didáctica: Who wants fracking in town? 2015}

durante periodos glaciales hasta las 300 ppm durante periodos interglaciares (Ciais et al., 2014).

Fue con la llegada de la revolución industrial, en torno al año 1750, cuando la velocidad de aumento de las concentraciones de los principales GHG aumentó a nivel global. Las concentraciones de $\mathrm{CO}_{2}$ aumentaron en un 40\%, pasando de $278 \mathrm{ppm}$ alrededor de $1750 \mathrm{a}$ 390.5 ppm en 2011, mientras que las de metano aumentaron en un $150 \%$, pasando de 722 ppb a 1803 ppb en el mismo periodo. Es inequívoco que la actual concentración de $\mathrm{CO}_{2}$ en la atmósfera excede los niveles medidos para al menos los últimos 800.000 años, el periodo registrado por los testigos de hielo. Además, el ritmo de aumento de los GHG y en concreto de $\mathrm{CO}_{2}$ y metano observados a lo largo del siglo pasado supera cualquier tasa de incremento de los últimos 20.000 años (Ciais et al., 2014).

Las emisiones antropogénicas de $\mathrm{CO}_{2}$ fueron de $555 \pm 85 \mathrm{PgC}\left(1 \mathrm{PgC}=10^{15} \mathrm{gC}\right)$ entre 1750 y 2011. La Tabla 2.1 muestra el origen y la cuantía de estas emisiones, desde la revolución industrial y en los últimos años. Como se puede observar, las dos fuentes principales de emisiones son la quema de combustibles fósiles y la producción de cemento, junto con el cambio del uso del suelo, incluyendo la deforestación y reforestación (Ciais et al., 2014).

Tabla 2.1. Balance del $\mathrm{CO}_{2}$ antropogénico global, acumulado desde 1750, y de media en el periodo 2002-2011. El flujo tierra-atmósfera es el resultado del balance entre el cambio del uso del suelo y el sumidero terrestre residual. (Ciais et al., 2014)

\begin{tabular}{|c|c|c|}
\hline & $\begin{array}{c}\text { Acumulación en el periodo } \\
\mathbf{1 7 5 0 - 2 0 1 1}(\mathbf{P g C})\end{array}$ & $\begin{array}{c}\text { Periodo 2002-2011 } \\
\text { (PgC/año) }\end{array}$ \\
\hline Incremento en la atmósfera & $240 \pm 10$ & $4,3 \pm 0,2$ \\
\hline $\begin{array}{c}\text { Quema de combustible fósiles y } \\
\text { producción de cemento }\end{array}$ & $375 \pm 30$ & $8,3 \pm 0,7$ \\
\hline Flujo océano-atmósfera & $-155 \pm 30$ & $-2,4 \pm 0,7$ \\
\hline Flujo tierra-atmósfera & $30 \pm 45$ & $-1,6 \pm 1,0$ \\
\hline Cambio en los usos del suelo & $180 \pm 80$ & $0,9 \pm 0,8$ \\
\hline Sumidero terrestres residual & $-160 \pm 90$ & $-2,5 \pm 1,3$ \\
\hline
\end{tabular}

EI IPPC atribuye, con un grado muy alto se seguridad, el aumento observado en las concentraciones de $\mathrm{CO}_{2}$ atmosférico a las emisiones provenientes de la quema de 
combustibles fósiles y a los cambios en el uso del suelo. En la Figura 2.2 vemos como alrededor de la mitad de estas emisiones $(240 \pm 10 \mathrm{PgC})$ siguen en la atmósfera desde 1750, el resto ha sido eliminado de la atmósfera por distintos sumideros y almacenado en los reservorios del ciclo natural del carbono: $155 \pm 30 \mathrm{PgC}$ almacenados en los océanos, y $160 \pm 90 \mathrm{PgC}$ en la biomasa y los suelos no afectados por los cambios de uso del suelo citados anteriormente (Ciais et al., 2014).
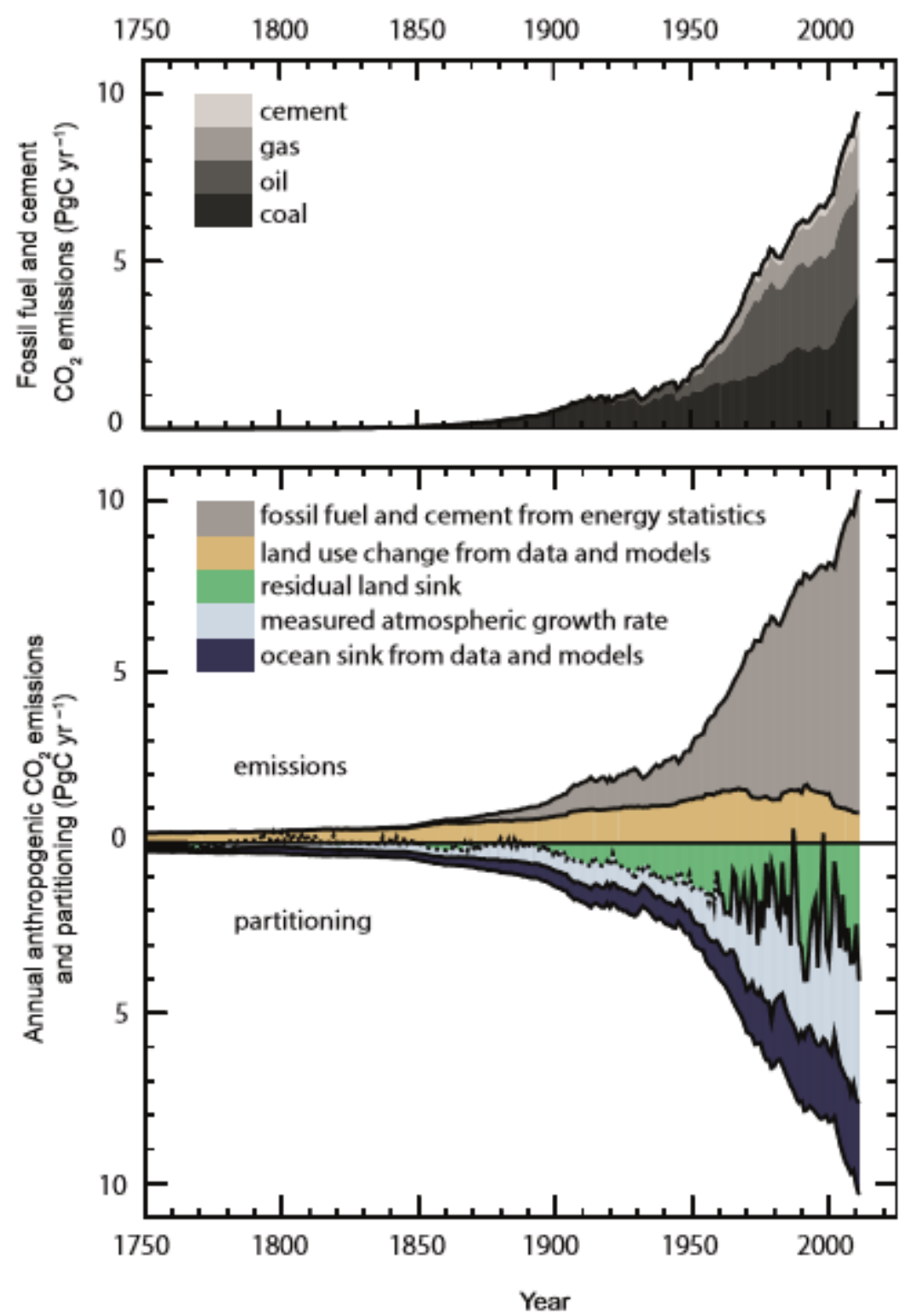

Figura 2.2. (Arriba) Emisiones antropogénicas de $\mathrm{CO}_{2}$ por producción de cemento y quema de combustibles fósiles por categorías. (Abajo) Emisiones antropogénicas de $\mathrm{CO}_{2}$ anuales y su reparto entre atmósfera, suelo y océanos (PgC/año) desde 1750 hasta 2011. (Ciais et al., 2014)

Las emisiones antropogénicas de $\mathrm{CO}_{2}$ provenientes de la combustión de combustibles fósiles y la producción de cemento aumentaron más rápidamente durante el periodo 2000- 


\section{Unidad Didáctica: Who wants fracking in town? 2015}

2011 que en el pasado. En cuanto a las emisiones debidas al cambio en el uso del suelo disminuyeron con respecto a la década anterior (Ciais et al., 2014).

En cuanto al metano, tras una década de estabilidad en sus concentraciones desde finales de los noventa, las mediciones atmosféricas muestran un repunte de las concentraciones desde 2007. La Tabla 2.2 muestra claramente que las principales fuentes de emisión de este gas son los humedales; la agricultura (principalmente arroz), ganadería y residuos; las relacionadas con los combustibles fósiles; otras emisiones naturales; y la quema de biomasa y biocombustibles. De éstas, entre el 50 y el $65 \%$ son de origen humano, mientras que la cantidad de $\mathrm{CH}_{4}$ proveniente de depósitos fósiles (por causas naturales o humanas) suman el $30 \%$ del total de emisiones (Ciais et al., 2014).

Tabla 2.2. Estimación de las emisiones de metano por fuentes (Ciais et al., 2014)

\begin{tabular}{|c|c|}
\hline Fuente de emisión de metano & Emisiones anuales estimadas $\left(\mathrm{TgCH}_{4} / \mathbf{a n ̃ o}\right)$ \\
\hline Humedales & $177-284$ \\
\hline Agricultura, ganadería y residuos & $187-224$ \\
\hline Combustibles fósiles & $85-105$ \\
\hline Otras emisiones naturales & $61-200$ \\
\hline Quema de biomasa y biocombustibles & $32-39$ \\
\hline
\end{tabular}

De acuerdo con diferentes modelos de proyección con los que se trabaja en el informe del IPCC sobre "Carbono y otros ciclos biogeoquímicos" (Ciais et al., 2014), el ciclo del carbono sufriría una serie de cambios, descritos a continuación, en los próximos años.

- Los océanos seguirán captando el $\mathrm{CO}_{2}$ de origen antropogénico emitido a la atmósfera.

- La captación de carbono por parte de la tierra es incierta.

- El aumento de la temperatura compensará el aumento del carbono secuestrado en los sumideros terrestres y oceánicos a causa del aumento de las emisiones de $\mathrm{CO}_{2}$.

- La escasez de nutrientes derivada del cambio climático limitará el efecto de los sumideros terrestres de $\mathrm{CO}_{2}$.

- Teniendo en cuenta el ciclo del carbono y los cambios en el clima se puede cuantificar las emisiones de combustibles fósiles compatibles con cada escenario. Éstas varían de $270 \mathrm{PgC}$ en el mejor de los casos hasta los $1685 \mathrm{PgC}$ en el más pesimista. 
- La reducción en la extensión del permafrost provocará que se deshiele parte del carbono $\left(\mathrm{CO}_{2}\right.$ y $\left.\mathrm{CH}_{4}\right)$ que contiene, sin embargo no está clara la magnitud de este flujo de carbono hacia la atmósfera.

- El aumento de la temperatura y las concentraciones de $\mathrm{CO}_{2}$ pueden provocar la liberación de metano en los humedales.

- El aumento del almacenamiento de $\mathrm{CO}_{2}$ en los océanos continuará acidificándolos, prosiguiendo con la tendencia actual.

Es muy probable que el ciclo físico y biogeoquímico del carbono en océanos y en la tierra continúe respondiendo al cambio climático y aumentando las concentraciones de $\mathrm{CO}_{2}$ creadas durante el siglo XXI. Así mismo, la acidificación de los océanos continuará aumentando en el futuro mientras el océano siga absorbiendo $\mathrm{CO}_{2}$ atmosférico. Los cambios en el ciclo del carbono de los ecosistemas terrestres acontecidos se manifestarán más allá del siglo XXI. Además, se seguirán derritiendo grandes áreas de permafrost durante siglos (Ciais et al., 2014).

La magnitud y el signo de la respuesta de los reservorios de carbono naturales a los cambios en el clima varían sustancialmente dependiendo de la escala temporal. Sin embargo, la respuesta de éstos al aumento de $\mathrm{CO}_{2}$ es aumentar la absorción de esta sustancia en océanos y reservorios terrestres, independientemente de la escala temporal (Ciais et al., 2014). La eliminación del $\mathrm{CO}_{2}$ emitido por el hombre a la atmósfera por parte de procesos naturales tardará cientos de miles de años. Dependiendo del escenario, entre el 15 y el $40 \%$ del $\mathrm{CO}_{2}$ emitido permanecerá en la atmósfera por más de 1.000 años, lo que lo convierte en un proceso irreversible a escala humana (Ciais et al., 2014).

Aunque bien es cierto que existen métodos de Eliminación de Dióxido de Carbono (CDR), que podrían teóricamente contribuir a la reducción de los niveles de $\mathrm{CO}_{2}$ atmosférico, esto métodos sufren grandes limitaciones biogeoquímicas y técnicas, por lo que la confianza en ellos es baja (Ciais et al., 2014). En la Tabla 2.3 se muestran algunas de estos métodos. 


\section{Unidad Didáctica: Who wants fracking in town? 2015}

Tabla 2.3. Ejemplos de métodos CDR y sus efectos sobre el ciclo del carbono. (Ciais et al., 2014)

\begin{tabular}{|c|c|c|c|}
\hline $\begin{array}{c}\text { Proceso del ciclo del carbono } \\
\text { a modificar }\end{array}$ & $\begin{array}{l}\text { Nombre del método } \\
\text { CDR }\end{array}$ & Lugar de almacenamiento & $\begin{array}{l}\text { Implicaciones sobre ciclo } \\
\text { del carbono y el clima }\end{array}$ \\
\hline $\begin{array}{l}\text { Producción biológica } \\
\text { mejorada y almacenamiento } \\
\text { terrestre }\end{array}$ & $\begin{array}{l}\text { Reforestación } \\
\text { Mejora de la gestión } \\
\text { forestal } \\
\text { Secuestro de madera en } \\
\text { edificios } \\
\text { Enterramiento de } \\
\text { biomasa } \\
\text { Siembra directa } \\
\text { Uso de carbón vegetal en } \\
\text { los suelos } \\
\text { Agricultura conservativa } \\
\text { Fertilización de plantas } \\
\text { terrestres } \\
\text { Creación de humedales }\end{array}$ & $\begin{array}{l}\text { Tierra (como biomasa, suelo } \\
\text { o humedales) } \\
\text { Océanos (superficie } \\
\text { oceánica, formaciones } \\
\text { geológicas) }\end{array}$ & $\begin{array}{l}\text { Alteración del albedo y la } \\
\text { evapotranspiración } \\
\text { Poca permanencia/ } \\
\text { potencialmente } \\
\text { permanentes en el caso de } \\
\text { enterrarse en el fondo } \\
\text { oceánico y en reservorios } \\
\text { geológicos }\end{array}$ \\
\hline $\begin{array}{c}\text { Producción biológica } \\
\text { mejorada y almacenamiento } \\
\text { en océanos }\end{array}$ & $\begin{array}{l}\text { Fertilización del océano } \\
\text { con hierro } \\
\text { Cultivo y enterramiento de } \\
\text { algas } \\
\text { Carbón "azul" (manglares } \\
\text { y cultivo de algas) } \\
\text { Modificar los } \\
\text { afloramientos oceánicos } \\
\text { para reflotar nutrientes }\end{array}$ & Océanos & $\begin{array}{l}\text { Amplias regiones con baja } \\
\text { concentración de oxígeno } \\
\text { Excesiva producción de } \\
\mathrm{N}_{2} \mathrm{O} \\
\text { Acidificación de los } \\
\text { océanos } \\
\text { Alteración de ecosistemas } \\
\text { marinos } \\
\text { Alteraciones del ciclo } \\
\text { regional del carbono }\end{array}$ \\
\hline Meteorización acelerada & $\begin{array}{l}\text { Favorecer la } \\
\text { meteorización en el suelo } \\
\text { Favorecer la } \\
\text { meteorización en el } \\
\text { océano }\end{array}$ & $\begin{array}{l}\text { Suelos } \\
\text { Océanos }\end{array}$ & $\begin{array}{l}\text { Eliminación permanente } \\
\text { Alteración del pH de suelos } \\
\text { y océanos }\end{array}$ \\
\hline Otros & $\begin{array}{l}\text { Captura directa con } \\
\text { almacenamiento }\end{array}$ & $\begin{array}{l}\text { Océanos } \\
\text { Formaciones geológicas }\end{array}$ & $\begin{array}{l}\text { Eliminación permanente si } \\
\text { se almacena en reservorios } \\
\text { geológicos }\end{array}$ \\
\hline
\end{tabular}

\subsubsection{Extracción de hidrocarburos por fracturación hidráulica o "Fracking"}

Como hemos visto, las dos principales fuentes de emisión de $\mathrm{CO}_{2}$ y $\mathrm{CH}_{4}$ a la atmósfera por parte del ser humano son la quema de combustibles fósiles y los cambios en los usos del suelo. A lo largo de esta unidad didáctica se abordará el estudio de una controvertida técnica de extracción de hidrocarburos conocida como fracturación hidráulica, o "fracking", como hilo conductor de la misma. La elección de este tópico se debe a que es un tema de actualidad, que está relacionado con las dos principales fuentes antrópicas de emisión de GHG, lo cual encaja con el enfoque CTSA con el que se trabajará. 
La fracturación hidráulica es una técnica de extracción de gas natural y petróleo de manera no convencional, que permite extraer estos hidrocarburos de yacimientos que no eran rentables hasta la época. Los yacimientos sobre los que se aplica esta técnica son principalmente de pizarra. La técnica consiste en la estimulación de una bolsa de hidrocarburos, alojada en la matriz de una de estas rocas, mediante el bombeo de un fluido formado por numerosas sustancias químicas (al menos 260 (Greenpeace, s.f.)) junto con un material apuntalante (material que impide que las grietas provocadas por la fractura se cierren al terminar el bombeo, generalmente arena u óxido de aluminio) a altas presiones, con el objetivo de fracturar la roca que contiene el hidrocarburo. La inyección de estas sustancias se hace a través de numerosos pozos horizontales excavados en el terreno (Broderick et al., 2011).

El primer experimento sobre fracking fue realizado, en Estados Unidos en 1947, y el proceso fue aceptado comercialmente en 1950. Desde entonces su popularidad ha ido aumentando, estimándose 1 millón de fracturas solo en EEUU (King, 2012). En Europa existen países como Polonia, Francia, Noruega, Suecia y Ucrania cuyo potencial para este tipo de extracción es muy alto (Energy Information Administration, 2011). Sin embargo, la postura de los países de la UE con respecto a esta técnica son muy diferentes: Francia, Alemania, Bulgaria e Irlanda del Norte han prohibido esta actividad o han suspendido temporalmente las licencias de explotación, mientras que Reino Unido, Polonia y España la permiten. En el caso de España, existen proyectos de prospección en varias comunidades, entre ellas Andalucía (Rubio, 2012).

La controversia sobre si se debe o no utilizar la fracturación hidráulica como método de extracción de hidrocarburos ha trascendido el ámbito científico. Los argumentos en contra de esta actividad se centran en el potencial impacto negativo que tendría sobre la salud pública, el medio ambiente y las comunidades más próximas a las zonas de extracción (más abajo se detallan). Por otro lado, los científicos que se sitúan a favor señalan que el fracking supondría un mayor crecimiento económico, creación de empleos, seguridad en el abastecimiento energético doméstico y facilitaría una transición rápida hacia formas de generar electricidad más limpias que las basadas en el carbón y el petróleo (Boudet et al., 2014). Sin embargo, un estudio realizado por el Tyndall Centre de la Universidad de Manchester (Broderick et al., 2011) concluye que la fracturación hidráulica, no solo no supondría una reducción de la emisiones de GHG, sino que podría incluso aumentarlas. 
Entre los impactos derivados de la fracturación hidráulica se encuentran:

- Consumo de agua. Una actuación media consume entre 54000 y $174000 \mathrm{~m}^{3}$ de agua, solo durante el primer proceso de fracturación (Broderick et al., 2011). Esto podría causar problemas de sostenibilidad hidráulica y un aumento del estrés hídrico en la zona de actuación (Greenpeace, s.f.).

- Contaminación de las aguas tanto superficiales como subterráneas. El fluido que se inyecta en el terreno durante el proceso de fracking contiene más de 260 sustancias químicas (que forman 197 productos químicos diferentes). Actualmente no existe información sobre los efectos que estas sustancias pueden tener sobre los ecosistemas y la salud pública, aunque 58 de ellos han sido señaladas como preocupantes. Entre ellas se encuentran benceno, etil-benceno, isopropilbenceno, naftaleno, tetrasodio, acrilamida, etc.). Teniendo en cuenta que cada pozo requiere un volumen de entre 180 y $580 \mathrm{~m}^{3}$ de este "cóctel químico" y que solo se recupera entre un 15 y un $80 \%$ del fluido inyectado, existe un volumen importante de sustancias químicas que se incorporan a los suelos y aguas subterráneas. Además de por esta vía, las aguas pueden contaminarse debido a eventos catastróficos o errores humanos en las distintas fases de la operación (Broderick et al., 2011).

- Cambios en el uso del terreno. Los procesos descritos en el punto anterior pueden dar lugar a la contaminación de suelos cercanos a la zona de fracking 0 de acuíferos que abastezcan a terrenos más lejanos, imposibilitando así la práctica de la agricultura en los territorios afectados. Además, cada prospección requiere una extensión de alrededor de 1 hectárea, más las infraestructuras adicionales necesarias, como carreteras (Broderick et al., 2011).

- Emisiones de gases de efecto invernadero. Las distintas operaciones que se realizan durante un solo proceso de fractura emiten a la atmósfera entre 348 y 438 $\mathrm{tCO}_{2}$ (Broderick et al., 2011). Por su parte, las fugas de metano durante el proceso de extracción están cifradas en un $4 \%$ del total (Tollefson, 2012) sin contar las fugas en el sistema de tuberías y el metano disuelto en el fluido de retorno.

- Otros impactos asociados. Además de los impactos señalados anteriormente, el fracking puede producir contaminación atmosférica local (se ha detectado benceno en los vapores que salen de los pozos de extracción (Greenpeace, s.f.)); Problemas 


\section{Unidad Didáctica: Who wants fracking in town? 2015}

derivados del intenso tráfico de camiones asociados a esta actividad (como contaminación acústica, atmosférica, ocupación de territorio, etc.) (Broderick et al., 2011); Seísmos provocados por las fracturas como los registrados en Lorca (Murcia) y Blackpool (Inglaterra) (Doblado, 2013); Impacto visual y paisajístico derivados de la amplia extensión de territorio ocupado (Broderick et al., 2011).

Por otro lado, autores como Terry Engelder (Howarth et al., 2011) defienden que la sensación de miedo excede las evidencias científicas, señalando los siguientes contraargumentos:

- Aunque se utiliza más agua por cada pozo, el número se pozos por unidad de superficie es mucho menor, por lo que el impacto ambiental no es necesariamente alto.

- Muchos de los aditivos industriales utilizados en el fluido inyectado son de uso común en los productos del hogar, y cumplen con la normativa estadounidense.

- El fluido que contiene las sustancias químicas se inyecta por debajo de las aguas subterráneas, y no hay evidencias de que pueda contaminar las de abajo a arriba. Además, la presión con la que es inyectado hace que el flujo sea principalmente hacia abajo.

- La industria está avanzando en el reciclado de los fluidos. No obstante, el fluido que se recupera es almacenado de forma segura.

- Los pozos son lo suficientemente seguros como para evitar fugas y filtraciones del fluido que se recupera. El principal riesgo son los errores humanos, un riesgo con el que la sociedad debe vivir.

- Es posible que existan fugas de metano entre el pozo y las aguas subterráneas. Sin embargo, su consumo no es tóxico.

- En cuanto al efecto invernadero causado por el metano, la vida media de este gas en la atmósfera es corto. Aún así, la industria debe reducir las emisiones capturando el metano y mediante una transición de los motores de diesel a gas natural.

Los numerosos posibles riesgos e impactos asociados a los procesos de fractura hidráulica, ponen de manifiesto la necesidad de realizar una evaluación de impacto ambiental (EIA) previa a la realización de estas intervenciones. Así se recoge en la Directiva Europea de Evaluación de Impacto Ambiental (Dir. 2011/92/UE) que establece la necesidad de evaluar los proyectos públicos y privados que puedan tener repercusiones importantes sobre el medio ambiente. 


\section{Unidad Didáctica: Who wants fracking in town? 2015}

\subsection{Fundamentación didáctico-pedagógica}

Tres aspectos metodológicos especialmente relevantes de la unidad didáctica que se presenta en este TFM son la educación integrada de idiomas y contenidos (CLIL), la enseñanza desde la perspectiva de las relaciones entre ciencias, tecnología, sociedad y medio ambiente (CTSA) y el aprendizaje cooperativo (AC). En el presente apartado se describen estos tres elementos así como su utilidad y la conveniencia de su aplicación en el sistema educativo actual.

\subsubsection{CLIL}

La metodología CLIL, como se ha mencionado anteriormente, del inglés Content and Language Integrated Learning, es definida por la Universidad de Cambridge ESOL Examinations (2009, p. 2) como " una aproximación en la que un idioma extranjero es utilizado como herramienta en el aprendizaje de una disciplina no lingüística en la cual ambos, el idioma y la materia, tienen un papel conjunto".

Por lo tanto, el CLIL no consiste en enseñar el idioma extranjero con un abanico más amplio de contenidos, ni tampoco en traducir los contenidos de la materia a otro idioma. En un aula CLIL existen cuatro elementos básicos conocidos como las $4 \mathrm{Cs}$, representados gráficamente en la Figura 2.3, estos son: Contenidos, comunicación, conocimiento y cultura (Coyle, 2005).

- Contenidos. El centro del proceso de aprendizaje es la adquisición de los conocimientos conceptuales, procedimentales y actitudinales propuestos en la unidad didáctica.

- Comunicación. El idioma es una herramienta para la comunicación y el aprendizaje. Se trata de aprender a usar el lenguaje y usar el lenguaje para aprender, es decir, el lenguaje es un medio de aprendizaje en lugar del objeto de aprendizaje (Coyle, 2006).

- Conocimiento. Para que el CLIL sea efectivo debe suponer un aprendizaje significativo para el alumnado. No se trata de transferir conocimientos de un experto a los aprendices, sino de que cada alumno construya su propio conocimiento, al mismo tiempo que se mantiene a los alumnos motivados.

- Cultura. En el mundo pluricultural y plurilingüe en el que vivimos la comprensión y tolerancia de otras culturas es imprescindible. Estudiar una lengua extranjera da a 


\section{Unidad Didáctica: Who wants fracking in town? 2015}

los alumnos la posibilidad de conocer otras culturas al mismo tiempo que obtienen una visión más internacional de la realidad.

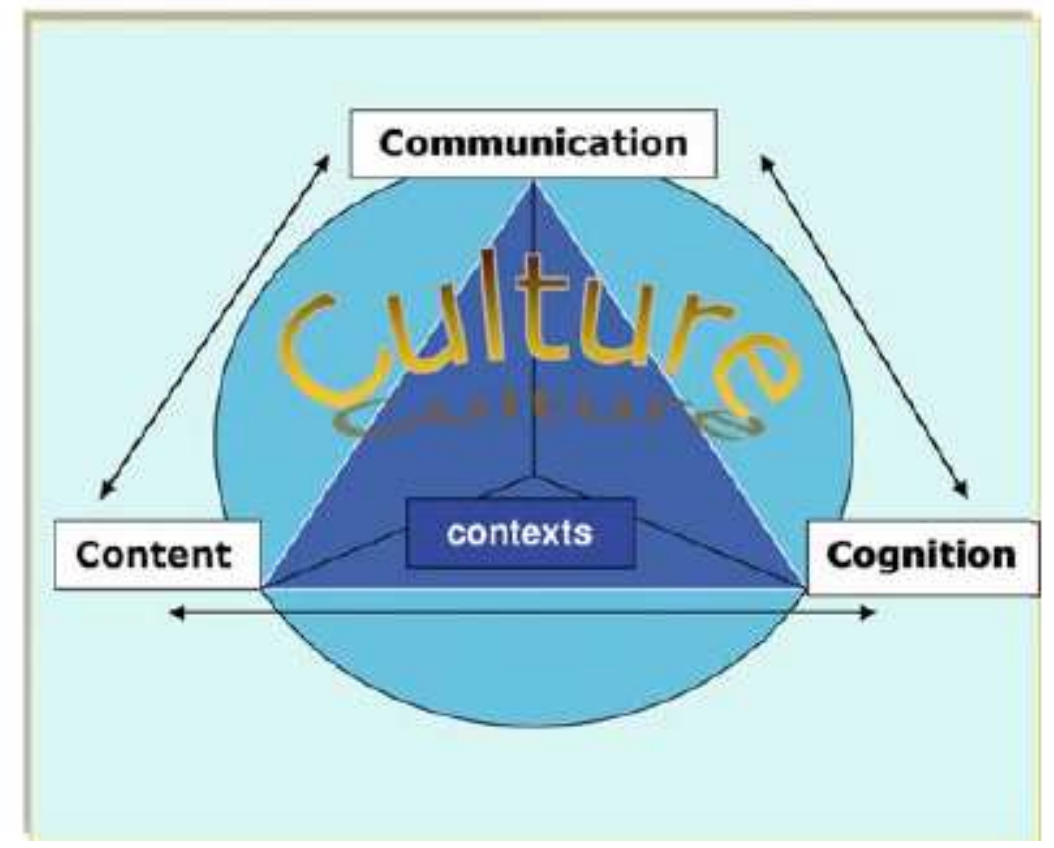

Figura 2.3. Estructura de las 4 Cs para el CLIL (Coyle, 2005).

EI CLIL es un método flexible y existe un amplio rango de modelos que comparten, de algún modo, la integración del aprendizaje de contenidos e idiomas.

Trabajar con un modelo bilingüe supone una serie de ventajas solo por el hecho de trabajar con un idioma diferente al materno. Diversos estudios recogidos por Relji et al. (2015) concluyen que el alumnado bilingüe, en comparación con sus equivalentes monolingües, tienen un mayor control de la atención, puesto que tienen que estar constantemente atentos para seleccionar el idioma requerido (Bialystok, 1999; Bialystok \& Martin, 2004 en Relji et al. 2015). Así mismo, muestran tener una mejor memoria de trabajo (Engle, 2002; Kane, Bleckley, Conway, \& Engle, 2001 en Relji et al. 2015) y una mayor conciencia metalingüística, que es la habilidad de tratar el lenguaje como objeto del pensamiento (García, 2009 en Relji et al. 2015). La capacidad para identificar las palabras como símbolos es otra cualidad que parece estar más desarrollada en el alumnado bilingüe. Por otro lado, tal y como señala Cummins (2000) en Relji et al. (2015), existe una interdependencia entre los dos idiomas hablados por una persona bilingüe, esto quiere decir que los progresos alcanzados en uno de los idiomas ayuda a reforzar el otro y viceversa. 


\section{Unidad Didáctica: Who wants fracking in town? 2015}

También existen otro tipo de beneficios, más aplicados como pueden ser el bagaje cultural que adquiere el estudiante, la posibilidad de comunicarse con un número mayor de personas, o las oportunidades laborales derivadas de bilingüismo.

Además de las ventajas propias del bilingüismo, en la metodología CLIL se han señalado específicamente una serie de ventajas (Coyle, 2006):

- Elevar la competencia lingüística y la confianza. Incrementar la calidad del tiempo empleado en una lengua extranjera, mediante el uso del idioma para aprender a la vez que se aprende a usar el idioma, supone un incremento en las competencias lingüísticas del alumnado, que repercute en un aumento de su confianza a la hora de utilizarla.

- Elevar las expectativas. Existen evidencias de que el uso del CLIL puede ser beneficioso, no solo para el alumnado más capaz, sino para estudiante de todos los niveles. Esto puede deberse a que los estudiantes incrementan sus expectativas al enfrentarse al reto del CLIL. El alumnado sienten que están aprendiendo a un nivel apropiado a su edad y madurez, y no al nivel determinado por sus capacidades lingüísticas.

- Desarrollar un rango más amplio de habilidades. Al fusionar el aprendizaje de contenidos con el del idioma, el CLIL provoca un mayor número de situaciones propicias para la resolución problemas, asunción de riesgos, desarrollo de la confianza y habilidades comunicativas, ampliación de vocabulario, expresión, espontaneidad, etc. por parte del alumnado.

- Aprendizaje cultural. Como ya se ha mencionado anteriormente, un parte importante de la metodología CLIL es el acercamiento a otras culturas. El aprendizaje de un idioma va necesariamente ligado al conocimiento de las costumbres y formas de vida en los países en los que se habla. Esto supone una ventaja en un mundo tan globalizado como el actual.

- Motivación del alumnado y profesorado. El modelo CLIL supone un reto tanto para el alumnado como para el profesorado, lo cual repercute en un aumento de su motivación. Por otra parte, los participantes en este tipo de programas señalan como aspecto positivo el sentirse parte de una comunidad de aprendizaje en la que se apoyan los unos a los otros.

No obstante también ha habido críticas a la metodología CLIL. Burton (2013) señala, entre otros, el problema de la segregación, puesto que son los alumnos académica, lingüística y 


\section{Unidad Didáctica: Who wants fracking in town? 2015}

económicamente más capaces los que los que suelen participar en este tipo de programas. Esto influiría también en los beneficios atribuidos al CLIL, los cuales serían fruto, en cierto grado, de la selección de los mejores alumnos a la hora de realizar los estudios. Por otro lado, plantea la pérdida de relevancia de la enseñanza de idiomas tradicional en los centros donde de trabaja con CLIL. Por último, Burton cuestiona en la práctica el éxito del CLIL en cuanto a otros beneficios como intensificar el aprendizaje de la lengua extranjera o promover la lectura, escritura y el trabajo en equipo, especialmente en los alumnos con mayores carencias académicas, idiomáticas o económicas.

La aplicación en los países miembros de la UE de modelos de enseñanza plurilingüe viene sugerida desde el Consejo de Europa, el cual recomienda el aprendizaje de dos lenguas comunitarias además de la materna. Esta recomendación quedó reflejada a nivel nacional en el documento "Una educación por y para todos" del Ministerio de Educación y Ciencia en 2004 (García Sepúlveda, 2009).

A nivel regional, el Plan de Plurilingüismo de la Junta de Andalucía (Junta de Andalucía, 2005) establece, en los centros adscritos al Plan, la impartición de varias disciplinas no lingüísticas en dos lenguas vehiculares (la lengua materna más una lengua extranjera). La lengua extranjera debe suponer entre un 30 y $50 \%$ de la carga lectiva de la materia. Así mismo, señala que se deben seleccionar adecuadamente los contenidos impartidos en cada uno de los idiomas, la metodología (cuándo utilizar una lengua u otra, estrategias de comunicación...) y el sistema de evaluación, tanto del programa como del alumnado.

El campo de las ciencias experimentales cuenta con una serie de peculiaridades que lo hacen óptimo para la implementación de la metodología CLIL. En primer lugar, el inglés (lengua a través de la cual se enseñarán la materia de Ciencias de la Tierra y el Medio Ambiente en esta unidad didáctica) es el idioma internacional de las ciencias, por lo que es interesante que los estudiantes empiecen a relacionarse con estas disciplinas a través del inglés a una edad lo más temprana posible. Por otro lado, el vocabulario técnico y científico utilizado en estas ciencias es, en ocasiones, similar en los distintos idiomas, lo que facilita la comprensión por parte del alumnado. Esto supone que al ampliar su vocabulario en inglés estén ampliándolo también en español (Grandinetti et al., 2013; García Sepúlveda, 2009).

Sin embargo, existe un problema derivado del uso exclusivo de la lengua extranjera (en este caso inglés) a la hora de impartir una clase de ciencias. En este tipo de materia el alumnado está continuamente aprendiendo palabras nuevas, específicas de la especialidad, por lo que 


\section{Unidad Didáctica: Who wants fracking in town? 2015}

al excluir la lengua materna de las sesiones se dificulta el aprendizaje de una parte de los contenidos. Esto supone un impedimento para el alumnado, tanto a la hora de realizar evaluaciones externas o estudiar la misma materia en otro idioma en años sucesivos, como para aplicar los conocimientos adquiridos fuera el ámbito escolar (en la familia, amigos, mudo laboral, etc.) (Floimayr, 2010). Por otra parte, los estudiantes se sienten más motivados cuando la lengua materna está incorporada en el lenguaje de una clase CLIL, especialmente para clarificar contenidos o secciones difíciles (Langer et al., 2006).

Para fomentar el aprendizaje de las ciencias experimentales siguiendo una metodología CLIL, el profesor ha de proponer actividades adecuadas. Son especialmente interesantes las actividades útiles para potenciar el discurso científico, puesto que al hacerlo en inglés el alumnado presta más atención al aspecto lingüístico, asimilando mejor el lenguaje científico, mientras que al hacerlo en la lengua materna el alumnado puede no prestarle la misma atención al lenguaje utilizado. Al tratarse de un método bilingüe, también resulta conveniente proponer actividades que desarrollen las capacidades cognitivo-lingüísticas, como son describir, definir, justificar, argumentar, explicar, resumir, etc. En cualquier caso, el profesor debe tender siempre a diseñar diferentes tipos de actividades: ejercicios y problemas, actividades prácticas, ciencia recreativa, actividades a partir de textos, vídeos, cómics, utilización de las TICs, etc. Desde el punto de vista de la lengua, las actividades deben cubrir tanto la comprensión como la expresión oral y escrita, adaptando el nivel idiomático al del alumnado (Escoba y Evnitskaya, 2014) .

\subsubsection{Alfabetización científica y CTSA}

Actualmente, existe una tendencia a nivel internacional que señala la alfabetización científica de la sociedad como objetivo central de la enseñanza de las ciencias (Alonso et al. (2003). Esta tendencia se aplica especialmente en la enseñanza secundaria obligatoria, aunque debido a su importancia puede ser extrapolada al Bachillerato.

El concepto "alfabetización científica" se remonta a los años 50 (Bydee, 1997), pero es a partir del siglo XXI cuando ha adquirido un papel central entre los investigadores, didactas y profesores dedicados al mundo de las ciencias. Podemos definir la alfabetización científica como un proceso de investigación orientada que permite al alumnado enfrentarse a problemas científicos relevantes para así construir su propio conocimiento científico, lo que favorece un aprendizaje más eficiente y significativo (Sabariego y Manzanares, 2006). 


\section{Unidad Didáctica: Who wants fracking in town? 2015}

Por su parte, Shen (1975) señala las tres dimensiones que debe recoger la alfabetización científica:

- Alfabetización científica práctica. Comprende los conocimientos que pueden ser utilizados para lidiar con los problemas diarios (alimentación, salud, hábitos de consumo, competencia tecnológica, etc.).

- Alfabetización científica cívica. Son los conocimientos habilidades, actitudes y valores necesarios para tomar decisiones en materias como políticas energéticas, uso de recursos naturales, protección medioambiental y problemas éticos y morales derivados del desarrollo de la tecnología.

- Alfabetización científica cultural. Incluye el conocimiento de las principales teorías e ideas de las ciencias, así como el ambiente sociocultural en el que se produjeron.

Muchos autores, entre ellos Alonso et al. (2003), consideran la educación CTSA como la mejor metodología para trasladar la alfabetización científica a las aulas. La educación CTSA (Ciencia, Tecnología, Sociedad y Ambiente) entiende el centrarse en problemas actuales y tratar de resolverlos como la mejor forma de preparar a los estudiantes para su futuro papel como ciudadanos. Esto significa identificar problemas locales, nacionales e internacionales, involucrar al alumnado en la planificación de actividades individuales y grupales que analicen el problema, y pasar a acciones diseñadas para resolver el problema investigado. Durante el proceso se enfatiza la responsabilidad en la toma de decisiones que afectan al mundo real (Akcay y Yager, 2010).

Con esto se pretende que los estudiantes aprendan a participar en acciones sociopolíticas y tengan experiencia en la participación. Además, deben animar a otros a que también participen: padres, abuelos, amigos, familiares, vecinos, negocios locales, etc., no basta con que se conviertan en críticos pasivos (Hodson, 2010).

Existen una serie de características comunes a la alfabetización científica y la enseñanza CTSA, recogidas por Alonso et al. (2003). Estas son:

1. Incluir el aspecto social en la enseñanza de las ciencias.

2. La utilización de la tecnología como nexo de unión entre las ciencias y el "mundo real", facilitando así la comprensión de la materia.

3. Dotar a la enseñanza de una relevancia personal y social a través de la resolución de problemas y la toma de decisiones consecuentes con la sociedad.

4. Tratar de acercar la ciencia y la tecnología al conjunto de la sociedad. 


\section{Unidad Didáctica: Who wants fracking in town? 2015}

5. Señalar el papel cultural de la ciencia y la tecnología.

6. Poner la ciencia al servicio de la acción social y cívica.

7. Poner de manifiesto la dimensión ética y los valores asociados a la ciencia y la tecnología.

8. Promulgar un pensamiento crítico.

Son numerosos los beneficios derivados de la aplicación de una metodología CTSA en las aulas. En primer lugar, puede contribuir a aumentar el interés del alumnado por las ciencias, al mismo tiempo que les proporciona una idea más completa y contextualizada de las aplicaciones de las ciencias (Solbes, 2011). A esto hay que añadir el desarrollo de valores morales y éticos que deben tener científicos, técnicos, políticos y ciudadanos en general (Jenkins (1997) en Alonso et al., 2003). Otro tipo de ventajas asociadas a las CTSA son las de carácter socioeconómico, culturales, de autonomía personal, práctico de utilidad para la vida cotidiana, cívicos y democráticos para la participación social en las decisiones sobre muchos asuntos de interés público relacionados con la ciencia y la tecnología, etc. (Fourez, 1997; Sjøberg, 1997 en Alonso et al., 2003).

Además de por los autores citados hasta ahora, la conveniencia del uso de las CTSA está respaldada por organismos internacionales como son la UNESCO y el ICSU (Declaración de Bucarest sobre la Ciencia y el uso del saber científico y el Proyecto de programa en pro de la ciencia: Marco general de acción) o la Organización de Estados Iberoamericanos (OEI) en su Programa CTS+l (Alonso et al., 2003). Sin embargo, su aplicación en España no está siendo tan exitosa como sería deseable, debido, entre otras razones, a la falta de formación del profesorado hasta la fecha, al gran volumen de contenidos en comparación con las horas lectivas, la utilización de libros de texto centrados en los contenidos conceptuales (Solbes, 2011), y aspectos relativos al ambiente en el aula como son el tiempo, los recursos disponibles o el ambiente físico (Membienal, 1997). En esta línea, con la entrada en vigor de la LOE se introdujo la asignatura de "Ciencias para el mundo contemporáneo", que pretendía aportar un enfoque CTSA a las ciencias. Sin embargo, las pocas horas lectivas (2 a la semana) y la falta de preparación del profesorado supuso según Solbes (2011) el fracaso de esta iniciativa. La entrada en vigor de la LOMCE en $1^{\circ}$ de Bachillerato el curso 2015-2016, supondrá la eliminación de esta materia. Sin embargo, la LOMCE trate la asignatura de Cultura Científica para $4^{\circ}$ de ESO y $1^{\circ}$ de Bachillerato, con un planteamiento similar. 


\section{Unidad Didáctica: Who wants fracking in town? 2015}

A la hora de diseñar las actividades de la unidad didáctica, la aplicación de la metodología CTSA implica crear una secuenciación a través de la cual el alumnado adquiera los conocimientos necesarios, desarrolle una actitud crítica, reflexione sobre la problemática propuesta y lleve a cabo alguna acción concreta. Algunos de los métodos de enseñanza más utilizados en los enfoques CTSA son los debates, toma de decisiones, juegos de roles, resolución de problemas, aprendizaje cooperativo y trabajo en grupos (Membienal, 1997).

Francisco-Rivero et al., (2013) hacen una propuesta CTSA basada en 5 fases (ver Figura 2.4), en la que se va evaluando el trabajo realizado en cada uno de ellas.

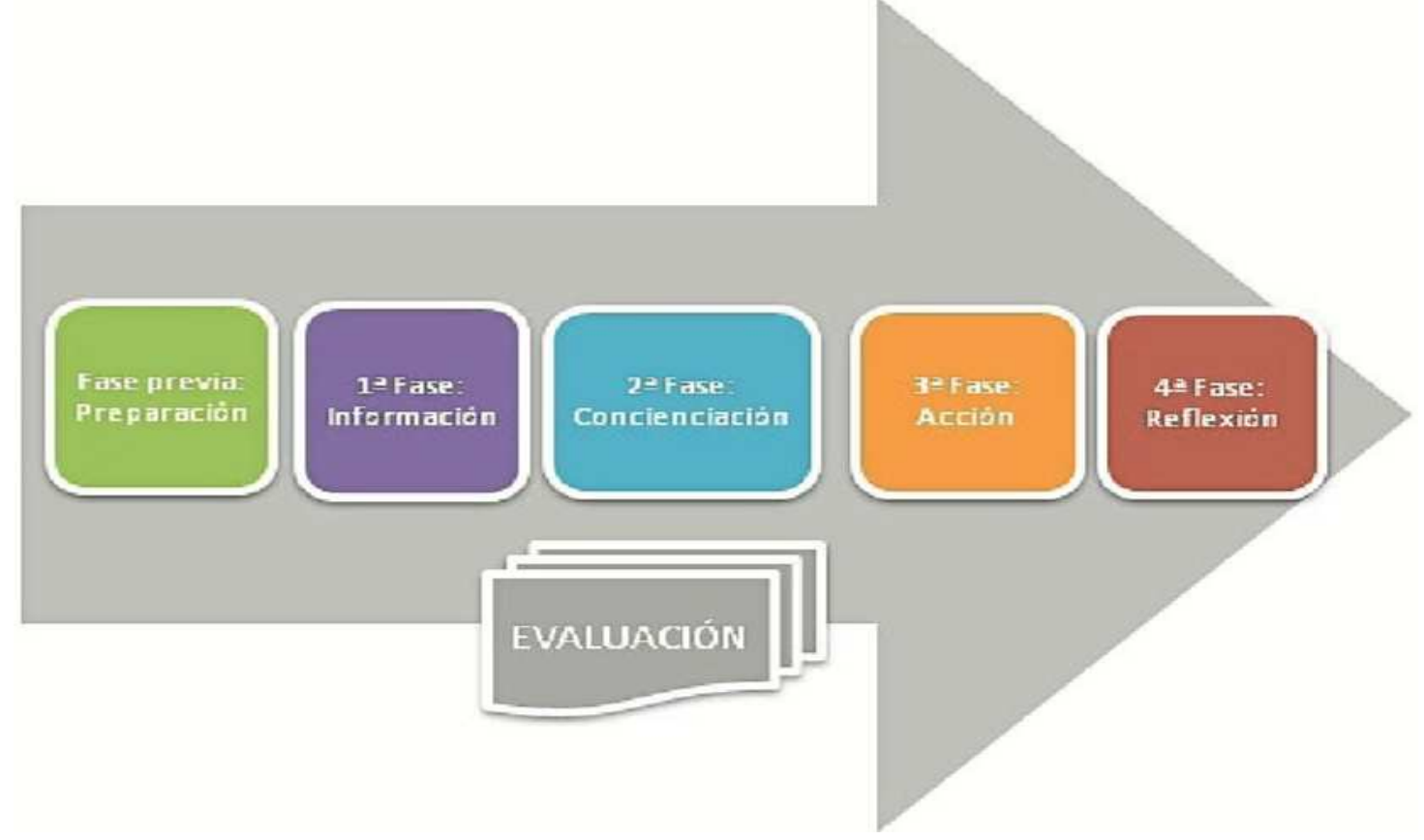

Figura 2.4. Fases de la propuesta de CTSA (Francisco-Rivero et al., 2013)

Esta propuesta comienza con una fase previa de preparación cuyo objetivo es despertar el interés del alumnado sobre el tema a tratar. En esta fase se plantean preguntas abiertas que el alumnado tratará de resolver por sí mismo, se explica la metodología con la que se trabajará en clase y se organizan los equipos de trabajo. La fase de información tiene como objetivo que el alumnado asimile y profundice en la información referente al problema que se esté tratando. Esta fase consta de diferentes actividades diseñadas para adquirir estos conocimientos, como pueden ser clases magistrales, visionado de documentales, charlas, etc. En la fase de concienciación se supone que el alumnado ya ha adquirido unos conocimientos esenciales sobre el tema a tratar, por lo que en este punto se propone la realización de alguna actividad para la toma de conciencia como puede ser un juego de roles, mediante el cual el alumnado pueda comprender los puntos de vista y los intereses de cada uno de los actores que intervienen en el conflicto planteado. La fase de acción es 


\section{Unidad Didáctica: Who wants fracking in town? 2015}

quizás la fase más característica del proceso CTSA, en ella cada grupo de alumnos ha de diseñar e implementar algún tipo de acción social que repercuta sobre el problema planteado. Con esto se pretende que los conocimientos adquiridos y la posterior toma de consciencia cristalicen en una voluntad de transformar la realidad, buscando soluciones a situaciones concretas a través del análisis crítico. Se busca con esta fase contribuir a que los ciudadanos del mañana no solo sean "sillones críticos", sino que participen y animen a otros a participar activamente en la resolución de los problemas sociales, ambientales y políticos (Hodson, 2010). La última fase ha de ser una fase de reflexión, en la que el alumnado relacione todos los conceptos vistos durante la unidad didáctica y haga una reflexión sobre el problema tratado. Con ellos se pretende que adquieran una visión global del problema al mismo tiempo que se busca una implicación del alumnado más allá de la escuela (Francisco-Rivero et al., 2013).

\subsubsection{Aprendizaje cooperativo}

El aprendizaje cooperativo es un método de aprendizaje centrado en el alumnado, en el que un pequeño grupo de estudiantes es responsable de su propio aprendizaje, así como del de sus compañeros de grupo (Li \& Lam, 2005).

Esta metodología es coherente con el constructivismo, situando al alumnado en el centro de su proceso de aprendizaje. Así, el papel del profesorado es meramente el de facilitador: Controla el ambiente de aprendizaje, diseña las actividades y estructura los grupos de trabajo. Por su parte, el rol de los alumnos es el de resolver problemas o alcanzar un objetivo mediante la interacción entre los miembros de un equipo. Al trabajar juntos, los alumnos maximizan su propio aprendizaje y el de cada miembro de su equipo (Li \& Lam, 2005).

Los dos elementos clave del aprendizaje cooperativo son el trabajo en equipo y los objetivos del equipo. Todos los miembros del equipo son responsables de alcanzar esos objetivos que, por otra parte, se logran sí, y solo sí, cada miembro del equipo los alcanza (Servicio de Innovación Educativa de UPM, 2008).

Existen cinco características básicas que deben incluirse en cualquier propuesta de aprendizaje cooperativo (Johnson et al., 1991): 


\section{Unidad Didáctica: Who wants fracking in town? 2015}

1. Interdependencia positiva. Cada miembro del equipo tiene que realizar una tarea propia para contribuir al éxito del grupo, esto se consigue asignando a cada alumno un rol definido. De este modo cada miembro del equipo depende de que el resto cumpla sus objetivos, por lo que el esfuerzo de cada miembro es necesario e indispensable para el éxito del grupo.

2. Responsabilidad individual. Todos los estudiantes deben ser responsables y cumplir su tarea dentro del equipo, para que el grupo pueda alcanzar sus objetivos.

3. Interacción cara a cara. Los miembros del grupo interactúan entre sí dándose feedbacks, discutiendo sobre los argumentos y las conclusiones, pero sobre todo, ayudando a aprender a sus compañeros (aprendizaje entre iguales), apoyándose mutuamente y animando los unos a los otros para conseguir los objetivos.

4. Desarrollo de habilidades sociales, interpersonales y colaborativas. Mediante la interacción, el alumnado desarrolla habilidades de liderazgo, toma de decisiones, comunicativas, confianza en los compañeros y resolución de conflictos.

5. Auto-evaluación del grupo. El alumnado tiene la posibilidad de evaluar su propio trabajo, guiado por el docente. Así pueden evaluar si sus decisiones han sido útiles o no, ver qué están haciendo bien como equipo y cambiar los aspectos negativos para ser más eficientes en el futuro.

Como señala Prieto (2007), el aprendizaje cooperativo, no es siempre la metodología más eficaz, sino que conviene combinarlo con otros tipos de aprendizaje como pueden ser el individualista o el competitivo.

No obstante, la aplicación de esta metodología supone una serie de ventajas señaladas por diversos autores. Benito y Cruz (2005) señala como ventajas el desarrollo de habilidades interpersonales, y de trabajo en equipo; el desarrollo de habilidades intelectuales de alto nivel; un aumento de la responsabilidad y la autoestima del estudiante; conseguir que todos trabajen (cada alumno tiene una parte de responsabilidad de cara a otros compañeros, dentro y fuera del aula); genera redes de apoyo para el alumnado (los de los primeros cursos con dificultades para integrarse se benefician claramente de este modo de trabajar); genera mayor entusiasmo y motivación; promueve el aprendizaje profundo frente al superficial o memorístico. Otro tipo de beneficios de índole académica, social y psicológica son el fomento la metacognición, el desarrollo de habilidades sociales, la disminución de la ansiedad por parte del alumnado al trabajar como parte de un equipo, aumento del rendimiento académico, mejora de la actitud del alumnado frente al aprendizaje, atención a la diversidad, etc. (Servicio de Innovación Educativa de UPM, 2008) 


\section{Unidad Didáctica: Who wants fracking in town? 2015}

\section{MARCO LEGISLATIVO}

La presente unidad didáctica está pensada para su implementación en $2^{\circ}$ de Bachillerato durante el año escolar 2015/2016, por lo que se desarrollará dentro del marco legislativo de la LEY ORGÁNICA 2/2006, de 3 de Mayo, de Educación o LOE. En cualquier caso, pese a estar fundamentada en la LOE, esta unidad didáctica podría adaptarse a la LOMCE en años venideros, dentro de la asignatura de Ciencias de la Tierra y del Medioambiente (que pasa a ser una asignatura específica), previa incorporación de algunas modificaciones.

Esta ley, en su artículo 32.1, Principios generales, señala como una de las finalidades del Bachillerato el "proporcionar a los alumnos formación, madurez intelectual y humana, conocimientos y habilidades que les permitan desarrollar funciones sociales e incorporarse a la vida activa con responsabilidad y competencia." (MEC, 2006, p.17172). Por otra parte, en el artículo 35.1, establece como uno de sus principios pedagógicos que "Las actividades educativas en el bachillerato favorecerán la capacidad del alumno para aprender por sí mismo, para trabajar en equipo y para aplicar los métodos de investigación apropiados." Ambos principios se pretenden cumplir mediante la aplicación en el aula de un método educativo que combine la enseñanza CTSA con el Aprendizaje cooperativo.

La LOE, en su artículo 34.3, dispone que el Gobierno establecerá la estructura de las modalidades del bachillerato, las materias específicas de cada modalidad y el número de estas materias que se deben cursar. Esto se recoge en el REAL DECRETO 1467/2007 (MEC, 2007), el cual incluye en su artículo 7.3 las Ciencias de la Tierra y medioambientales como una de las materias de la modalidad de Ciencias y Tecnología. Además, la disposición adicional cuarta, enseñanzas del sistema educativo español impartidas en lenguas extranjeras, establece que "las administraciones educativas podrán autorizar que una parte de las materias del currículo se impartan en lenguas extranjeras sin que ello suponga modificación de los aspectos básicos del currículo regulados en este real decreto. En este caso, procurarán que a lo largo de ambos cursos se adquiera la terminología básica de las materias en ambas lenguas" (MEC, 2007, p. 45385). Esto justifica aplicar una metodología CLIL en el aula.

La LOE se concreta a nivel andaluz con la LEY 17/2007, de 10 de diciembre, de Educación de Andalucía o LEA (CE, 2007) y el DECRETO 416/2008, de 22 de julio, por el que se establece la ordenación y las enseñanzas correspondientes al Bachillerato en Andalucía 


\section{Unidad Didáctica: Who wants fracking in town? 2015}

(CE, 2008a). El artículo 13.1 de este decreto, hace referencia a que la asignatura de Ciencias de la Tierra y Medioambientales se impartirá en el segundo curso de Bachillerato de la modalidad de Ciencias y Tecnología. Así mismo, en el artículo 15.2 se recoge que "Las materias optativas reforzarán, mediante una configuración diferente basada en proyectos y trabajos de investigación, la metodología activa y participativa propia de esta etapa educativa" (CE, 2008a, p. 17), lo cual subraya la idoneidad de la aplicación de CTSA y aprendizaje cooperativo en dicho curso.

Por otra parte, la Orden de 5 de Agosto de 2008, por la que se desarrolla el currículo correspondiente al Bachillerato en Andalucía, sugiere una metodología "caracterizada por un fuerte protagonismo del análisis y la valoración por el alumnado de las informaciones sobre problemas reales y actuales." (CE, 2008b, p. 181) en la que el alumnado tenga que "buscar información relacionada con los problemas que van a trabajarse, valorar su fiabilidad y seleccionar la que resulte más relevante para su tratamiento, formular conjeturas e hipótesis y diseñar estrategias que permitan contrastarlas, elaborar conclusiones que validen o no las hipótesis formuladas, y comunicarlas adecuadamente" (CE, 2008b, p. 181). Todo ello encaja, una vez más, con la metodología propuesta.

Por su parte la Junta de Andalucía publicó en 2005 el Plan de Fomento del Plurilingüismo (CE, 2005), en el que se asientan las bases para dotar al alumnado andaluz de competencias plurilingües y pluriculturales. En el caso de bachillerato, este plan está enfocado especialmente a los usos técnicos y científicos de la lengua. 


\section{CONTEXTUALIZACIÓN}

\subsection{Curso}

La presente unidad didáctica se enmarca en el segundo curso de Bachillerato, un curso con ciertas peculiaridades ya que está enfocado, en muchos casos, hacia las pruebas de acceso a la Universidad. En esta prueba se valora objetivamente la madurez académica y los conocimientos adquiridos en la etapa de bachillerato.

La materia en la que se desarrolla esta unidad didáctica es Ciencias de la Tierra y el Medioambiente (CTM), la cual está incluida en el segundo curso de la modalidad de Ciencias y Tecnología como una materia específica de esta modalidad.

\subsection{Características del centro}

La presente unidad didáctica está pensada para ser llevada a cabo en un instituto de enseñanza secundaria de Andalucía, en el que se esté realizando un programa de bilingüismo o plurilingüismo, y cuyo alumnado tengan un nivel sociocultural medio que le predisponga a desarrollar una actitud crítica y responsable para con los problemas ambientales y sociales. Un ejemplo de centro con estas características es el I.E.S. Generalife de Granada, cuyas características se describen en el anexo 1.

\subsection{Características del alumnado}

El alumnado de segundo de bachillerato tiene, por lo general, edades comprendidas entre los 16 y los 20 años. Esto los sitúa en la etapa de desarrollo evolutivo de la adolescencia, que comprende aproximadamente de los 12 a los 22 años. Erikson (1995) identifica esta etapa con el conflicto entre y identidad y la búsqueda de roles, en la que el adolescente busca sus propios criterios, principios, valores, decisiones, etc., libre y personalmente asumidos.

La adolescencia se caracteriza por la presencia de una serie de cambios en el desarrollo físico y sexual, en la consolidación del pensamiento adulto, cambios afectivos y en las relaciones sociales, y cambios en la construcción de la identidad (Santrock, 2003). Estos cambios vienen determinados por diversos factores (Piaget, 1966): biológicos (como la 


\section{Unidad Didáctica: Who wants fracking in town? 2015}

maduración del sistema nervioso); la capacidad para actuar sobre el entorno y aprender de él; autorregulación de los sentimientos; factores sociales como las interacciones con otros individuos; la transmisión educativa y cultural.

Por su parte, Piaget (1966) identifica estas edades con la adultez, periodo en el que el individuo es capaz de realizar operaciones formales como:

-Aparición del pensamiento abstracto y la coordinación de variables.

- Capacidad de imaginar situaciones sin experimentarlas y solucionar problemas utilizando únicamente razonamientos verbales.

-Utilización del razonamiento hipotético deductivo, e inductivo (hipótesis, soluciones tentativas, resolución adecuada de problemas).

-Proponer distintas soluciones para un mismo problema.

-Aparición de la metacognición.

Algunos autores señalan una etapa posterior a la adultez descrita por Piaget, denominada pensamiento postformal (Lombardo et al., 2007), que se caracterizaría por la comprensión de que la respuesta a un problema puede conllevar pensamiento reflexivo, depender de la situación, y que la búsqueda de la verdad es constante e interminable. Ésta supone un pensamiento realista y pragmático, reflexivo y relativista, que asume que las emociones también influyen en los procesos cognitivos.

Una parte esencial del desarrollo evolutivo en esta etapa es el desarrollo moral, entendido como "el incremento en la interiorización de las reglas culturales básica" (Kohlberg, 1977, 223). Este desarrollo moral forma es un aspecto fundamental en la educación de ciudadanos con valores democráticos, puesto que favorece las interacciones sociales basadas en normas y principios que constituyen la moralidad de los individuos (Barba, 2001). Kohlberg (1987), basándose en el modelo de Piaget, identifica tres niveles de razonamiento moral, cada uno de los cuales consta de dos estadios:

- Nivel preconvencional. El individuo interpreta las normas culturales en términos de "bueno" y "malo". En el estadio 1 las decisiones se toman en función de las consecuencias directas que tendrán las acciones para el propio individuo (castigo, recompensa, intercambio de favores...) y la obediencia. En el estadio 2 se actúa en base al interés propio, dejando a otros hacer lo mismo. 


\section{Unidad Didáctica: Who wants fracking in town? 2015}

- Nivel convencional. El individuo se siente miembro de una sociedad y actúa para mantener el orden. En el estadio 3 se actúa para ser una buena persona tanto para sí mismo como para lo demás, siguiendo el principio "haz a otros lo que quieras para ti”. En el estadio 4 el individuo entiende como bueno el cumplimiento del deber propio y acepta la ley por convencimiento, no por miedo.

- Nivel postconvencional. El individuo juzga el bien y el mal, no en base a sí mismo ni a la sociedad, sino principios universales, inherentes al ser humano, como la justicia, democracia, reciprocidad, derechos humanos, etc. En el estadio 5, se busca el bien para la mayoría de personas respetando las individualidades, y diferencia la legalidad de la moralidad. En el estadio 6, se reconocen los principios morales universales de los que derivan las normas sociales, y reconoce a las personas como un fin en sí mismo.

Según este modelo, la madurez cognitiva es una condición necesaria pero no suficiente para alcanzar un nivel de madurez del juicio moral equivalente, puesto que también intervienen factores de índole social, afectiva, ambiental y física (Romo Martines, 2005). De este modo, en condiciones favorables, durante la etapa de bachillerato el desarrollo tanto cognitivo y como moral de del alumnado pasará de un nivel formal a uno postformal (Barba, 2001).

Varios estudios (Barba, 2001 y Romo Martines, 2005) muestran que el alumnado de bachillerato suele encontrarse en un nivel convencional (estadio 4) de desarrollo moral, con cierta presencia de niveles postformales y muy poca de desarrollo preformal. Estos niveles son superiores a los obtenidos en secundaria, por lo que se deduce un aumento del desarrollo moral a medida que se desarrollan las capacidades cognitivas de los estudiantes.

Dado que las personas a las que va dirigida esta unidad didáctica se encuentran en una edad crucial para el desarrollo de su personalidad adulta, y aprovechando que ya poseen las herramientas cognitivas para razonar de forma crítica, es la intención de esta actuación el transmitir valores medioambientales y educar en el pensamiento crítico al alumnado a través de la educación CTS. 


\section{Unidad Didáctica: Who wants fracking in town? 2015}

\subsection{Ubicación en la programación}

Podemos considerar que la idea general en la que se basa esta unidad didáctica son los problemas ambientales. Debido al diseño en espiral del currículo educativo, este tema se trata desde diferentes perspectivas en cursos anteriores, como se ilustra en la tabla 4.1, cristalizando en el segundo curso de bachillerato en el sexto bloque de la materia Ciencias de la Tierra y Medioambientales.

Tabla 4.1. Estudio de los problemas ambientales durante la ESO y el Bachillerato.

\begin{tabular}{|c|c|c|}
\hline Curso & Asignatura & Bloque y contenidos \\
\hline $1^{\circ} \mathrm{ESO}$ & $\begin{array}{c}\text { Ciencias } \\
\text { Naturales }\end{array}$ & $\begin{array}{l}\text { 4. Los seres vivos y su diversidad. } \\
\text { - Valoración de la importancia de mantener la diversidad de los } \\
\text { seres vivos. Análisis de los problemas asociados a su pérdida. }\end{array}$ \\
\hline 2 ESO & $\begin{array}{c}\text { Ciencias } \\
\text { Naturales }\end{array}$ & $\begin{array}{l}\text { 4. Transformaciones geológicas debidas a la energía interna de la } \\
\text { Tierra. } \\
\text { - Erupciones volcánicas y terremotos. } \\
\text { - Valoración de los riesgos volcánicos y sísmicos e importancia de } \\
\text { su predicción y prevención. }\end{array}$ \\
\hline $3^{\circ} \mathrm{ESO}$ & $\begin{array}{l}\text { Ciencias } \\
\text { Naturales }\end{array}$ & $\begin{array}{l}\text { 6. Las personas y el medio ambiente. } \\
\text { - Consecuencias ambientales del consumo humano de energía. } \\
\text { - Importancia del uso y gestión sostenible de los recursos hídricos. } \\
\text { La potabilización y los sistemas de depuración. Utilización de } \\
\text { técnicas sencillas para conocer el grado de contaminación y } \\
\text { depuración del aire y del agua. } \\
\text { - Los residuos y su gestión. Valoración del impacto de la actividad } \\
\text { humana en los ecosistemas. } \\
\text { - Principales problemas ambientales de la actualidad. } \\
\text { - Valoración de la necesidad de cuidar del medio ambiente y } \\
\text { adoptar conductas solidarias y respetuosas con él. }\end{array}$ \\
\hline $4^{\circ} \mathrm{ESO}$ & $\begin{array}{l}\text { Biología y } \\
\text { Geología }\end{array}$ & $\begin{array}{l}\text { 4. Las transformaciones en los ecosistemas. } \\
\text { - Ciclo de materia y flujo de energía. Ciclos biogeoquímicos. } \\
\text { - Cuidado de las condiciones medioambientales y de los seres } \\
\text { vivos como parte esencial de la protección del medio natural. }\end{array}$ \\
\hline 1 Bach. & $\begin{array}{l}\text { Biología y } \\
\text { Geología }\end{array}$ & $\begin{array}{l}\text { 3. Geodinámica externa e historia de la Tierra. } \\
\text { - El sistema tierra: una perspectiva global. } \\
\text { - } \quad \text { Riesgos geológicos. Predicción y prevención. } \\
\text { - Cambios en la corteza terrestre provocados por la acción humana. }\end{array}$ \\
\hline $2^{\circ}$ Bach. & $\begin{array}{l}\text { Ciencias de } \\
\text { la Tierra y } \\
\text { Medioambie } \\
\text { ntales }\end{array}$ & $\begin{array}{l}\text { 1. Medio ambiente y fuentes de información ambiental. } \\
\text { - Concepto de impacto ambiental. Riesgos naturales e inducidos. } \\
\text { Consecuencias de las acciones humanas sobre el medio } \\
\text { ambiente. } \\
\text { 2. Los sistemas fluidos externos y su dinámica. } \\
\text { - Detección, prevención y corrección de la contaminación hídrica. } \\
\text { 3. La geosfera. }\end{array}$ \\
\hline
\end{tabular}




\section{Unidad Didáctica: Who wants fracking in town? 2015}

\begin{tabular}{|c|c|c|}
\hline & & $\begin{array}{l}\text { - Riesgos volcánicos y sísmicos. } \\
\text { - Impactos derivados de la explotación de los recursos. } \\
\text { 4. La ecosfera. } \\
\text { - Impactos sobre la biosfera: deforestación y pérdida de } \\
\text { biodiversidad. } \\
\text { 5. Interfases. } \\
\text { - Erosión, contaminación y degradación de los suelos. } \\
\quad \text { Desertización. Problemas asociados a la desertización. }\end{array}$ \\
\hline
\end{tabular}

\subsection{Temporalización}

La asignatura de Ciencias de Tierra y Medioambientales de $2^{\circ}$ de Bachillerato comprende seis grandes bloques de contenidos (Ver Tabla 4.2). Esta unidad didáctica se enmarca principalmente en el sexto bloque de contenidos "La gestión del planeta", por lo que tendrá lugar durante la tercera evaluación del curso.

Tabla 4.2. Bloques de contenidos impartidos en cada trimestre.

\begin{tabular}{|c|c|}
\hline Trimestre & Bloques de contenidos \\
\hline 10 & $\begin{array}{c}\text { Medio ambiente y fuentes de información ambiental } \\
\text { Los sistemas fluidos externos y su dinámica }\end{array}$ \\
\hline 20 & La geosfera \\
La ecosfera
\end{tabular}

La tercera evaluación de $2^{\circ}$ de Bachillerato tiene la peculiaridad de ser más corta que en el resto de cursos, debido a las pruebas de acceso a la universidad. Pese a que a la fecha de entrega del presente TFM aún no ha sido publicado el calendario escolar oficial para el curso 2015/2016, tomando como referencia años anteriores vemos que la docencia en este curso se interrumpe unas cuatro semanas antes de final de curso, lo que nos deja un tercer trimestre de 8 semanas. De estas 8 semanas, dedicaremos 4 a la unidad didáctica de "La gestión del planeta". El Anexo III de la ORDEN de 5 de Agosto de 2008 (CE, 2008b) asigna a las materias de modalidad, como es CTM, un horario de 4 horas lectivas semanales, lo que nos proporciona un total de 16 sesiones de una hora de duración para el desarrollo de la unidad didáctica. 


\section{Unidad Didáctica: Who wants fracking in town? 2015}

\section{OBJETIVOS}

En la presente unidad didáctica se pretende contribuir a alcanzar los objetivos generales que consideran la LEY ORGÁNICA 2/2006 (MEC 2006) y el REAL DECRETO 1467/2007 (MEC 2007) que se encuentran recogidos en el anexo 2.

Los objetivos didácticos propios propuestos para la presente unidad didáctica son los recogidos en la tabla 5.1 :

Tabla 5.1. Objetivos didácticos propios.

\begin{tabular}{|c|l|}
\hline № & \multicolumn{1}{|c|}{ Objetivos propios } \\
\hline Ob.1 & $\begin{array}{l}\text { Relacionar los principales problemas ambientales de la sociedad actual con sus causas } \\
\text { (históricas, sociológicas, económicas y culturales) e impactos sociales y ambientales } \\
\text { (tanto positivos como negativos). }\end{array}$ \\
\hline Ob.2 & $\begin{array}{l}\text { Identificar los principales reservorios y procesos de los ciclos biogeoquímicos y su } \\
\text { relación con el cambio climático. }\end{array}$ \\
\hline Ob.3 & $\begin{array}{l}\text { Describir el proceso de fracturación hidráulica y analizar de forma crítica la } \\
\text { conveniencia o no de su aplicación. }\end{array}$ \\
\hline Ob.4 & $\begin{array}{l}\text { Conocer distintas herramientas de carácter técnico para la resolución de problemas } \\
\text { ambientales (EIA, ordenación del territorio y legislaciones ambientales) y su ámbito de } \\
\text { aplicación }\end{array}$ \\
\hline Ob.5 & Producir medidas de prevención y corrección de los problemas ambientales locales. \\
\hline Ob.6 & $\begin{array}{l}\text { Desarrollarse como ciudadanos críticos ante los problemas sociales y } \\
\text { medioambientales }\end{array}$ \\
\hline Ob.7 & Tomar conciencia de los problemas ambientales. \\
\hline Ob.8 & $\begin{array}{l}\text { Utilizar las tecnologías de información y comunicación para buscar información y } \\
\text { contrastar su veracidad. }\end{array}$ \\
\hline Ob.9 & Expresarse con fluidez en inglés. \\
\hline Ob.10 & Promover el trabajo cooperativo y en equipo. \\
\hline
\end{tabular}




\section{COMPETENCIAS}

Aunque tanto en la LOE como en la LOMCE la educación por competencias está circunscrita a la ESO, el desarrollo de estas competencias puede ser extrapolable al bachillerato. En este sentido, las competencias de la LOE aplicables a esta unidad didáctica son las siguientes:

C1. Competencia en comunicación lingüística, se desarrolla en esta materia a través de la transmisión de ideas y construcción de un discurso de carácter científico, al mismo tiempo que incorpora terminología específica de las ciencias al vocabulario del alumnado.

C3. Competencia en el conocimiento y la interacción con el mundo físico, para ellos es necesario el conocimiento de los conceptos de cada una de las ciencias y las interacciones entre ellas. Requiere especial atención las implicaciones de determinadas actuaciones sociales científicas y tecnológicas sobre el medioambiente, sobre las que se debe aportar una visión sistémica que permita al alumnado conocer los grandes problemas ambientales, buscar soluciones mediante el desarrollo sostenible, dotándoles de la formación necesaria para tomar decisiones al respecto.

C4. Tratamiento de la información y competencia digital, mediante la búsqueda, recogida, selección, procesamiento y presentación de la información característica del trabajo científico. Por otro lado, en la actividad científica es habitual el uso de diversas tecnologías de carácter digital.

C5. Competencia social y ciudadana puesto que la alfabetización científica es clave a la hora de que la ciudadanía participe en debates sociales y tome decisiones fundamentadas acerca de problemas ambientales y sociales.

C7. Competencia para aprender a aprender, al dotar al alumnado de las herramientas para construir conocimiento científico, a la vez que se les proporcionan los conocimientos básicos a partir de los cuales seguir desarrollando el conocimiento científico.

C8. Autonomía e iniciativa personal, mediante la formación de una mentalidad crítica que les permita cuestionar dogmas y prejuicios. 


\section{Unidad Didáctica: Who wants fracking in town? 2015}

\section{CONTENIDOS}

De los contenidos especificados en el REAL DECRETO 1467/2007 (MEC 2007) para la materia "Ciencias de la tierra y medioambientales", esta unidad didáctica incluirá todos los contenidos del bloque 6, más el contenido del bloque 4, la ecosfera, referente a los ciclo biogeoquímicos. Los contenidos a tratar son los especificados en la tabla 7.1.

Tabla 7.1. Contenidos generales tratados en la unidad didáctica.

\begin{tabular}{|c|c|}
\hline Contenido & Bloque \\
\hline $\begin{array}{c}\text { Los ciclos biogeoquímicos del oxígeno, el carbono, el } \\
\text { nitrógeno, el fósforo y el azufre }\end{array}$ & 4. La ecosfera \\
\hline $\begin{array}{c}\text { Los principales problemas ambientales. } \\
\text { Sostenibilidad }\end{array}$ & 6. La gestión del planeta \\
\hline $\begin{array}{c}\text { Evaluación de impacto ambiental. Manejo de matrices sencillas } \\
\text { Ordenación del territorio. Legislación medioambiental. La } \\
\text { protección de espacios naturales. }\end{array}$ & 6. La gestión del planeta \\
\hline
\end{tabular}

Por su parte, la Orden de 5 de Agosto de 2008, por la que se desarrolla el currículo correspondiente al Bachillerato en Andalucía (CE, 2008b) sugiere trabajar los contenidos que figuran en el Real Decreto 1467/2007 relacionándolos con problemas ambientales como el calentamiento de la superficie terrestre, la desertización favorecida por el uso insostenible de la Tierra o el impacto de los desastres naturales sobre el ser humano.

Los contenidos propios de esta unidad didáctica, divididos en conceptuales, procedimentales y actitudinales, son los que se recogen en la tabla 7.2.

Tabla 7.2. Contenidos conceptuales, procedimentales y actitudinales

\begin{tabular}{|l|l|l|}
\hline \multicolumn{1}{|c|}{ Contenido conceptuales } & Contenidos procedimentales & \multicolumn{1}{c|}{ Contenidos actitudinales } \\
\hline $\begin{array}{l}\text { CC1. Principales problemas } \\
\text { ambientales } \\
\text { efectos sobre el ser humano y y } \\
\text { el medio ambiente. }\end{array}$ & $\begin{array}{l}\text { CPr.1 Búsqueda y } \\
\text { comprobación de la veracidad } \\
\text { de información en internet. }\end{array}$ & $\begin{array}{l}\text { CAc.1 Sensibilización con los } \\
\text { problemas ambientales como } \\
\text { el cambio climático o la } \\
\text { contaminación. }\end{array}$ \\
\cline { 1 - 1 } CC2. Ciclos biogeoquímicos & CPrabajo en grupo. & CAc.2 Consideración de la \\
\hline
\end{tabular}

\footnotetext{
${ }^{3}$ Los problemas ambientales ya se han estudiado en detalle en unidades didácticas anteriores a lo largo del curso. Los que aquí se pretende es tener una visión global de todos ellos, profundizando en sus causas y efectos tanto ambientales como sociales.
} 


\section{Unidad Didáctica: Who wants fracking in town? 2015}

\begin{tabular}{|l|l|l|}
\hline $\begin{array}{l}\text { del carbono, oxígeno, } \\
\text { nitrógeno, fósforo y azufre. }\end{array}$ & $\begin{array}{l}\text { CPr. 3 Preparación y } \\
\text { argumentación de un debate } \\
\text { (sólo en CC4 y CC5) }\end{array}$ & $\begin{array}{l}\text { dimensión social a la hora de } \\
\text { abordar problemas } \\
\text { ambientales. }\end{array}$ \\
\cline { 1 - 1 } $\begin{array}{l}\text { CC3. La fracturación hidráulica } \\
\text { como ejemplo de actividad con } \\
\text { un alto impacto ambiental. }\end{array}$ & $\begin{array}{l}\text { CAc.3 Actitud crítica ante la } \\
\text { información recibida. }\end{array}$ \\
\cline { 1 - 1 } $\begin{array}{l}\text { CC4. Conflicto de intereses en } \\
\text { los problemas } \\
\text { medioambientales. }\end{array}$ & $\begin{array}{l}\text { CAc.4 Aumento del respeto y } \\
\text { la confianza hacia otros } \\
\text { compañeros. }\end{array}$ \\
\cline { 1 - 1 } $\begin{array}{l}\text { CC5. Sostenibilidad. } \\
\text { CAc.5 Mejora de la confianza a } \\
\text { la hora de hablar en público y } \\
\text { expresarse en inglés. }\end{array}$ \\
\cline { 1 - 1 } $\begin{array}{l}\text { CC6. Evaluación de impacto } \\
\text { ambiental y manejo de } \\
\text { matrices sencillas. }\end{array}$ & $\begin{array}{l}\text { CC7. Ordenación del territorio. } \\
\text { Legislación medioambiental }\end{array}$ & \\
\hline
\end{tabular}

Los contenidos conceptuales de la unidad didáctica, se pueden concretar en conceptos más específicos que están relacionados entre sí, tal y como se muestra en el mapa conceptual recogido en el Anexo 3.

\subsection{Big Ideas}

Por lo general parece haber una falta de conciencia generalizada por parte del alumnado con respecto a la relación que existe entre los conceptos científicos aprendidos en el aula y el mundo que les rodea. Este hecho se va agravando a medida que se avanza en el sistema escolar, puesto que los conceptos se van tornando cada vez más abstractos. Sin embargo, el objetivo de la enseñanza de las ciencias no debe ser el de dotar a los estudiantes con un gran volumen de hechos y teorías científicas, sino conseguir relacionar las ideas que el alumnado tiene con respecto al mundo real (ideas previas) con conceptos clave que, juntos, permitan la comprensión de los eventos y fenómenos relevantes para la vida del estudiante (Harlen, 2010). Estos conceptos clave de gran poder explicativo se conocen como "big ideas" y pueden definirse como "ideas que pueden ser usadas para explicar y hacer predicciones sobre un gran rango de fenómenos del mundo natural' (Harlen, 2010, p. 17).

Dentro del campo de las ciencias de la tierra, en el que se enmarca esta unidad didáctica, la iniciativa Earth Science Literacy (NSF, 2010) recoge 9 big ideas. Los contenidos recogidos en la tabla 7.2 pueden correlacionarse con las siguientes big ideas (entre paréntesis se indica el concepto de la tabla 7.2 con la que se relaciona cada idea): 
Big Idea 3. La Tierra es un sistema complejo en el que interaccionan rocas, agua, aire y seres vivos (CC2). Esta big idea alberga el concepto de que todos los procesos de la Tierra son el resultado del flujo de energía y ciclos de la materia entre los cuatro principales sistemas (geosfera, hidrosfera, atmósfera y biosfera).

Big Idea 7. El ser humano depende de los recursos de la tierra (CC1 y CC3). Esto engloba las ideas de que los recursos naturales son limitados y se distribuyen de forma irregular por el planeta; el agua y el suelo son recursos esenciales para la agricultura, el petróleo y el gas natural son recursos esenciales en las sociedades contemporáneas, por diversos motivos; los combustibles fósiles son la principal fuente de energía en la actualidad; uno de los objetivos de los científicos e ingenieros es desarrollar nuevas tecnologías que reduzcan la contaminación, los desechos y la degradación de ecosistemas producidas por las extracciones.

Big Idea 8. Los riesgos naturales suponen un riesgo para los seres humanos (CC1). Dentro de esta big idea se incluyen las ideas de que los riesgos naturales son el resultado de los procesos terrestres, incluyendo terremotos, tsunamis, huracanes, inundaciones, sequías, corrimientos de tierra, erupciones volcánicas, climatología extrema, incendios, procesos de erosión, etc.; las actividades humanas pueden alterar la frecuencia e intensidad de algunos riesgos naturales; los riesgos naturales pueden ser catastróficos o graduales y producirse a nivel local, regional o global; los riesgos naturales no pueden ser eliminados, pero se puede mitigar su impacto; para reducir el riesgo de impacto ambiental es esencial la alfabetización científica de la población.

Big Idea 9. Los seres humanos alteran la Tierra de forma significativa (CC1 y CC3). Esta big idea hace referencia a que la actividad humana altera significativamente muchos procesos de la superficie terrestre; se pueden utilizar registros geológicos para distinguir la influencia humana de la natural en los sistemas terrestres; El ser humano causa el cambio climático mediante la quema de combustibles fósiles, el cambio en el uso de la tierra, prácticas agrícolas y procesos industriales.

\subsection{Ideas previas}

Un concepto muy importante dentro de la teoría constructivista son las ideas previas, entendidas como construcciones mentales, fruto de la experiencia cotidiana, elaboradas 


\section{Unidad Didáctica: Who wants fracking in town? 2015}

para dar explicación, describir y hacer predicciones sobre fenómenos naturales. Estas construcciones son útiles en la vida cotidiana, pero no carecen de carácter científico, y en muchos caso suponen un obstáculo para el aprendizaje científico (Mora y Herrera, 2009). El conocimiento de estas concepciones previas permite al docente plantear conflictos cognitivos al alumnado, a partir de los cuales se realice un aprendizaje significativo (Gudovitch y Orion, 2001). Algunas características de las ideas previas señaladas por Mora y Herrera (2009) son:

- No dependen de la edad, género ni nivel cultural de la persona.

- La persona no es consciente de la existencia de estas ideas previas.

- Son fruto de razonamientos causa-efecto.

- Pueden ser contradictorias si se aplican en diferentes conceptos.

- Son difíciles de cambiar.

- Existe una correspondencia con los errores históricos en las ciencias.

- Surgen de las experiencias cotidianas, interacción entre iguales y enseñanzas recibidas.

- Obstaculizan el aprendizaje científico.

- Tienen, para el sujeto, coherencia interna.

En el caso del estudio del medio ambiente existen una serie de ideas previas generales ya identificadas. Vega et al. (2009) recoge las siguientes:

- Creer que la especie humana no está sujeta a procesos de extinción.

- Identificar la contaminación como un fenómeno siempre perceptible sensorialmente.

- Reducir la importancia de la contaminación a motivos económicos.

- Subestimar la capacidad autorreguladora de los sistemas naturales.

- Adoptar posturas de conservacionismo radical, expresadas como intervención cero.

- Simplificar los impactos ambientales a las agresiones sobre la fauna y los espacios naturales, obviando la dimensión social.

- Considerar al ser humano al margen de los natural, entendiendo lo natural como lo opuesto a lo humano.

- No considerar el ruido como un problema ambiental.

Centrándonos en el estudio del ciclo del carbono, Gudovitch y Orion (2001), señalan que las ideas previas del alumnado con respecto a este tema se basan principalmente en los siguientes factores: 


\section{Unidad Didáctica: Who wants fracking in town? 2015}

- Identificar el "agujero" de la capa de ozono con el cambio climático. Los estudiantes atribuyen dos causas al calentamiento climático: el "agujero" de la capa de ozono y el efecto invernadero.

- No identificar el efecto invernadero como un proceso natural. Atribuirle únicamente causas antrópicas.

- Mala percepción del tamaño relativo de los diferentes reservorios de carbono en la tierra.

- No considerar la geosfera como el principal reservorio de carbono $(99 \%$ del total).

- Considerar la atmósfera como el mayor reservorio de carbono.

- Sobreestimar la importancia de la biosfera como reservorio de carbono, situándola a un nivel igual o superior al de la geosfera o la hidrosfera.

- Describir los cambios en las concentraciones de $\mathrm{CO}_{2}$ como resultado del aumento de la temperatura.

- Ignorar los efectos de cambio climático sobre la biosfera (erosión y sedimentación) y la acidificación oceánica.

- Creer que las plantas obtienen los nutrientes (incluidos el $\mathrm{CO}_{2}$ ) principalmente del suelo, ignorando la importancia de la fotosíntesis en la nutrición vegetal (O’Connell, 2010).

Además de estas ideas previas, el mismo estudio señala algunas de las principales dificultades que presenta el alumnado en este tema: problemas para comprender conceptos abstractos como el balance radiativo, gases de efecto invernadero o albedo; problemas a la hora de identificar e interpretar las interacciones entre subsistemas; y dificultades para aplicar el principio de conservación de la masa a los ciclos biogeoquímicos (Gudovitch y Orion, 2001).

\subsection{Contenidos transversales}

La LOE establece la práctica democrática y la educación en valores como elementos transversales que deben estar presentes en todas las actividades escolares. Por su parte, el artículo 6.4 del Decreto 416/2008 (CE, 2008) establece una serie de contenidos transversales que deben ser incluidos en el currículo. De estos contenidos, los que tienen una presencia más relevante en esta unidad didáctica son: 


\section{Unidad Didáctica: Who wants fracking in town? 2015}

- Fortalecimiento de los valores que preparan al alumnado para asumir una vida responsable en una sociedad libre y democrática (se relaciona con CAc.3). Uno de los principales objetivos de la presente unidad didáctica es despertar un espíritu crítico en el alumnado, que les permita el cuestionamiento de la información recibida y la elaboración de ideas propias. Estos conceptos son claves para el desarrollo de una vida democráticamente sana.

- Respeto al medio ambiente (se relaciona con CAc.1). Es el pilar fundamental de la asignatura en general y de esta unidad didáctica en concreto. Este respeto al medio ambiente se materializa en el estudio de los problemas ambientales en general y particularmente del fracking.

- Contenidos y actividades relacionadas con el medio natural y el patrimonio de Andalucía, mediante la puesta en valor de los espacios naturales andaluces (se relaciona con CC3), en especial de aquellos amenazados por la práctica del fracking como es el Parque Nacional de Doñana.

- Formación para la utilización de las TIC (se relaciona con CPr.1). La utilización de las TICs es una constante en el desarrollo de actividades CTSA como las que se llevan a cabo en esta unidad didáctica. Este contenido se trabaja durante la actividad de búsqueda de información fiable, así como en los momentos en los que el busca información para abordar los contenidos. 


\section{METODOLOGÍA}

\subsection{Modelos didácticos}

El aprendizaje cooperativo, utilizado a lo largo de esta unidad didáctica, está directamente relacionado con el modelo didáctico del constructivismo. El paradigma del constructivismo defiende el conocimiento como una construcción del ser humano, más que una mera copia de la realidad. Así, la construcción del conocimiento se realiza mediante esquemas internos, entendidos como representaciones internas que nos sirven para enfrentarnos a situaciones iguales o parecidas en la realidad (Carretero, 1997). Podemos considerar a Piaget y Vygotsky los autores más relevantes del pensamiento constructivista en el ámbito educativo.

Como ya se indica en el apartado 4.3, Jean Piaget muestra cómo la inteligencia va atravesando fases o estadios cualitativamente diferentes. Es decir, en las sucesivas fases del desarrollo humano existen estructuras distintas que sirven para ordenar la realidad de manera diferente, por lo que cuando se pasa de un estadio a otro se adquieren esquemas y estructuras nuevos que permiten entender la realidad desde otros puntos de vista. Además, el autor da una especial importancia al papel que juega la interacción del individuo con el medio en la construcción del conocimiento. Por su parte, Lev Vygotsky considera que el conocimiento es un producto de la interacción social y cultural. De este modo, cualquier tipo de aprendizaje se produce a raíz de una interacción social con otros, especialmente los padres y profesores, que posteriormente se internaliza (Carretero, 1997).

Un elemento central en la obra de Vygostky es el concepto de zona de desarrollo próximo, definido como "la distancia entre el nivel real de desarrollo, determinado por la capacidad de resolver independientemente un problema, y el nivel de desarrollo potencial, determinado a través de la resolución de un problema bajo la guía de un adulto o en colaboración con un compañero más capaz" (Vygotsky, 1978, 133-134 de la traducción castellana). Esto implica la idea de que las tareas que son demasiado difíciles para que las realice el alumno por sí mismo, pueden ser completadas con la ayuda de un adulto u otros alumnos con mayores conocimientos, ampliando así su zona de desarrollo próximo. La asistencia proporcionada, por el profesor o sus iguales, para completar una tarea que el alumno no puede resolver por sí mismo se conoce como andamiaje (Li y Lam, 2013). 


\section{Unidad Didáctica: Who wants fracking in town? 2015}

El proceso de andamiaje es esencialmente cultural. En él los padres, profesores y otros iguales juegan un papel importante en el proceso de aprendizaje, dando directrices e instrucciones, comentarios y feedbacks al estudiante. De este modo el aprendizaje deja de ser un proceso pasivo, ya que el alumno se comunica con el adulto o sus compañeros, resolviendo los problemas de forma interactiva mediante el entendimiento y el desarrollo de conocimientos (Li y Lam, 2013).

A la hora de aplicar la orientación constructivista a la enseñanza de las ciencias Gil Pérez et al. (1999) sugiere plantear el aprendizaje a través del planteamiento de problemas abiertos que sean de interés para el alumnado. Por lo tanto, las actividades propuestas deben tener un carácter científico a la vez que ser creativas y estar abiertas a la actuación del alumnado, siendo el papel del profesor el de orientar la actividad. Algunas de las características que debe incluir este tipo de actividades son:

- Ser de interés y relevantes para el alumnado, para tratar de motivarlos.

- Estudiar cualitativamente las situaciones, para que el alumnado explique sus ideas previas aplicadas al problema.

- Emisión de hipótesis y conceptos por parte del alumnado para así comprobar la validez de las ideas previas.

- Elaboración de estrategias para probar las hipótesis.

- Resolución y análisis de resultados para poner en conflicto las diferentes hipótesis.

- Aplicación de los conocimientos generados a diferentes situaciones.

Sin embargo, esta no es una receta exacta, sino que conviene adaptar estas indicaciones a cada caso concreto. Para ello hay que tener en cuenta los aspectos metodológicos, afectivos (motivación, clima de trabajo) y la contextualización (campo en el que es de especial interés las CTSA). Se trata en definitiva de un proceso de investigación orientada en el que el alumnado reconstruye sus conocimientos gracias al andamiaje provisto por el profesor, propiciando así un aprendizaje significativo (Gil Pérez et al. 1999).

\subsection{Orientaciones metodológicas}

Como ya se señaló en el apartado 2.2, existen tres elementos característicos de esta unidad didáctica, que son el uso de una orientación CTSA, el aprendizaje cooperativo y el CLIL. A continuación se detalla la aplicación de estos métodos en el aula. 


\section{Unidad Didáctica: Who wants fracking in town? 2015}

\subsubsection{CTSA}

Por lo general, el hilo conductor de la unidad didáctica será la utilización del método CTSA, en el que se pretende conectar los conocimientos científicos con problemas cercanos al alumnado, tanto de carácter técnico como científico. Para ello, la unidad didáctica consta de 5 fases diferenciadas siguiendo el modelo propuesto por Francisco-Rivero et al., (2013), aunque modificado, de tal forma que la fase 1 se dividirá en dos partes, una previa y otra posterior a la Fase 2. Las 5 fases planteadas son: Fase 0, de preparación; Fase 1, de información; Fase 2, de concienciación; Fase 3, de acción; Fase 4, de reflexión. La estructura general de las sesiones será diferente en cada una de estas fases.

La Fase 0 es la fase previa. El objetivo de esta fase es doble, por un lado se busca despertar el interés del alumnado, y por otro, preparar el desarrollo general de las actividades del resto de la unidad didáctica. Durante esta fase la organización del aula será la de gran grupo, bajo la dirección del profesor.

En primer lugar el docente explicará la forma de trabajar (metodología) que se seguirá durante la unidad didáctica, así como las formas de evaluación. Puesto que la forma de trabajo durante gran parte de la unidad didáctica es mediante aprendizaje cooperativo, en esta fase el profesor formará los equipos de trabajo, como se especificará más adelante.

Dado que la estrategia CTSA requiere de la búsqueda de información por parte del alumnado, es conveniente que el docente de unas nociones de búsqueda de información fiable. Estas nociones se transmitirán mediante una breve lección magistral en la que los estudiantes participarán en momentos puntuales a petición del docente.

Por último, se plantean una serie de preguntas al gran grupo que los alumnos tratarán de resolver entre todos, a modo de debate. Con esto se pretende que el profesor identifique las ideas previas que pueda tener el alumnado con respecto a los temas tratados a lo largo de la unidad didáctica. Las respuestas a estas cuestiones las irá construyendo el alumnado a lo largo de la unidad didáctica, planteándoles las mismas preguntas al final de la unidad, a modo de autoevaluación, para que comprueben su progreso.

La Fase 1 es la fase de información y tiene como objetivo la adquisición de conocimientos por parte del alumnado. En esta unidad didáctica en concreto la fase 1 se divide en dos partes, una primera parte en la que se tratarán los temas de "los principales problemas ambientales", "los ciclos biogeoquímicos de la materia" y "el fracking"; Y una segunda, en la 


\section{Unidad Didáctica: Who wants fracking in town? 2015}

que se estudiarán la "evaluación de impacto ambiental (EIA), ordenación del territorio y legislación ambiental".

En todos los casos se trabajará mediante un modelo de aprendizaje cooperativo detallado más adelante. La estructura general de las sesiones consistirá en:

1. El planteamiento de una pregunta o un problema por parte del profesor el alumnado.

2. Proporcionar a cada equipo el material necesario para la resolución del problema.

3. Producción de un contenido por parte de cada equipo.

4. Al final de cada actividad el profesor plantea una pregunta a modo de introducción para la siguiente sesión.

Puesto que se dispone de tiempo suficiente, el trabajo se realizará mayoritariamente en clase, tratando de reducir la cantidad de trabajo que el alumnado tenga que realizar en sus casas al mínimo.

La Fase 2, de concienciación, consistirá en un debate planteado como un juego de roles. En el debate, cada equipo asumirá el papel de uno de los actores relacionados con el fracking (Empresa extractora, ciudadanos, administración, grupos ecologistas, etc.). Para ello el profesor proporcionará a cada equipo un documento y unas palabras clave que les sirvan como guía, pero son los alumnos los que deben buscar la información y preparar la argumentación para el debate.

Durante el debate, el profesor actuará como moderador (en el papel de alcalde), guiándolo hacia los temas que interesan tratar.

La Fase 3 es la fase de acción, en la que cada equipo debe desarrollar una acción de carácter social que tenga una repercusión real sobre algún aspecto del tema tratado.

El tipo de acción a tomar es elección del grupo, con el visto bueno del profesor, algunos ejemplo de acción pueden ser: Elaboración de carteles informativos, podcast, vídeos de concienciación, una entrada en Wikipedia, una propuesta para la fase de participación ciudadana de una EIA, la redacción y envío de una carta al director de algún medio de comunicación, campañas de información y sensibilización, recogida de firmas en colaboración con algún grupo ecologistas o partido político, dar una charla a cursos inferiores, etc. 


\section{Unidad Didáctica: Who wants fracking in town? 2015}

La temática de la acción realizada puede ser tanto a favor como en contra del conflicto planteado, para favorecer el pensamiento crítico del alumnado. Puesto que la acción ha de ser fruto del trabajo de todo el equipo, se destinará dos sesiones a la planificación en clase de la medida a adoptar, contando con la ayuda del profesor en clase.

La Fase 4, de reflexión, consistirá en la elaboración de un breve informe en el que se relacionen los elementos vistos a lo largo de la unidad didáctica y en el que el alumnado exponga sus reflexiones y visión personal. Esta actividad la deberá realizar cada alumno individualmente en su casa.

\subsubsection{Aprendizaje cooperativo}

Como se ha visto en el apartado 8.2.1, durante la fase de información (Fase 1) se utilizará el aprendizaje cooperativo como método de trabajo. Existen numerosas formas de implementar el aprendizaje cooperativo (Servicio de Innovación Educativa UPM, 2008). En este caso utilizaremos el método del Jigsaw o rompecabezas (Aronson et al., 1975), con algunas modificaciones. Los pasos a seguir serían los siguientes [2]:

1. Se divide la clase en equipos de 5 ó 6 estudiantes. Los equipos deben ser lo más heterogéneos posible en términos de género, habilidades y procedencias. Dado que el número de alumnos en bachillerato suele no ser mayor de 30 por aula, se formarán un máximo de 5 grupos. En cada grupo se nombrará un capitán (en principio, el miembro más maduro del grupo) y se asignará un número a cada miembro del equipo, como se representa en la figura 8.1 para facilitar la asignación de tareas.

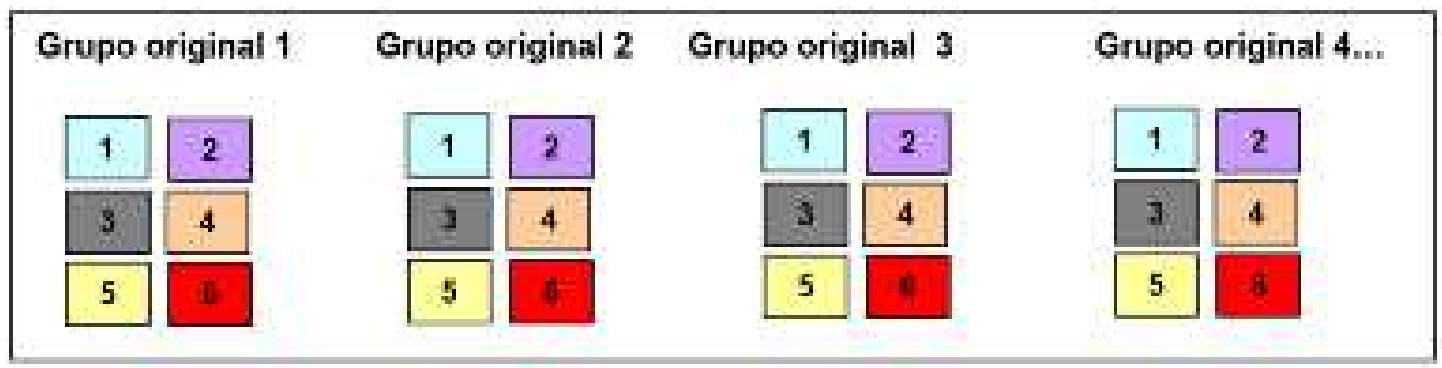

Figura 8.1. Formación de los equipos originales en el método Jigsaw (UPM, 2008) 


\section{Unidad Didáctica: Who wants fracking in town? 2015}

2. Se divide el material en partes y asignar una parte a cada miembro del equipo. A continuación se da un tiempo para que cada alumno lea su parte, al menos dos veces, y se familiarice con el contenido. No es necesario que lo memoricen.

3. Se forman "grupos de expertos", juntando a los alumnos de cada grupo que han trabajado el mismo contenido, como se muestra en la figura 8.2. Estos grupos de expertos tienen un tiempo para discutir los puntos principales de su parte y preparar la presentación que van a trasladar a su equipo.

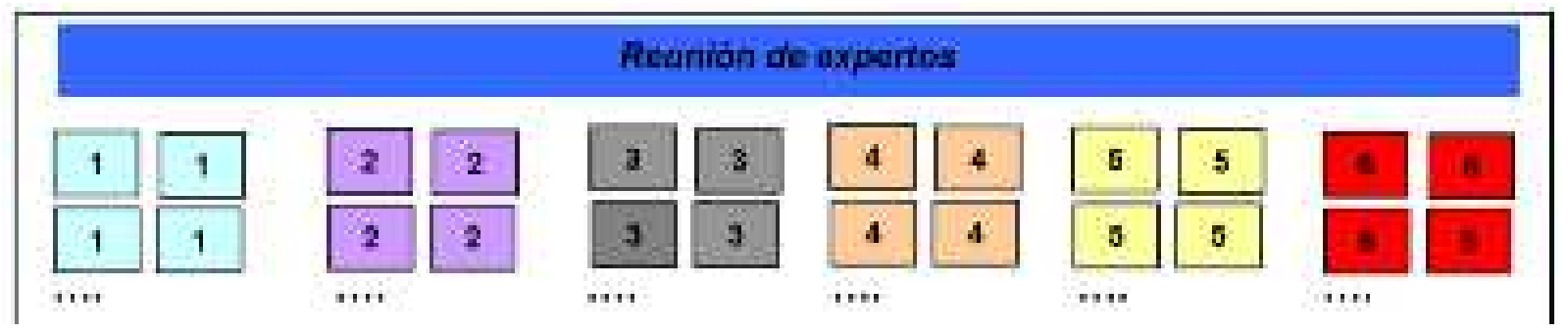

Figura 8.2. Formación de grupo de expertos en el método Jigsaw (UPM, 2008)

4. Todos los estudiantes vuelven a sus equipos (figura 8.1) y presentan, en orden, su parte de información. En este punto el profesor debe animar al resto de componentes del grupo a preguntar cualquier duda que tengan al respecto de la información planteada. En caso de producirse algún problema en un grupo, como tener un miembro disruptivo o demasiado dominante, el capitán (con la colaboración del profesor) será el encargado de lidiar con la situación.

5. Un vez puesta en común toda la información, cada equipo elaborará un informe con la información tratada durante la actividad, que será evaluado y servirá como base de estudio para la evaluación sumativa final.

Puesto que este modo de trabajar requiere que el alumnado cambie de tarea regularmente, es conveniente controlar los tiempos, por ejemplo, con la ayuda de un cronómetro virtual [3]

\subsubsection{CLIL}

El tercer aspecto importante señalado en el apartado 2.2 es el enfoque CLIL. Esta unidad didáctica está pensada para centro con enseñanza plurilingüe o bilingüe en los que una de las lenguas de docencia sea la inglesa. Hay que tener en cuenta que una de las características del CLIL es el hecho de que priman los contenidos por encima de la enseñanza del idioma (Coyle, 2005), por lo que el nivel de los contenidos debe mantenerse 


\section{Unidad Didáctica: Who wants fracking in town? 2015}

igual al de una enseñanza no bilingüe, utilizando la lengua inglesa únicamente como herramienta para transmitir los conocimientos.

El artículo 3 de la Orden de 28 de junio de 2011 (CE, 2011) establece que, al menos, el $50 \%$ de los contenidos del currículo deben impartirse en la lengua extranjera. Durante la unidad didáctica se combinarán ambos idiomas en las actividades. Los documentos facilitados al alumnado se entregarán en el idioma original en el que hayan sido redactados (español o inglés). Puesto que la mayor parte de los materiales proporcionados al alumnado durante las actividades es de índole científica, éstos serán documentos en inglés. No obstante, se utilizarán también documentos en español, como artículos periodísticos, o cualquier otro material referente a problemas locales, lo que supondrá un mayor nivel de confianza del alumnado puesto que podrán apoyarse en su lengua materna en caso de necesidad (Langer et al., 2006). Con esto se pretende que el alumnado asuma con naturalidad la utilización de ambos idiomas a la hora de trabajar una determinada temática.

En el segundo curso de bachillerato de una enseñanza bilingüe se presupone al alumnado un nivel medio-alto de inglés (equivalente al B2 del marco de referencia internacional), por lo que no se considera necesario proporcionar un glosario de términos al alumnado de forma previa. No obstante, para facilitar la lectura y comprensión de los textos, se recomendará el uso de diccionarios en clase, tanto en papel como en cualquier tipo de formato electrónico (en el Smartphone, portátil, tableta, etc.). Además, sería conveniente coordinar la unidad didáctica con el departamento de lengua inglesa, de tal modo que el alumnado trabaje el vocabulario de forma previa en clases de inglés.

Las explicaciones académicas del profesor (las cuales suponen una pequeña parte del tiempo de las sesiones) se harán en inglés. En caso de que algún estudiante tenga problemas puntuales para comprender lo expuesto el profesor podrá traducir el término problemático, o recurrir a estrategias diferentes como la reformulación, simplificación o la ejemplificación (Pavesi et al., 2001).

El debate propuesto para la Fase 2 se realizará principalmente en inglés, aprovechando el juego de roles para situarlo en un contexto internacional en el que la lengua común sea la inglesa. Durante el desarrollo de estas sesiones lo ideal es que el alumnado utilice el idioma de forma fluida, por lo que el profesor tenderá a no corregir en exceso el uso del idioma de los estudiantes, interviniendo solo en caso de errores graves y reiterados. 


\section{Unidad Didáctica: Who wants fracking in town? 2015}

Por último, un elemento esencial del CLIL es el contacto con la cultura que va ligada al idioma extranjero usado (Coyle, 2005), por ello se utilizarán durante las sesiones documentos referentes a Estados Unidos (país pionero en la aplicación del fracking) y Reino Unido (citando, por ejemplo, el caso de Blackpool).

Como forma de evaluar el manejo del inglés por parte del alumnado, cada uno de ellos confeccionará un diccionario de términos en inglés, con sus definiciones. Los estudiantes podrán hacer uso de él durante el examen.

\subsection{Recursos}

Para la completa realización de la presente unidad didáctica son necesarios una serie de recursos resumidos en la tabla 8.1 .

Tabla 8.1. Recursos necesarios para la implementación de la unidad didáctica.

\begin{tabular}{|c|}
\hline Recursos necesarios \\
\hline Dispositivos electrónicos con acceso a internet \\
\hline Conexión wi-fi \\
\hline Ordenador con proyector o pizarra digital \\
\hline Mesas y las sillas móviles \\
\hline
\end{tabular}

Una de las características más representativas de esta unidad didáctica es la búsqueda y el tratamiento de la información, en el aula, por parte del alumnado, a la hora de abordar los contenidos. Por ello un recurso esencial son los dispositivos electrónicos con acceso a internet (ordenadores portátiles, tabletas, Smartphone, etc.), bien sean del alumno o formen parte del equipamiento TIC del centro. Por el mismo motivo es importante que el alumnado tenga acceso a la conexión wi-fi del centro.

Por lo general, estos requisitos no deben suponer un impedimento para la implementación de la unidad didáctica, puesto que en Andalucía existen más de 5.800 centros TIC (CGA, 2012). En caso de no disponerse de estos recursos en el aula, las actividades podrían adaptarse de tal forma que la búsqueda de información la realizasen los alumnos de forma individual en sus hogares, haciendo coincidir esta parte de la actividad con el fin de una sesión y el inicio de la siguiente. 


\section{Unidad Didáctica: Who wants fracking in town? 2015}

También es necesaria la presencia de un ordenador con proyector o pizarra digital en el aula, que el profesor pueda utilizar para proyectar las presentaciones cuando sea necesario.

Por último, es imprescindible que las mesas y las sillas del aula sean móviles, de tal forma que el alumnado pueda cambiar su posición cuando sea necesario. Así podrán agrupar las mesas para trabajar en equipos, ponerlas en círculo a la hora de debatir, o por parejas cuando tengan que trabajar por pares.

\subsection{Atención a la diversidad}

Según la LEA (2007) se considera necesidades específicas de apoyo a aquellas derivadas de los diferentes grados de capacidades de orden físico, psíquico, cognitivo o sensorial que presenta el alumnado, así como las condiciones de incorporación tardía al sistema educativo, y aquellos que presentan altas capacidades intelectuales.

El aprendizaje cooperativo utilizado en esta unidad didáctica se muestra como una herramienta útil para la atención de las distintas necesidades del alumnado en función de sus características personales, competencias curriculares y estilo de aprendizaje. Esta técnica permite adaptar el currículo a las necesidades de cada alumno, para que cada uno de ellos alcance los mismos objetivos de forma diferente (Sánchez, 1999). Ferguson y Jeanchild (1991) señalan tres aspectos básicos para la adaptación del currículo a las necesidades específicas de cada alumno a través del aprendizaje cooperativo:

- Formar grupos heterogéneos en cuanto a criterios de habilidades interpersonales, incluyendo en cada grupo al menos una persona con destreza para desenvolverse en el grupo y otra con necesidad de ayuda para relacionarse; y capacidad cognitiva, buscando un equilibrio entre el alumnado con mayor capacidad y con necesidades de ayuda. También es conveniente que cada estudiante esté en un grupo en el que tenga afinidad con al menos otro miembro del grupo. Los estudiantes con mayores problemas para relacionarse deberá compartir grupo con alumnos capaces de proporcionar apoyo e integrarlos socialmente.

- Favorecer la interdependencia positiva para que el alumnado aprenda a depender de los demás, sentirse útiles y ayudarse mutuamente para conseguir objetivos comunes. Para ello es necesario establecer metas grupales y diseñar actividades en las que sea necesario el esfuerzo de todos los miembros del grupo. 


\section{Unidad Didáctica: Who wants fracking in town? 2015}

- Adaptar el aprendizaje individual a las capacidades de cada alumno. Para ello es conveniente el establecimiento de objetivos individuales flexibles que se adecuen a las necesidades, destrezas, intereses y habilidades únicas de cada uno.

En la presente unidad didáctica, la misma metodología utilizada sirve como respuesta a las necesidades específicas de cada tipo de estudiante. Además, la técnica Jigsaw es también beneficiosa para el alumnado con menos capacidades intelectuales, con altas capacidades y alumnado disruptivo, tal y como se especifica en el anexo 4.

\subsection{Descripción de las actividades}

Para facilitar la descripción de las actividades, la unidad didáctica se dividirá en las 5 fases descritas en el apartado 8.2.1 (Francisco-Rivero et al., 2013). Al inicio de cada actividad se presenta un cuadro resumen en el que se indica su duración e idioma en el que se realiza, así como los objetivos y contenidos tratados. La distribución aproximada de las actividades a lo largo de las 16 sesiones se hará conforme se indica en la tabla 8.2.

Tabla 8.2. Distribución de las actividades.

\begin{tabular}{|c|c|}
\hline Sesión & Actividad \\
\hline 1 & Actividad 1 y 2 \\
\hline 2 & Actividad 3 \\
\hline 3 y 4 & Actividad 4 \\
\hline 5 y 6 & Actividad 5 \\
\hline 7 y 8 & Actividad 6 \\
\hline 9 y 10 & Actividad 7 \\
\hline 11 y 12 & Actividad 8 \\
\hline 13 y 14 & Actividad 9 \\
\hline 15 & Actividad 11 \\
\hline 16 & Actividad 12 \\
\hline
\end{tabular}




\subsubsection{Fase 0. Preparación}

\section{Actividad 1. What we gonna do?}

Tabla 8.3. Resumen actividad 1

\begin{tabular}{|c|c|c|c|}
\hline \multicolumn{4}{|c|}{ Explicación de la actividad } \\
\hline Contenidos & Objetivos & Duración & Idioma \\
\hline- & - & 20 min & Español \\
\hline
\end{tabular}

El profesor explica al gran grupo el método de trabajo que se utilizará durante las próximas sesiones (detallado en el apartado 8.2). Subrayando la necesidad de que el alumnado vaya confeccionando su propio diccionario, que será evaluado conjuntamente con el examen.

El profesor designa los equipos de trabajo (conforme a lo establecido en los apartados 8.1 y 8.4) y asigna un número a cada miembro del equipo, que éstos deben recordar y anotar. El profesor habrá diseñado los grupos con anterioridad.

\section{Actividad 2. What do we already know?}

Tabla 8.4. Resumen actividad 2

\begin{tabular}{|c|c|c|c|}
\hline \multicolumn{4}{|c|}{ Explicación de la actividad } \\
\hline Contenidos & Objetivos & Duración & Idioma \\
\hline- & - & 40 min & Inglés \\
\hline
\end{tabular}

Dispuestos los alumnos individualmente, se reparte a cada uno una hoja con preguntas (Anexo 5). Cada alumno debe anotar la respuesta que cree correcta para, posteriormente debatirla con el resto de la clase. El profesor guía el debate con preguntas, cuestionando las respuestas del alumnado.

El objetivo del profesor es identificar las ideas previas del alumnado con el fin de adaptar las siguientes sesiones en consecuencia. 


\section{Unidad Didáctica: Who wants fracking in town? 2015}

\section{Actividad 3. Who can I trust on the internet?}

Tabla 8.5. Resumen actividad 3

\begin{tabular}{|c|c|c|c|}
\hline \multicolumn{4}{|c|}{ Explicación de la actividad } \\
\hline Contenidos & Objetivos & Duración & Idioma \\
\hline CPr.1, CAc.3 & Ob.8 & 60 min & Español \\
\hline
\end{tabular}

El profesor da una clase magistral sobre búsqueda de información fiable apoyándose en la presentación recogida en el anexo 6 (esta misma presentación fue utilizada durante la realización de mis prácticas en el IES Generalife, con alumnos de $1^{\circ}$ de bachillerato, con un resultado muy satisfactorio). La presentación será puesta a disposición del alumnado para que puedan consultarla cuando sea necesario. El contenido a explicar en cada diapositiva es el siguiente:

1. Presentación del tema (cómo buscar información fiable) y mención de que la información que se va a explicar será útil para las sesiones posteriores.

2. Comentario sobre la fiabilidad de algunas de las fuentes de información más utilizadas por el alumnado. Sobre "El rincón del vago", indicación de la baja calidad de la información y el riesgo de plagio, puesto que no se suelen especificar las fuentes. Sobre Wikipedia, explicación de su funcionamiento (condiciones de uso, cómo modificarla, control de errores etc.). En este punto el profesor mostrará la página de preguntas frecuentes de la Wikipedia [4] y editará un artículo para mostrar cómo de fácil es modificar la información en esta página (el alumnado podrá comprobar cuánto tiempo dura la información modificada en la web). Sobre los medios de comunicación, ejemplificados en los periódicos, comentario sobre el hecho de que responden a intereses, que no son fuentes académicas y que pueden contradecirse entre sí; para ejemplificarlo, el profesor invitará a 3 alumnos a buscar (usando sus Smartphone, ordenadores portátiles o los ordenadores del centro) una misma información en diferentes medios, y pedirá que lean el titular en voz alta para comprobar que la información es contradictoria. Un ejemplo podrían ser estas tres noticias en las cuyos titulares son: "El trasplante de cabeza es posible y este será el primer hombre que se opere" que establece la fecha del trasplante en 2016 [5], "Hoy en día es absolutamente imposible trasplantar una cabeza humana" hasta dentro de un siglo, aseguran [6], y "Primer trasplante de cerebro humano" situado en Japón 


\section{Unidad Didáctica: Who wants fracking in town? 2015}

hace 4 años [7]. Por último, reflexión a cerca de la importancia de consultar varias fuentes distintas para comprobar su veracidad.

3. Explicación de la importancia de evaluar los factores que se muestran en la diapositiva antes de dar por buena una información. En el caso de la vigencia, advertencia de que un artículo científico con más de 5 años de antigüedad, dependiendo del área de conocimiento, puede considerarse obsoleto.

4. Enfatización de la importancia de consultar varias fuentes a la hora de buscar información.

5. Descripción de algunas de las herramientas que se mencionan en el artículo [8]

6. Listado de algunos organismos oficiales a los que el alumnado puede acudir para buscar información, como ONGs, organismos gubernamentales, etc. Mención a la necesidad de contrastar la información debido a posibles conflictos de intereses, poniendo como ejemplo el caso de los sindicatos y la patronal.

7. Explicación de otras herramientas útiles para la búsqueda de información como son los operadores lógicos [9], las normas de citación APA [10], así como una invitación a los estudiantes interesados a consultar más información al respecto [11].

Esta actividad tiene un carácter genérico. Aunque está incluida en esta unidad didáctica, se podría haber trabajado en otras. En el caso de hubiera sido así, obviamente, no sería necesario repetirla.

\subsubsection{Fase 1. Información}

\section{Actividad 4. How do environmental problems affect us?}

Tabla 8.6. Resumen actividad 4

\begin{tabular}{|c|c|c|c|}
\hline \multicolumn{4}{|c|}{ Explicación de la actividad } \\
\hline Contenidos & Objetivos & Duración & Idioma \\
\hline $\begin{array}{c}\text { CC1, CPr.1, CPr.2 } \\
\text { CAc.1, CAc.3, CAc.4 }\end{array}$ & $\begin{array}{c}\text { Ob.1, Ob.7, Ob.8, } \\
\text { Ob.10 }\end{array}$ & 2 horas & Inglés \\
\hline
\end{tabular}

Para iniciar la sesión, el profesor pide al alumnado que nombre algunos de los principales problemas ambientales que conozcan y los anota en la pizarra (10 min). En unidades anteriores se han estudiado diferentes aspectos del medio ambiente y los problemas ambientales asociados, por lo que espera que el alumnado cubra la mayor parte de los problemas que se van a tratar en la actividad que se menciona posteriormente. 


\section{Unidad Didáctica: Who wants fracking in town? 2015}

A continuación, los alumnos se disponen conforme a los grupos designados en la actividad 1. Se asigna aleatoriamente, utilizando un dado virtual [12], un problema medioambiental a cada alumno:

- Cambio climático

- Agujero en la capa de ozono

- Pérdida de biodiversidad

- Contaminación atmosférica

- Erosión y contaminación de suelos y aguas

- Terremotos y erupciones volcánicas ${ }^{4}$

Los aspectos de cada problema ambiental a trabajar son:

- ¿En qué consiste este problema ambiental?

- ¿Cuáles son sus causas?

- ¿Qué consecuencias tiene sobre el medioambiente?

- ¿Cómo afecta al ser humano?

Para responder a estas preguntas el alumnado contará con el libro de texto ${ }^{5}$, además de la información que busquen a través de internet.

Siguiendo la técnica Jigsaw, descrita en el apartado 8.2.2, cada alumno busca y comprende información relacionada con el problema medioambiental que le ha sido asignado (20 min). Pasado el tiempo, se forman los grupos de expertos en los que se pone en común la información y deciden qué contenidos va a exponer cada alumno en su equipo (20 min). Tras la discusión en el grupo de expertos, cada alumno vuelve a su grupo y se exponen las ideas centrales de cada apartado (10 min). Por último, cada grupo redacta un pequeño informe, en inglés, en el que se responde a la preguntas planteadas para cada apartado y lo entregarán al profesor (40 min).

\footnotetext{
${ }^{4}$ Aunque los terremotos y erupciones volcánicas son procesos naturales y se suelen estudiar con estos, existen terremotos de origen antrópico. Éstos suelen ser de pequeña magnitud (existe controversia sobre el terremoto de Lorca (Doblado, 2013), uno de los más graves), pero en todo caso los daños que ocasionan sí dependen en gran parte de la actuación humana.

${ }^{5}$ Es práctica habitual que los alumnos de bachillerato tengan un libro de texto para cada asignatura.
} 


\section{Unidad Didáctica: Who wants fracking in town? 2015}

El profesor preguntará, de manera aleatoria, a un miembro de cada grupo sobre conceptos clave del contenido tratado (15 min). Es responsabilidad de todo el grupo que cada uno de sus miembro maneje bien la información, ya que la calificación del grupo dependerá de la respuesta a esta pregunta.

Para finalizar la actividad, el profesor preguntará si los terremotos pueden tener causas humanas, tras la respuesta del alumnado (presumiblemente negativa) se les entregará un artículo del diario estadounidense Huffington Post [13] en el que se señala la posibilidad de que las actividades humanas hubieran desencadenado el terremoto de Lorca (Murcia) en el año 2012 (5 min).

\section{Actividad 5. Where does matter come from and go to?}

Tabla 8.7. Resumen actividad 5

\begin{tabular}{|c|c|c|c|}
\hline \multicolumn{4}{|c|}{ Explicación de la actividad } \\
\hline Contenidos & Objetivos & Duración & Idioma \\
\hline $\begin{array}{c}\text { CC2, CPr.1, CPr.2, } \\
\text { CAc.3, CAc.4 }\end{array}$ & Ob.2, Ob.8, Ob.10 & 2 horas & Inglés \\
\hline
\end{tabular}

Como introducción, el profesor se dirige al gran grupo retomando los contenidos trabajados en la actividad anterior, en concreto el cambio climático, y explicando la importancia de la movilización del carbono secuestrado hacia la atmósfera, relacionándolo con el ciclo del carbono (10 min).

A continuación, los alumnos se colocan por equipos y se asigna aleatoriamente, utilizando un dado virtual [12], uno de los siguientes apartados a cada alumno:

- Ciclo del carbono

- Ciclo del oxígeno

- Ciclo del nitrógeno

- Ciclo del fósforo

- Ciclo del azufre

En los grupos de 6 componentes, dos de ellos trabajan el ciclo del carbono. 


\section{Unidad Didáctica: Who wants fracking in town? 2015}

Para cada uno de los ciclos el alumnado deberá estudiar cuáles son sus principales reservorios y procesos, así como comprender el concepto de ciclicidad que llevan asociados. Para ello contarán con un esquema mudo de cada ciclo (ver anexo 7), además deberán buscar información complementaria tanto en su libro de texto como a través de internet.

La forma de proceder es la misma que en la actividad anterior. Siguiendo la técnica Jigsaw, cada alumno busca y comprende información pertinente (20 min). Se expone y debate la información en el grupo de expertos (20 min). Los alumnos vuelven a sus grupos y exponen las ideas (10 min). Por último cada grupo diseña un esquema para cada uno de los ciclos y lo entregarán al profesor (40 min).

Para concluir la actividad, cada grupo entrega los ciclos con los espacios en blanco rellenos, y el profesor realiza preguntas, sobre los conceptos clave de los ciclos biogeoquímicos, a miembros de cada equipo elegidos aleatoriamente. Algunos ejemplos de estas preguntas serían: ¿Cuál es el principal reservorio del ciclo del carbono?, ¿Cómo se llama el proceso por el que el oxígeno pasa de la atmósfera a la biosfera?, ¿En qué formas se encuentra el nitrógeno en el suelo?, etc. (10 min). Partiendo de las respuestas del alumnado, el profesor relaciona el ciclo del carbono con el cambio climático, señala el fracking como uno de los procesos que movilizan el carbono inmovilizado en compartimentos estanco (10 min).

\section{Actividad 6. Fracking is coming!}

Tabla 8.8. Resumen actividad 6

\begin{tabular}{|c|c|c|c|}
\hline \multicolumn{4}{|c|}{ Explicación de la actividad } \\
\hline Contenidos & Objetivos & Duración & Idioma \\
\hline $\begin{array}{c}\text { CC3, CPr.1, CPr.2, } \\
\text { CAc.3, CAc.4 }\end{array}$ & $\begin{array}{c}\text { Ob.3, Ob.8, } \\
\text { Ob.10 }\end{array}$ & 2 horas & Inglés \\
\hline
\end{tabular}

Para comenzar la actividad, el profesor proyecta un vídeo [14] en el que se describe el proceso de fracking y sus consecuencias (10 min). La figura 8 muestra una captura de pantalla de dicho vídeo. 


\section{Unidad Didáctica: Who wants fracking in town? 2015}

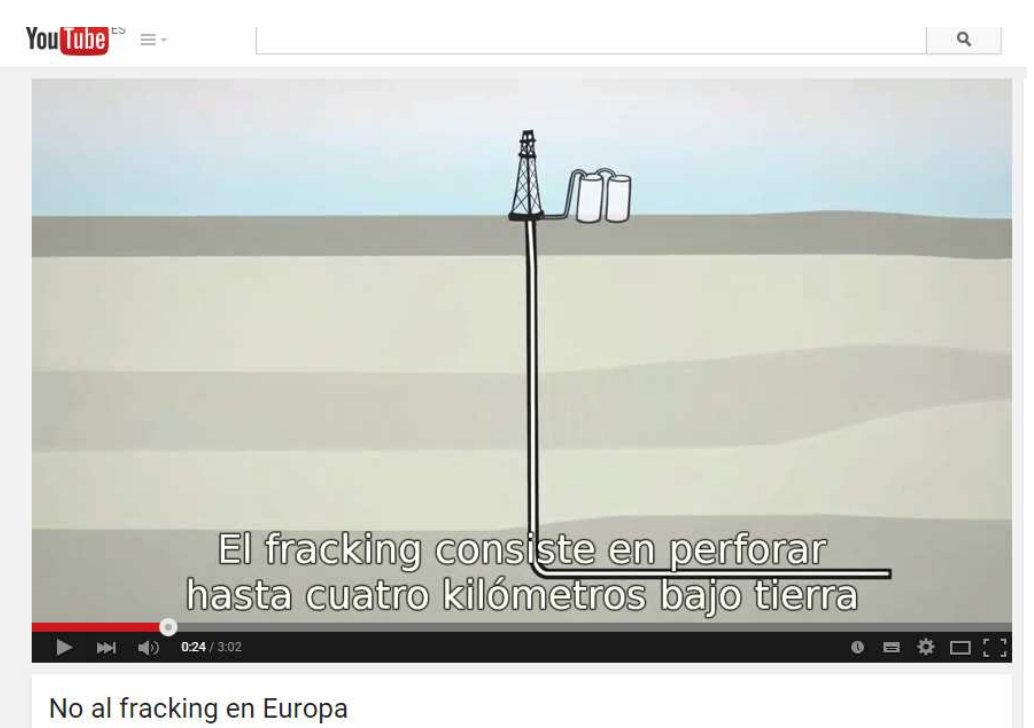

Figura 8.3. Captura de pantalla del vídeo "No al fracking en Europa" [14]

A continuación, se trabaja el tema del "fracking" utilizando el método Jigsaw habitual. Los contenidos a repartir entre los miembros del equipo son:

- Descripción de la técnica de fracturación hidráulica

- Legislación

- Impactos sobre el medioambiente y la sociedad

- Situación actual del fracking en España y el resto del mundo

- Casos de estudio

Puesto que el libro de texto no es un recurso especialmente útil en este caso, el profesor repartirá el documento correspondiente, de recogidos en el anexo 8, a cada alumno. Esta información debe servir como punto de partida para la investigación de los estudiantes y ser completada con otras fuentes buscada por ellos mismos.

Los tiempos se repartirán de la siguiente manera: búsqueda y comprensión de la información (20 min). Exposición y debate la información en el grupo de expertos (20 min). Planteamiento de las ideas principales en el equipo (10 min). Redacción del informe y entrega al profesor (40 min).

Para concluir la actividad, el profesor realiza preguntas, sobre los conceptos clave acerca del fracking a miembros de cada equipo elegidos aleatoriamente (10 min). Tras las preguntas, el profesor explica la actividad que se realizará la siguiente sesión. 


\section{Unidad Didáctica: Who wants fracking in town? 2015}

\subsubsection{Fase 2. Concienciación}

\section{Actividad 7. Who wants fracking in town?}

Tabla 8.9. Resumen actividad 7

\begin{tabular}{|c|c|c|c|}
\hline \multicolumn{3}{|c|}{ Explicación de la actividad } \\
\hline Contenidos & Objetivos & Duración & Idioma \\
\hline CC3, CC4, CC5, CPr.1, & $\begin{array}{c}\text { Ob.6, Ob.7, Ob.8, } \\
\text { Ob.9, Ob.10 }\end{array}$ & 2 horas & Inglés \\
$\begin{array}{c}\text { CPr.2, CPr.3, CAc.1, CAc.2, } \\
\text { CAc.3, CAc.4, CAc.5 }\end{array}$ & & & \\
\hline
\end{tabular}

Esta actividad consiste en la realización de un debate a través de un juego de roles (con un esquema similar al de Francisco-Rivero et al., 2013).

En la sesión previa, el profesor explica la actividad de juego de roles y reparte los distintos papel entre los equipos. Cada equipo recibe un documento describiendo las bases del juego (Anexo 9) y otro en el que se plasma la línea argumental del grupo al que representan y se aporta un documento y un vídeo con los que iniciar la investigación (Anexo 10). No obstante para preparar el debate cada grupo debe buscar la información y argumentos utilizados por el actor que interpretan (noticias, páginas web, vídeos, etc.).

Los roles asignados son:

- Empresa internacional extractora de hidrocarburos

- Grupos ecologistas

- Gobierno central

- Población local

- Agricultores de la zona

Se reúnen los grupos para poner sus posiciones en común y preparar el debate (30 min). Tras la preparación, comienza el debate regulado por el profesor (75 min). El papel del profesor (adoptando el rol del alcalde local) será el de moderar el debate e introducir preguntas para dinamizar y reconducirlo para que afloren los conceptos de sostenibilidad, evaluación de impacto ambiental y ordenación del territorio. Al finalizar el debate, el profesor hará un resumen de lo expuesto en el debate y tomará una decisión (en el papel de alcalde) a modo de conclusión (15 min). 


\section{Unidad Didáctica: Who wants fracking in town? 2015}

La duración de la actividad completa es de dos horas (dos sesiones) lo cual permite a los grupos replantearse sus posiciones y buscar nuevos argumentos entre una sesión y otra.

\subsubsection{Fase 1.2. Información}

\section{Actividad 8. How do we manage this?}

Tabla 8.10. Resumen actividad 8

\begin{tabular}{|c|c|c|c|}
\hline \multicolumn{4}{|c|}{ Explicación de la actividad } \\
\hline Contenidos & Objetivos & Duración & Idioma \\
\hline $\begin{array}{c}\text { CC6, CC7, CPr.1, CPr.2, } \\
\text { CAc.2, CAc.3, CAc.4 }\end{array}$ & $\begin{array}{c}\text { Ob.4, Ob.8, } \\
\text { Ob.10 }\end{array}$ & 2 horas & Inglés \\
\hline
\end{tabular}

Como introducción, el profesor se dirige al gran grupo retomando los conceptos clave tratados en el debate, a modo de resumen. Como parte del resumen, señala las distintas herramientas propuestas para solucionar el problema, especialmente las EIA, la ordenación del territorio y la legislación ambiental (10 min).

Seguidamente, se trabajan estos conceptos según la metodología Jigsaw. Los apartados a tratar repartir son:

- Qué es una evaluación de impacto ambiental

- Metodología de una EIA

- Ordenación del territorio

- Legislación ambiental internacional

- Legislación ambiental en España

Para el estudio de cada uno de los apartados el alumnado contará con los documentos recogidos en el anexo 11, además de información complementaria que busquen el libro de texto $\mathrm{u}$ otras fuentes.

Los tiempos se repartirán de la siguiente manera: Búsqueda y comprensión de la información (20 min). Exposición y debate la información en el grupo de expertos (20 min). Planteamiento de las ideas principales en el equipo (10 min). Redacción del informe y entrega al profesor (40 min). 


\section{Unidad Didáctica: Who wants fracking in town? 2015}

Para concluir la actividad, el profesor realiza preguntas, sobre los conceptos clave acerca del fracking a miembros de cada equipo elegidos aleatoriamente (10 min).

\subsubsection{Fase 3. Acción}

Actividad 9. Let's do it!

Tabla 8.11. Resumen actividad 9

\begin{tabular}{|c|c|c|c|}
\hline \multicolumn{4}{|c|}{ Explicación de la actividad } \\
\hline Contenidos & Objetivos & Duración & Idioma \\
\hline $\begin{array}{c}\text { CC1, CC2, CC3, CC4, } \\
\text { CC5, CC6, CC7, CPr.1, } \\
\text { CPr.2, CAc.2, CAc.4 }\end{array}$ & Ob.5, Ob.10 & 2 horas & Español \\
\hline
\end{tabular}

Cada equipo trabaja en desarrollar una acción de carácter social que tenga una repercusión real en algún aspecto del tema tratado. Esta actividad consta de dos partes diferenciadas: planificación y ejecución del proyecto. Dependiendo de la naturaleza de la acción que plantee cada equipo, se abordarán durante estas dos sesiones ambas partes de la actividad o sólo la planificación.

El tipo de acción a tomar es elección del grupo, con el visto bueno del profesor. No obstante, el profesor aporta algunas ideas a modo de ejemplo:

- Elaborar carteles informativos

- Grabar un podcast o un vídeos de concienciación

- Redactar una propuesta para la fase de participación ciudadana de una EIA

- Escribir y enviar una carta al director de alguno de los medios de comunicación local

- Realizar una campaña informativa en el centro y la comunidad

- Colaborar con algún grupo ecologistas o partido político

- Iniciar una campaña de recogida de firmas ( de forma física o mediante plataformas online)

- Dar una charla de concienciación a cursos inferiores

- Redactar o modificar una entrada en Wikipedia 


\section{Unidad Didáctica: Who wants fracking in town? 2015}

El idioma en el que se realizará la mayor parte de los proyectos es el español, puesto que se circunscriben al ámbito local. Durante estas dos sesiones pueden reunirse para tomar decisiones, contando con la asistencia del profesor. En la mayoría de los casos la realización de la acción necesitará del trabajo del grupo en horas no lectivas.

\subsubsection{Fase 4. Reflexión}

\section{Actividad 10. So... What?}

Tabla 8.12. Resumen actividad 10

\begin{tabular}{|c|c|c|c|}
\hline \multicolumn{5}{|c|}{ Explicación de la actividad } \\
\hline Contenidos & Objetivos & Duración & Idioma \\
\hline $\begin{array}{c}\text { CC1, CC2, CC3, CC4, CC5, } \\
\text { CC6, CC7, CAC.1, CAC.2 }\end{array}$ & Ob.6, Ob.7 & - & Inglés \\
\hline
\end{tabular}

Cada alumno elabora individualmente un informe en el que se relacionan los elementos vistos a lo largo de la unidad didáctica y en el que exponga sus reflexiones y visión personal.

Esta actividad la realizará cada alumno individualmente fuera del horario lectivo.

\section{Actividad 11. The exam}

Tabla 8.13. Resumen actividad 11

\begin{tabular}{|c|c|c|c|}
\hline \multicolumn{4}{|c|}{ Explicación de la actividad } \\
\hline Contenidos & Objetivos & Duración & Idioma \\
\hline CC1, CC2, CC3, & $\begin{array}{c}\text { Ob.1, Ob.2, } \\
\text { Ob.3,Ob.4 }\end{array}$ & 1 hora & Inglés \\
CC5, CC6, CC7 & & \\
\hline
\end{tabular}

Realización de un examen que consta de dos preguntas de cada uno de los bloques de la batería de preguntas (Anexo 12). Mientras el alumnado realiza el examen, el profesor recogerá y corregirá los diccionarios. 


\section{Unidad Didáctica: Who wants fracking in town? 2015}

\section{Actividad 12. Check it out!}

Tabla 8.14. Resumen actividad 12

\begin{tabular}{|c|c|c|c|}
\hline \multicolumn{4}{|c|}{ Explicación de la actividad } \\
\hline Contenidos & Objetivos & Duración & Idioma \\
\hline $\begin{array}{c}\text { CC1, CC2, CC3, } \\
\text { CC5, CC6, CC7 }\end{array}$ & $\begin{array}{c}\text { Ob.1, Ob.2, } \\
\text { Ob.3,Ob.4 }\end{array}$ & 1 hora & Español \\
\hline
\end{tabular}

Al inicio de la actividad, el alumnado vuelve a contestar las preguntas de la actividad 2, y comparan sus respuestas con las dadas al inicio de la unidad didáctica, con el fin de comprobar el progreso realizado (20 min).

Una vez corregidos y evaluados los exámenes, el profesor comenta los errores más relevantes al gran grupo (20 min). Posteriormente, los alumnos se colocan por parejas y cada uno corrige los errores de su compañero. Finalmente cada uno explica los errores a su pareja y viceversa (20 min).

\subsection{Evaluación}

Atendiendo al momento en el que se realiza la evaluación, podemos distinguir entre evaluación inicial (diagnóstica), procesual (formativa) y final (sumativa) (Bordas y Cabrera, 2001). Por su parte, atendiendo al agente evaluador y evaluado nos encontramos con la heteroevaluación, autoevaluación y coevaluación (Casanova, 1998). Todos estos tipos de evaluación serán utilizados durante la presente unidad didáctica.

\subsubsection{Evaluación inicial}

Este tipo de evaluación se realiza al inicio de un proceso evaluador, en este caso una unidad didáctica. Su objetivo es identificar la situación de partida del alumnado, incluyendo sus ideas previas, para adaptar la enseñanza posterior a sus conocimientos (Casanova, 1998), permitiendo así un aprendizaje significativo (Gudovitch y Orion, 2001).

En esta unidad didáctica, la evaluación inicial se realizará durante la primera sesión (actividad 2), utilizando las preguntas que se recogen en el anexo 5. 


\section{Unidad Didáctica: Who wants fracking in town? 2015}

\subsubsection{Evaluación formativa}

La evaluación formativa se utiliza para valorar procesos de forma paralela a la actividad que se está evaluando. Para ello se obtienen datos a lo largo de los proceso, lo que permite al docente corregir los errores en el momento. De este modo se reduce el tiempo de resolución de las dificultades planteadas por el alumnado, evitando así la pérdida de interés en el tema que suponen las evaluaciones finales sumativas (Casanova, 1998).

Este tipo de evaluación se pone en práctica durante la fase de información (actividades 4, 5, 6 y 8) mediante la interacción del profesor con los distintos equipos y grupos de expertos, y mediante las preguntas realizadas a los equipos al final de cada actividad. También se aplicará durante el debate (actividad 7), utilizando una rúbrica (anexo 13), y durante la planificación de la acción (actividad 9) interactuando con los equipos. Con la actividad 11 se pretende convertir una evaluación a priori sumativa, como es un examen final, en un proceso formativo que posibilite continuar con el proceso de aprendizaje.

\subsubsection{Evaluación sumativa}

La evaluación sumativa se utiliza para valorar productos o procesos acabados. Su objetivo es determinar si el producto final es correcto o no, por lo que se aplica al final de un proceso, en este caso de la unidad didáctica. Este tipo de evaluación es esencial para determinar el grado de consecución de los objetivos planteados que ha alcanzado cada alumno (Casanova, 1998).

Este tipo de evaluación tiene lugar en la presente unidad didáctica mediante la acción social (Acividad 9), la reflexión final del alumnado (Actividad 10) y el examen final (Actividad 11)

\subsubsection{Heteroevaluación}

La heteroevaluación es la evaluación que realiza una persona sobre otra, normalmente el docente sobre el estudiante. Sus ventajas radican en la riqueza de datos y posibilidades que ofrece, aunque resulta dificultoso el enjuiciamiento del trabajo realizado por otras personas, por lo que conviene combinarlo con los otros tipos de evaluación (Casanova, 1998).

Es el tipo de evaluación más utilizada en esta unidad didáctica, ya que prácticamente toda las actividades y el examen final se evalúan de esta forma. 


\section{Unidad Didáctica: Who wants fracking in town? 2015}

\subsubsection{Autoevaluación}

Consiste en la evaluación de un sujeto de sus propias actuaciones. Para que el alumnado realice de forma correcta este tipo de evaluación es necesario transmitirle su importancia, con el fin de que la realicen de forma seria y correcta. Esto permite que el alumnado tome conciencia de su propio progreso. Por otro lado, la autoevaluación que realice el profesor de su propia actividad es esencial a la hora de mejorar sus actuaciones futuras (Casanova, 1998).

En la presente unidad didáctica, el alumnado realiza su propia autoevaluación analizando las respuestas dadas a las preguntas del anexo 5 al principio (actividad 2) y al final (actividad 11) de la unidad didáctica. En cuanto al profesor, la autoevaluación de la unidad didáctica se realiza comparando los resultados obtenidos por el alumnado con los objetivos propuestos, lo que nos dará una idea aproximada del éxito de la propuesta.

\section{$\underline{\text { 8.6.6 Coevaluación }}$}

La coevaluación se basa en la evaluación de una actividad o producto realizada entre iguales. Esto favorece retroalimentación mutua a través de críticas constructivas y observaciones personales. Con este proceso se pretende que el alumnado suma el rol de evaluadores del trabajo de sus compañeros, minimizando así la percepción de injusticia que pueden surgir de una evaluación realizada únicamente por el docente (Casanova, 1998).

En esta unidad didáctica la coevaluación está presente en la actividad 11, momento en el que cada alumno corrige el examen de un compañero una vez que el profesor ha señalado los fallos más relevantes.

\subsubsection{Criterios de evaluación}

El Real Decreto 1467/2007 de 2 de noviembre, por el que se establece la estructura del bachillerato y se fijan sus enseñanzas mínimas establece una serie de criterios aplicables a la materia de Ciencias de la Tierra y Medioambientales. De ellos, los aplicables a la presente unidad didáctica son los recogidos en la tabla 8.15 . 


\section{Unidad Didáctica: Who wants fracking in town? 2015}

Tabla 8.15. Criterios de evaluación del RD 1467/2007.

\begin{tabular}{|c|c|}
\hline Criterio de evaluación & Bloque \\
\hline Reconocer los ciclos de materia y flujos de energía. & 7 \\
\hline Diferenciar entre el crecimiento económico y el desarrollo sostenible & 9 \\
\hline $\begin{array}{l}\text { Proponer medidas encaminadas a aprovechar mejor los recursos, a disminuir los } \\
\text { impactos, a mitigar los riesgos y a conseguir un medioambiente más saludable }\end{array}$ & 9 \\
\hline $\begin{array}{c}\text { Comprender que la visión de los problemas ambientales también depende de criterios } \\
\text { sociales, políticos y económicos }\end{array}$ & 9 \\
\hline $\begin{array}{c}\text { Propone posibles mejoras que mitiguen la situación basándose en modelos } \\
\text { conservacionista y/o de desarrollo sostenible. }\end{array}$ & 9 \\
\hline $\begin{array}{c}\text { Elaborar propuestas a escala local, regional y global para aprovechar racionalmente los } \\
\text { recursos y disminuir los impactos (como ahorrar energía y agua, reciclar, reducir el } \\
\text { vertido de contaminantes, prevenir riesgos ambientales) }\end{array}$ & 9 \\
\hline $\begin{array}{c}\text { Presentar propuestas de desarrollo para las personas que aseguren al mismo tiempo la } \\
\text { sostenibilidad ambiental, y de valorar las acciones ciudadanas encaminadas a la } \\
\text { protección del medio ambiente. }\end{array}$ & 9 \\
\hline
\end{tabular}

Por otra parte, los criterios de evaluación propios de la presente unidad didáctica, basados en los objetivos propios, son los descritos en la tabla 8.16.

Tabla 8.16. Criterios de evaluación propios.

\begin{tabular}{|c|l|c|}
\hline № & \multicolumn{1}{|c|}{ Criterio de evaluación } & Objetivo \\
\hline CE1 & $\begin{array}{l}\text { Relaciona los principales problemas ambientales de la sociedad actual con sus } \\
\text { causas (históricas, sociológicas, económicas y culturales) e impactos sociales y } \\
\text { ambientales (tanto positivos como negativos). }\end{array}$ & Ob.1 \\
\hline CE2 & $\begin{array}{l}\text { Identifica los principales reservorios y procesos de los ciclos biogeoquímicos y los } \\
\text { relaciona con el cambio climático. }\end{array}$ & Ob.2 \\
\hline CE3 & $\begin{array}{l}\text { Interpreta los ciclos biogeoquímicos como ciclos cerrados e interpreta sus } \\
\text { implicaciones ambientales. }\end{array}$ & Ob.2 \\
\hline CE4 & Describe el proceso de fracturación hidráulica. & Ob.3 \\
\hline CE5 & $\begin{array}{l}\text { Plantea una opinión crítica sobre la conveniencia o no de aplicar la fracturación } \\
\text { hidráulica. }\end{array}$ & Ob.3 \\
\hline CE6 & $\begin{array}{l}\text { Reconoce las Evaluaciones de Impacto Ambiental, la Ordenación del Territorio y } \\
\text { la Legislación ambiental como herramientas técnicas para afrontar problemas } \\
\text { ambientales }\end{array}$ & Ob.4 \\
\hline CE7 & Localiza cada herramienta de gestión es su ámbito de aplicación. & Ob.4 \\
\hline CE8 & $\begin{array}{l}\text { Produce medidas de prevención y corrección del problema del fracking a nivel } \\
\text { local. }\end{array}$ & Ob.5 \\
\hline
\end{tabular}




\section{Unidad Didáctica: Who wants fracking in town? 2015}

\begin{tabular}{|c|l|c|}
\hline CE9 & Analiza críticamente los problemas ambientales y sociales. & Ob.6 \\
\hline CE10 & Demuestra preocupación por los problemas ambientales. & Ob.7 \\
\hline CE11 & $\begin{array}{l}\text { Utiliza las tecnologías de información y comunicación para buscar información y } \\
\text { contrastar su veracidad. }\end{array}$ & Ob.8 \\
\hline CE12 & Se expresa en inglés con naturalidad & Ob.9 \\
\hline CE13 & Trabaja en equipo de manera adecuada & Ob.10 \\
\hline
\end{tabular}

\subsubsection{Procedimientos e instrumentos de evaluación}

A lo largo de la presente unidad didáctica se utilizan varios procedimientos para evaluar las distintas actividades. Estos procedimientos pueden englobarse en las seis categorías descritas anteriormente.

Una de las principales herramientas de evaluación formativa de la unidad didáctica es la realización de preguntas al alumnado al final de las actividades de la fase de información (4, 5, 6 y 8). El procedimiento para efectuar estas evaluaciones consiste en elegir un número de forma aleatoria, utilizando un dado virtual [12], que corresponderá al miembro de cada equipo que debe responder la pregunta. Con este sistema se pretende que el equipo se responsabilice de que todos sus maneje con soltura toda la información trabajada en una actividad dada. Las preguntas realizadas se extraerán de la batería de preguntas del anexo 12 , las cuales serán utilizadas también en el examen final, con el fin de que el alumnado tenga claro cuáles son los contenidos que se le exige memorizar para el examen final.

El debate realizado en la actividad 7 se evaluará utilizando una rúbrica (anexo 13) en la que se valorarán aspectos individuales, como la participación y la expresión de cada alumno, como grupales, como la preparación de los argumentos. Con el fin de conseguir que el alumnado participe en el debate de forma seria, se recompensará en términos de calificación a aquel grupo que haya "ganado" el debate, es decir, al que presente mejores argumentos para defender su posición.

La acción social realizada, en la actividad 9, se evaluará en dos partes. Por un lado la planificación, de forma procesual mediante la observación e intervención (dando consejos y propuestas) del profesor durante el proceso de diseño de la misma. Y por otra parte la ejecución de la acción, mediante la presentación de una breve memoria en la que se refleje 


\section{Unidad Didáctica: Who wants fracking in town? 2015}

tanto el proceso como el resultado final. La calificación de esta actividad tendrá carácter sumativo, en la medida en que se evaluará el producto final.

La evaluación sumativa final se hará en base al examen final y la reflexión entregada por el alumnado de forma individual. La evaluación y calificación del examen será doble, puesto que la realizada por el profesor se complementará con una coevaluación llevada a cabo por el propio alumnado.

Por último, cada alumno evaluará su propio progreso mediante una autoevaluación consistente en contestar la misma batería de preguntas al inicio y al finalizar la unidad didáctica, y comparar las respuestas dadas por la misma persona en ambos momentos.

\subsubsection{Criterios de calificación}

La calificación de la unidad didáctica se realizará sobre 10 puntos, siendo el resultado de realizar una media ponderada entre las distintas calificaciones que se obtengan a lo largo de la unidad didáctica. Las calificaciones y sus pesos específicos son las siguientes:

- Preguntas de la fase de información: $20 \%$

- Debate: $10 \%$

- Acción Social: $40 \%$

- Reflexión: $15 \%$

- Examen: $15 \%$

La calificación correspondiente a "preguntas de la fase de información" será la media de las calificaciones de todas las preguntas realizadas al grupo al que pertenece el alumno evaluado durante la unidad didáctica. Cada una de estas preguntas se evaluará de 0 a 10, obteniendo el grupo un 10 si la respuesta es correcta, y disminuyendo la calificación progresivamente en caso de que la respuesta sea incompleta o necesite la ayuda del resto de sus compañeros para contestar.

En el debate se calificarán tanto aspectos individuales como grupales, teniendo un peso específico del $50 \%$ cada uno de ellos.

Para la acción social se evaluará el proceso y la memoria final, en la que se presenta el resultado final de la acción, con una repartición de la calificación al 50-50\%. 


\section{Unidad Didáctica: Who wants fracking in town? 2015}

Por su parte, la reflexión será puntuada sobre 10.

La calificación final del examen será el resultado de ponderar la calificación propuesta por el profesor y la dada otro alumno mediante la coevaluación. La calificación del profesor tendrá un peso del $60 \%$ y la coevaluación un 30\%, reservando un 10\% para la corrección del diccionario.

Esta repartición de la calificación final responde al espíritu de la unidad didáctica, que pretende centrarse en la acción social, dando al mismo tiempo relevancia al proceso de aprendizaje en sí mismo, y sin minusvalorar el examen sumativo final. 


\section{Unidad Didáctica: Who wants fracking in town? 2015}

\subsection{Relación entre los elementos de la Unidad Didáctica}

Tabla 8.17. Relación entre actividades, objetivos, contenidos, criterios de evaluación y competencias

\begin{tabular}{|c|c|c|c|c|}
\hline Actividades & Contenidos & Objetivos & $\begin{array}{l}\text { Criterios de } \\
\text { evaluación }\end{array}$ & Competencias \\
\hline 1 & - & - & - & - \\
\hline 2 & - & - & - & - \\
\hline 3 & $\begin{array}{l}\text { CPr.1 } \\
\text { CAc.3 }\end{array}$ & Ob.8 & CE11 & $\mathrm{C} 4, \mathrm{C} 7$ \\
\hline 4 & $\begin{array}{c}\text { CC1 } \\
\text { CPr.1, CPr.2 } \\
\text { CAc.1, CAc.3, CAc.4 }\end{array}$ & $\begin{array}{l}\text { Ob.1, Ob.7, } \\
\text { Ob.8, Ob.10 }\end{array}$ & $\begin{array}{l}\text { CE1, CE10, } \\
\text { CE11, CE13 }\end{array}$ & $\mathrm{C} 3, \mathrm{C} 4, \mathrm{C} 8$ \\
\hline 5 & $\begin{array}{c}\text { CC2 } \\
\text { CPr.1, CPr. } 2 \\
\text { CAc.3, CAc. } 4\end{array}$ & $\begin{array}{l}\text { Ob.2, Ob.8, } \\
\text { Ob.10 }\end{array}$ & $\begin{array}{l}\text { CE2, CE3, } \\
\text { CE13 }\end{array}$ & C3, C4, C8 \\
\hline 6 & $\begin{array}{c}\text { CC3 } \\
\text { CPr.1, CPr.2 } \\
\text { CAc.3, CAc. } 4\end{array}$ & $\begin{array}{l}\text { Ob.3, Ob.8, } \\
\text { Ob.10 }\end{array}$ & $\begin{array}{l}\text { CE4, CE5, } \\
\text { CE11, CE13 }\end{array}$ & C3, C4, C8 \\
\hline 7 & $\begin{array}{c}\text { CC3, CC4, CC5 } \\
\text { CPr.1, CPr.2, CPr. } 3 \\
\text { CAc. } 1, \text { CAc. } 2, \text { CAc. } 3, \text { CAc. } 4, \\
\text { CAc.5 }\end{array}$ & $\begin{array}{l}\text { Ob.6, Ob.7, } \\
\text { Ob.8, Ob.9, } \\
\text { Ob.10 }\end{array}$ & $\begin{array}{l}\text { CE9, CE10, } \\
\text { CE11, CE12, } \\
\text { CE13 }\end{array}$ & $\mathrm{C} 1, \mathrm{C} 4, \mathrm{C} 8$ \\
\hline 8 & $\begin{array}{c}\text { CC6, CC7, CPr.1 } \\
\text { CPr.2 } \\
\text { CAc.2, CAc.3, CAc. } 4\end{array}$ & $\begin{array}{l}\text { Ob. } 4, \text { Ob. } 8 \\
\text { Ob.10 }\end{array}$ & $\begin{array}{l}\text { CE6, CE7, } \\
\text { CE11, CE13 }\end{array}$ & C4, C8 \\
\hline 9 & $\begin{array}{c}\text { CC1, CC2, CC3, CC4, CC5, } \\
\text { CC6, CC7 } \\
\text { CPr.1, CPr.2 } \\
\text { CAc.2, CAc. } 4\end{array}$ & Ob.5, Ob.10 & CE8, CE13 & C4, C8 \\
\hline 10 & $\begin{array}{c}\mathrm{CC} 1, \mathrm{CC} 2, \mathrm{CC} 3, \mathrm{CC} 4, \mathrm{CC} 5, \\
\text { CC6, CC7 } \\
\text { CAc.1, CAc.2 }\end{array}$ & Ob.6, Ob.7 & CE9, CE10 & C5, C8 \\
\hline 11 & $\begin{array}{c}\mathrm{CC} 1, \mathrm{CC} 2, \mathrm{CC} 3, \mathrm{CC} 5, \mathrm{CC} 6 \\
\mathrm{CC} 7\end{array}$ & $\begin{array}{l}\text { Ob.1, Ob.2, } \\
\text { Ob.3,Ob.4 }\end{array}$ & $\begin{array}{l}\text { CE1, CE2, } \\
\text { CE3, CE4, } \\
\text { CE6, CE7 }\end{array}$ & C3 \\
\hline 12 & $\begin{array}{c}\mathrm{CC} 1, \mathrm{CC} 2, \mathrm{CC} 3, \mathrm{CC} 5, \mathrm{CC} 6 \\
\mathrm{CC} 7\end{array}$ & $\begin{array}{l}\text { Ob.1, Ob.2, } \\
\text { Ob.3,Ob.4 }\end{array}$ & $\begin{array}{l}\text { CE1, CE2, } \\
\text { CE3, CE4, } \\
\text { CE6, CE7 }\end{array}$ & C3, C7, C8 \\
\hline
\end{tabular}




\section{Unidad Didáctica: Who wants fracking in town? 2015}

\section{BIBLIOGRAFÍA}

- Akcay, H., \& Yager, R. E. (2010). The impact of a science/technology/society teaching approach on student learning in five domains. Journal of Science Education and Technology, 19(6), 602-611.

- Alonso, Á. V., Díaz, J. A. A., \& Mas, M. A. M. (2003). Papel de la educación CTS en una alfabetización científica y tecnológica para todas las personas. REEC: Revista electrónica de enseñanza de las ciencias, 2(2), 80-111.

- Aronson, E., Blaney, N., Sikes, J., Stephan, C., \& Snapp, M. (1975). Busing and racial tension: The jigsaw route to learning and liking. Psychology Today, 8, 43-50.

- Barba, B. (2001). Razonamiento moral de principios en estudiantes de secundaria y bachillerato. Revista Mexicana de investigación educativa, 6(13), 501-523.

- Benito, A. Y Cruz, B. (2005). Nuevas claves para la docencia universitaria. Madrid: Narcea

- Bordas, M. I., \& Cabrera, F. (2001). Estrategias de evaluación de los aprendizajes centrados en el proceso. Revista española de pedagogía, 218, 25-48.

- Bosque, I. (2012). Sexismo lingüístico y visibilidad de la mujer. El País, 4, 14-17.

- Boudet, H., Clarke, C., Bugden, D., Maibach, E., Roser-Renouf, C., \& Leiserowitz, A. (2014). "Fracking" controversy and communication: Using national survey data to understand public perceptions of hydraulic fracturing. Energy Policy, 65, 57-67.

- Broderick, J., Anderson, K., Wood, R., Gilbert, P., Sharmina, M., Footitt, A., ... \& Nicholls, F. (2011). Shale gas: an updated assessment of environmental and climate change impacts. A report commissions by the Co-operative and undertaken by researchers at the Tyndall Centre, University of Manchester.

- Burton A. ( 2013). CLIL. Some of the reasons why... and why not. System, 41(3), 587-597.

- Bybee, R. (1997). Achieving scientific literacy: From purposes to practices. Portsmouth, NH: Heinemann. 


\section{Unidad Didáctica: Who wants fracking in town? 2015}

- Carretero, M. (1997). ¿Qué es el constructivismo?. Constructivismo y educación, Desarrollo cognitivo y aprendizaje. México: Ed. Progreso, 39-71.

- Casanova, M. A. (1998). Evaluación: Concepto, tipología y objetivos. La evaluación educativa, México, Biblioteca para la Actualización del Maestro, SEP-Muralla, (pp. 67-102)

- Centro de Gestión Avanzado de Centros TIC (CGA), (2012). Un caso a replicar. Pp. 2-19

- Ciais, P., Sabine, C., Bala, G., Bopp, L., Brovkin, V., Canadell, J., ... \& Thornton, P. (2014). Carbon and other biogeochemical cycles. In Climate Change 2013: The Physical Science Basis. Contribution of Working Group I to the Fifth Assessment Report of the Intergovernmental Panel on Climate Change (pp. 465-570). Cambridge University Press.

- Consejería de Educación (2008a) Decreto 416/2008, de 22 de julio, por el que se establece la ordenación y las enseñanzas correspondientes al Bachillerato en Andalucía. Boletín Oficial de la Junta de Andalucía, 149, 8-15.

- Consejería de Educación (2008b). Orden de 5 de agosto de 2008, por la que se desarrolla el currículo correspondiente al Bachillerato en Andalucía. Boletín Oficial de la Junta de Andalucía, 169, 98-222.

- Consejería de Educación (2011). Orden de 28 de junio de 2011, por la que se regula la enseñanza bilingüe en los centros docentes de la Comunidad Autónoma de Andalucía. Boletín Oficial de la Junta de Andalucía, 135, 6-19.

- Consejería de Educación de la Junta de Andalucía (2005). Plan de Fomento del Plurilingüismo en Andalucía. Boletín Oficial de la Junta de Andalucía, 65, 8-39.

- Consejería de Educación de la Junta de Andalucía (2007). Ley 17/2007, de 10 de diciembre, de Educación de Andalucía. Boletín Oficial de la Junta de Andalucía, 252, 5-36.

- Coyle, D. (2005). CLIL: Planning tools for teachers. Nottingham: University of Nottingham

- Coyle, D. (2006). Content and language integrated learning: Motivating learners and 


\section{Unidad Didáctica: Who wants fracking in town? 2015}

teachers. Scottish Languages Review, 13, 1-18.

- Directiva 2011/92/UE del Parlamento Europeo y del Consejo, de 13 de diciembre de 2011, relativa a la evaluación de las repercusiones de determinados proyectos públicos y privados sobre el medio ambiente.

- Doblado, F. A. (2013). Riesgos del fracking. Agricultura: Revista agropecuaria, 964, 498-499.

- Energy Information Administration (2011). World Shale Gas Resources: An Initial Assessment of 14 Regions Outside the United States, U.S. Energy Information Administration, Washington, DC

- Erikson, E. H. (1995). Sociedad y adolescencia. Siglo xxi editors, S.A. de C.V. Cerro del Agua 248, delegación Coyocán, México D.F.

- Escobar, C. y Evnitskaya, N. (2014). 'Do you know Actimel?' The adaptive nature of dialogic teacher-led discussions in the CLIL science classroom: a case of study. The Language Learning Journal, 42(2), 165-180.

- Falkowski, P., Scholes, R. J., Boyle, E. E. A., Canadell, J., Canfield, D., Elser, J., ... \& Steffen, W. (2000). The global carbon cycle: a test of our knowledge of earth as a system. Science, 290(5490), 291-296.

- Fergurson, D.L., y Jeanchild, L. A. (1991). About How To Implement Curricular Decisions. In Stainback, S - Stainback, W.: Curriculum considerations in Inclusive Classrooms. Baltimore: Paul Brookes.

- Floimayr, T. (2010). CLIL in Biology-an evaluation of existing teaching materials for Austrian schools. Vienna English Working Papers, Current Research on CLIL, 3, 21-28.

- Francisco Rivero, G., Martínez Gutiérrez, G., \& Fernández Martínez, E. M. (2013). Piensa y actúa glocal. Coltán y residuos electrónicos en la enseñanza de problemas socio-ambientales asociados a la gestión de recursos minerales Thinking and acting glocally. Coltan and electronic waste in the teaching of social and environmental issues related. Enseñanza de las Ciencias de la Tierra, 21(1), 59-72.

- Garcia Sepulveda, S. (2009). Enseñanza bilingüe en las ciencias experimentales. 


\section{Unidad Didáctica: Who wants fracking in town? 2015}

Inovación y Experiencias Educativas, 16.

- Gil Pérez, D., Carrascosa Alís, J., Dumas-Carré, A., Furió Mas, C., Gallego, R., Duch, A. G., \& Valdés, P. (1999). ¿Puede hablarse de consenso constructivista en la educación científica?. Enseñanza de las Ciencias, 17, 503-512.

- Grandinetti, M., Langellotti, M., \& Ting, Y. T. (2013). How CLIL can provide a pragmatic means to renovate science education-Even in a sub-optimally bilingual context. International Journal of Bilingual Education and Bilingualism, 16(3), 354-374.

- Green Peace, s.f. Fractura hidráulica para obtener gas natural (Fracking)

- Gudovitch, Y., \& Orion, N. (2001). The Carbon Cycle and the Earth Systems-Studying the Carbon Cycle in Multidisciplinary Environmental Context. Science and Technology Education: Preparing Future Citizens. Proceedings of the IOSTE Symposium in Southern Europe. Paralimni, Cyprus,, 426-437.

- Harlen, W. (Ed.). (2010). Principles and big ideas of science education. Association for Science Education. Hatfield: ASE

- Hodson, D. (2010). Science education as a call to action. Canadian Journal of Science, Mathematics and Technology Education, 10(3), 197-206.

- Howarth, R. W., Ingraffea, A., \& Engelder, T. (2011). Natural gas: Should fracking stop?. Nature, 477(7364), 271-275.

- IES Generalife (2013). Plan de Centro. Proyecto Educativo. Granada

- Johnson, D. W., Johnson, R. T., \& Holubec, E. J. (1991). Cooperation in the classroom. Edina, MN: Interaction Book Company.

- Karl, T. R., \& Trenberth, K. E. (2003). Modern global climate change. Science, 302(5651), 1719-1723.

- King, G. E. (2012, January). Hydraulic fracturing 101: what every representative, environmentalist, regulator, reporter, investor, university researcher, neighbor and engineer should know about estimating frac risk and improving frac performance in unconventional gas and oil wells. In SPE Hydraulic Fracturing Technology Conference. Society of Petroleum Engineers. 


\section{Unidad Didáctica: Who wants fracking in town? 2015}

- Kohlberg, L. (1977). Moral, desarrollo. En D. L. Sills (dir.), Enciclopedia Internacional de las Ciencias Sociales (volumen 7), Madrid: Aguilar.

- Kohlberg, L. (1987). El enfoque cognitivo evolutivo de la moralidad. En Jordán, J. A. y F, Santolaria, La educación moral hoy. Cuestiones y perspectivas, Barcelona: PP

- Langer, E., Lasselsberger, A., Matiasek, S., \& Thurnher, E. (2006). Englisch als Arbeitssprache im handlungsorientierten naturwissenschaftlichen Unterricht.MNIFonds für Unterrichts-und Schulentwicklung S5 Entdecken, Forschen und Experimentieren, 1-34.

- Li, M., \& Lam, B. (2013). Cooperative learning. The Active Classroom. The Hong Kong Institute of Education.

- Lombardo, E., Krzemien, D., Sánchez, M., \& Monchietti, A. (2007). Contextualismo y multidimensionalidad del pensamiento en la adultez. Memorias de las XIV Jornadas de Investigación en Psicología y III Encuentro de Investigadores en Psicología del Mercosur, 2, 451-453.

- Membienal, P. (1997). Una revisión del movimiento educativo Ciencia-TecnologíaSociedad. Enseñanza de las Ciencias, 15, 51-57.

- Ministerio de Educación y Ciencia (2006) Ley Orgánica 2/2006, de 3 de mayo, de Educación (LOE). Boletín Oficial del Estado. 106, 17158-17207.

- Ministerio de Educación y Ciencia (2007). Real Decreto 1467/2007, de 2 de noviembre, por el que se establece la estructura del bachillerato y se fijan sus enseñanzas mínimas. Boletín Oficial del Estado, 266, 45381- 45477.

- Mora, C., \& Herrera, D. (2009). Una revisión sobre ideas previas del concepto de fuerza. Latin-American Journal of Physics Education, 3(1), 72-86.

- National Science Foundation (2010). Earth science literacy principles: The big ideas and supporting concepts of Earth science. Arlington, VA:. www. earthscienceliteracy. org/es_literacy_6may10_.pdf.

- O'Connell, D. (2010). Dust Thou Art Not \& unto Dust Thou Shan't Return: Common Mistakes in Teaching Biogeochemical Cycles. The American Biology Teacher, 72(9), $552-556$. 


\section{Unidad Didáctica: Who wants fracking in town? 2015}

- Pachauri, R. K., Allen, M. R., Barros, V. R., Broome, J., Cramer, W., Christ, R., ... \& van Vuuren, D. (2014). Climate Change 2014: Synthesis Report. Contribution of Working Groups I, II and III to the Fifth Assessment Report of the Intergovernmental Panel on Climate Change.

- Pavesi, M., Bertocchi, D., Hofmanová, M., \& Kasianka, M. (2001). Teaching through a foreign language: a guide for teachers and schools to using Foreign Language in Content Teaching. TIE-CLIL Project Publications, 32, 71-102.

- Piaget, J. (1966.) Muthematical epistemology and psychology. Dordrecht-Holland: D. Reidel.

- Prieto, L. (2007). El aprendizaje cooperativo. Madrid: PPC.

- Reljić, G., Ferring, D., \& Martin, R. (2015). A Meta-Analysis on the Effectiveness of Bilingual Programs in Europe. Review of Educational Research. 85(1), 92-128.

- Romo Martínez, J. M. (2005). Desarrollo del juicio moral en bachilleres de Aguascalientes. Revista mexicana de investigación educativa, 10(24), 43-66.

- Rubio, M. C. (2012). El fracking llega a España con polémica. Técnica Industrial, 298, 26-27.

- Sabariego, J., \& Manzanares, M. (2006). Alfabetización científica. In I Congreso Iberoamericano de Ciencia, Tenología, Sociedad e Innovación CTS+l. Palacio de la Minería, México.

- Sánchez, P. A. (1999). Curriculum y atención a la diversidad. In Hacia una nueva concepción de la discapacidad: Actas de las III Jornadas Científicas de Investigación sobre personas con discapacidad (pp. 39-62). Amarú.

- Santrock, J.W. (2003). Adolescence (9th ed.). New York: McGraw-Hill

- Servicio de Innovación Educativa UPM. (2008). Aprendizaje cooperativo. Guías rápidas sobre nuevas metodologías. Madrid: Universidad Politécnica de Madrid

- Shen, B. S. P. (1975). Scientific literacy and the public understanding of science. In S. B. Day (Ed.), The communication of scientific information (pp. 44-52). Basel, Switzerland: Karger. 


\section{Unidad Didáctica: Who wants fracking in town? 2015}

- Solbes Matarredona, J. (2011). Simposio: CTSA en el siglo XXI. In Enseñanza de las ciencias. Número Estra VIII, Barcelona (pp. 1432-1433).

- Tollefson, J. (2012). Air sampling reveals high emissions from gas field. Nature, 482(7384), 139-140.

- University of Cambridge ESOL Examinations (2009). Teaching knowledge test: Content and language integrated learning: Glossary. Cambridge, England: University of Cambridge Local Examinations Syndicate.

- Vega, M. Á. P., Ferra, M. P., \& López, R. Q. (2009). Valoración del cambio de actitudes hacia el medio ambiente producido por el programa didáctico" EICEA" en los alumnos de Educación Secundaria Obligatoria (14-16 años). REEC: Revista electrónica de enseñanza de las ciencias, 8(3), 1019-1036.

- Vygotsky, L. (1978). Interaction between learning and development. Reprint on Readings on the development of children, 23(3), 29-36. 


\section{Unidad Didáctica: Who wants fracking in town? 2015}

\subsection{Páginas web}

- [1] http://www.nasa.gov/images/content/544800main_globe-CarbonCycle-hi.jpg

- [2] https://www.jigsaw.org/\#steps

- [3] http://www.online-stopwatch.com/countdown-timer/

- [4] http://es.wikipedia.org/wiki/Ayuda:Preguntas_frecuentes/Colegios

- [5] http://www.elconfidencial.com/alma-corazon-vida/2015-04-10/el-trasplantede-cabeza-es-posible-y-este-sera-el-primer-hombre-que-se-opere_757085/

- [6] http://www.abc.es/ciencia/20150303/abci-trasplante-cabeza-imposible201503021650.html

- [7] http://www.taringa.net/posts/ciencia-educacion/8631953/Primer-Transplantede-Cerebro-Humano.html

- $[8]$ http://es.kioskea.net/faq/7029-encontrar-fuentes-de-informacion-confiables-eninternet,

- $[9]$

http://biblioteca.itson.mx/oa/educacion/oa34/como buscar informacion en internet/ $\underline{\text { b4.htm }}$

- [10] http://normasapa.com/

- [11] http://guides.library.jhu.edu/evaluatinginformation

- [12] http://dice.virtuworld.net/

- [13] http://www.huffingtonpost.com/2012/10/21/scientists-link-deepwell_n_1997629.html

- [14] https://www.youtube.com/watch?v=ZHHFTgJ0qEs

- [15] http://www.instituto-generalife.com/

- [16] https://www.jigsaw.org/tips/ 


\section{Unidad Didáctica: Who wants fracking in town? 2015}

- [17] https://upload.wikimedia.org/wikipedia/commons/f/fe/Nitrogen_Cycle.svg

- [18] http://image.slidesharecdn.com/oxygencyclepres1-140927235157-

phpapp02/95/oxygen-cycle-pres-1-4-638.jpg?cb=1411862009

- [19]

http://nagrascience10.wikispaces.com/file/view/bc10_u1c2_p85_fig2_46.jpg/5 2175459/800x651/bc10_u1c2_p85_fig2_46.jpg

- [20] http://www.nature.com/nrmicro/journal/v6/n6/images/nrmicro1892-f1.jpg

- [21]

http://www.earthworksaction.org/issues/detail/hydraulic fracturing 101\#.VYG WVfntmko

- [22] http://www.energiadiario.com/publicacion/el-fracking-queda-regulado-porprimera-vez-en-espana-con-la-ley-de-evaluacion-ambiental/

- [23] http://www.wwf.gr/crisis-watch/crisis-watch/energy-climate/10-energyclimate/new-eu-directive-allows-for-eia-free-fracking

- [24] http://www.brookings.edu/blogs/brookings-now/posts/2015/03/economicbenefits-of-fracking

- [25]

http://www6.mityc.es/aplicaciones/energia/hidrocarburos/petroleo/exploracion 2012/mapas/inicio.htm

- [26] http://www.eldiario.es/sociedad/fracking-gas-ley-gobierno-autonomiasmunicipios_0_286971907.html

- [27] http://mesadelaria.es/huelva/?p=950

- [28] http://www.bbc.com/news/uk-england-lancashire-15550458

- [29] http://www.eleconomista.es/materias-primas/noticias/6528992/03/15/Elfracking-en-Espana-sera-una-realidad-en-2016-podria-haber-gas-para-90anos.html\#.Kku863TniuXOdXA

- [30] https://vimeo.com/60482640 


\section{Unidad Didáctica: Who wants fracking in town? 2015}

- [31] http://www.bloomberg.com/news/articles/2012-10-23/fracking-will-support-1-7million-jobs-study-shows

- [32] https://www.youtube.com/watch?v=SXrJZYjEhkY

- [33] http://www.nationaljournal.com/new-energy-paradigm/how-many-jobs-doesfracking-really-create-20140414

- [34] https://www.youtube.com/watch?v=Uti2niW2BRA\&feature=youtu.be

- $[35]$

http://sociedad.elpais.com/sociedad/2014/03/10/actualidad/1394483341_512 298.html

- [36] https://www.youtube.com/watch?v=aJYX0-H6R9E

- [37] http://www.2bachillerato.es/CTM/tema18/p6.html

- [38] http://www.2bachillerato.es/CTM/tema18/p5.html

- [39] http://www.2bachillerato.es/CTM/tema18/p7.html 


\section{Unidad Didáctica: Who wants fracking in town? 2015}

\section{ANEXOS}

ANEXO 1. Características del IES Generalife.

EI IES Generalife es un centro público situado en Granada capital, en la Calle Huerta del Rasillo (Ver Figura 10.1). La zona en la que se encuentra es relativamente céntrica, aunque no está rodeada por núcleos poblacionales, lo que explica parte de las características de su alumnado, procedente de toda la periferia de Granada.

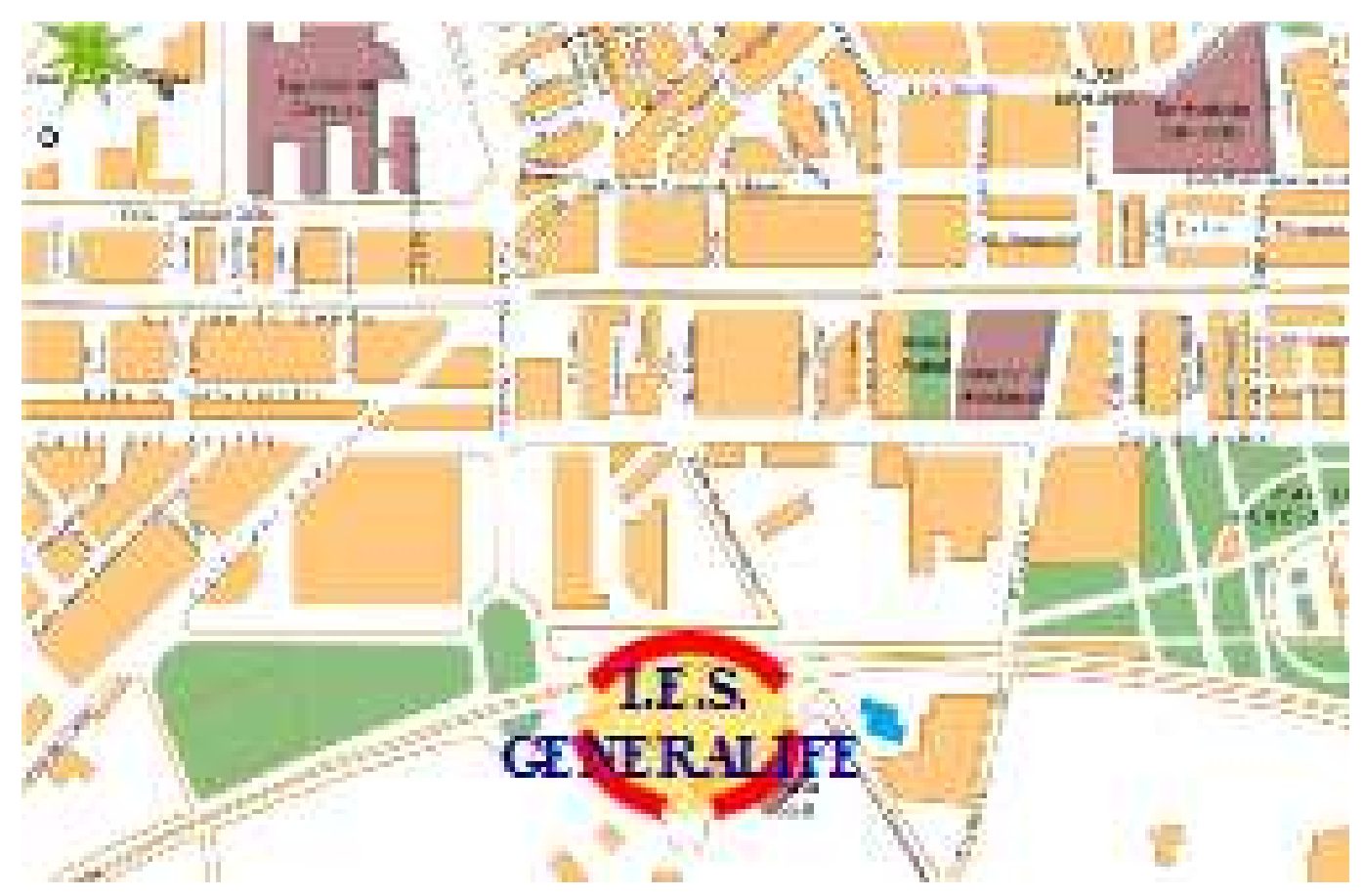

Figura 10.1. Ubicación del IES Generalife [15]

Este centro destaca por ser plurilingüe, al impartirse en él asignaturas en lengua inglesa y francesa. Esto hace que el nivel socioeconómico y cultural de los alumnos sea algo superior al de la media de la zona, ya que son los alumnos con, a priori, mayores capacidades o cuyos padres tienen un nivel de estudios mayor, y por tanto ambiciones más altas para sus hijos, los que se matriculan en el IES Generalife. Muchos de los alumnos que se incorporan a este centro en $1^{\circ}$ de ESO provienen a su vez de colegios de educación primaria con programas bilingües, tanto en francés como inglés.

En cuanto a la convivencia, es un centro muy tranquilo, en el que los únicos problemas disciplinarios son de orden menor (mascar chicle en clase, jugar al Cubo de Rubik en clase 


\section{Unidad Didáctica: Who wants fracking in town? 2015}

y, en una ocasión, una profesora de guardia vio a un alumno de Bachillerato fumando en una esquina del recreo).

Los recursos del centro son bastante amplios. En cuanto a los humanos, cuenta, además de con los profesores y equipo directivo pertinente, con profesores en calidad de prestación de servicios para cubrir necesidades específicas que se generan como consecuencia del carácter plurilingüe del centro, asistentes de lectura nativos (tanto de francés como de inglés) para apoyar a los profesores de inglés y francés, así como a los profesores que imparten otras materias en alguno de estos idiomas, y por último, el personal de limpieza, secretariado y conserjería es muy amplio, habiendo 2 y 3 personas por puesto cuando en otros centros esas mismas tareas las lleva a cabo una sola persona. Con respecto a los medios materiales, todas las aulas cuentan con un ordenador y un proyector, y las de los primeros cursos de la ESO, también con pizarra electrónica para complementar a la tradicional; además, en centro cuenta con dos laboratorios de ciencias (uno para biología y otro para geología) con una dotación bastante buena, aunque en la práctica su uso no es tan fácil como cabría esperar puesto que estos espacios se utilizan como aulas para grupos desdoblados, por lo que es difícil coordinar las sesiones para que coincidan con una hora en la que el laboratorio en cuestión esté libre.

El centro cuenta con entorno a 700 alumnos y alumnas, con edades comprendidas entre los 12 años, en 1ำ de la ESO, y sin límite de edad en Bachillerato y Ciclos Formativos. Entre las características del alumnado y sus familias, el Proyecto Educativo de su Plan de Centro (IES Generalife, 2013) destaca:

- La mayor parte pertenecen a la clase media (hijos de funcionarios de la educación, sanidad, profesores universitarios, trabajadores por cuenta propia, etc.)

- El nivel cultural es medio-alto. Parte del alumnado realiza estudios complementarios de música, idiomas, danza, etc.

- La presencia de las familias en el ambiente escolar es elevada.

- Los alumnos de otras culturas y nacionalidades son pocos y están bien integrados en el centro.

- El número de alumnos que repite curso es bajo.

- Existen alumnos con necesidades especiales, principalmente problemas de aprendizaje. 


\section{Unidad Didáctica: Who wants fracking in town? 2015}

Los niveles de absentismo escolar y problemas disciplinarios son bajos, ya que el alumnado es, por lo general, responsable y disciplinado, con buenos hábitos de trabajo y convivencia. 


\section{Unidad Didáctica: Who wants fracking in town? 2015}

\section{ANEXO 2. Objetivos generales}

De los objetivos propios de bachillerato recogidos en el artículo 33 de la LEY ORGÁNICA 2/2006, de 3 de Mayo, de Educación (LOE), la presente unidad didáctica pretende cubrir los indicados en la tabla 10.1.

Tabla 10.1. Objetivos propios de bachillerato (LOE, 2006)

\section{Objetivos propios del bachillerato}

a) Ejercer la ciudadanía democrática, desde una perspectiva global, y adquirir una conciencia cívica responsable, inspirada por los valores de la Constitución española así como por los derechos humanos, que fomente la corresponsabilidad en la construcción de una sociedad justa y equitativa.

b) Consolidar una madurez personal y social que les permita actuar de forma responsable y autónoma y desarrollar su espíritu crítico. Prever y resolver conflictos sociales.

f) Expresarse con fluidez y corrección en una o más lenguas extranjeras

h) Conocer y valorar críticamente las realidades del mundo contemporáneo. Participar de forma solidaria en el desarrollo y mejora de su entorno social.

i) Acceder a los conocimientos científicos propios de la modalidad elegida.

j) Conocer y valorar de forma crítica la contribución de la ciencia y la tecnología en el cambio de las condiciones de vida, así como afianzar la sensibilidad y el respeto hacia el medio ambiente.

Por su parte, el REAL DECRETO 1467/2007, de 2 de noviembre, por el que se establece la estructura del bachillerato y se fijan sus enseñanzas mínimas establece como objetivos de la enseñanza de las Ciencias de la Tierra y medioambientales en el bachillerato, el desarrollo de una serie de capacidades. De ellas, en esta unidad didáctica se alcanzarán las recogidas en la tabla 10.2 .

Tabla 10.2, Objetivos propios de las Ciencias de la Tierra y Medioambientales (Andalucía, 2007)

\section{Objetivos propios de las Ciencias de la Tierra y Medioambientales}

4. Analizar las causas que dan lugar a riesgos naturales, conocer los impactos derivados de la explotación de los recursos y considerar diversas medidas de prevención y corrección.

5. Reconocer la importancia de los aspectos históricos, sociológicos, económicos y culturales en los estudios sobre el medio ambiente.

6. Utilizar las tecnologías de la información y la comunicación para extraer y utilizar información de diferentes fuentes, evaluar su contenido, fundamentar los trabajos y realizar informes.

7. Promover actitudes favorables hacia el respeto y la protección del medio ambiente, desarrollando la capacidad de valorar las actuaciones sobre el entorno y tomar libremente iniciativas en su defensa. 
ANEXO 3. Mapa conceptual

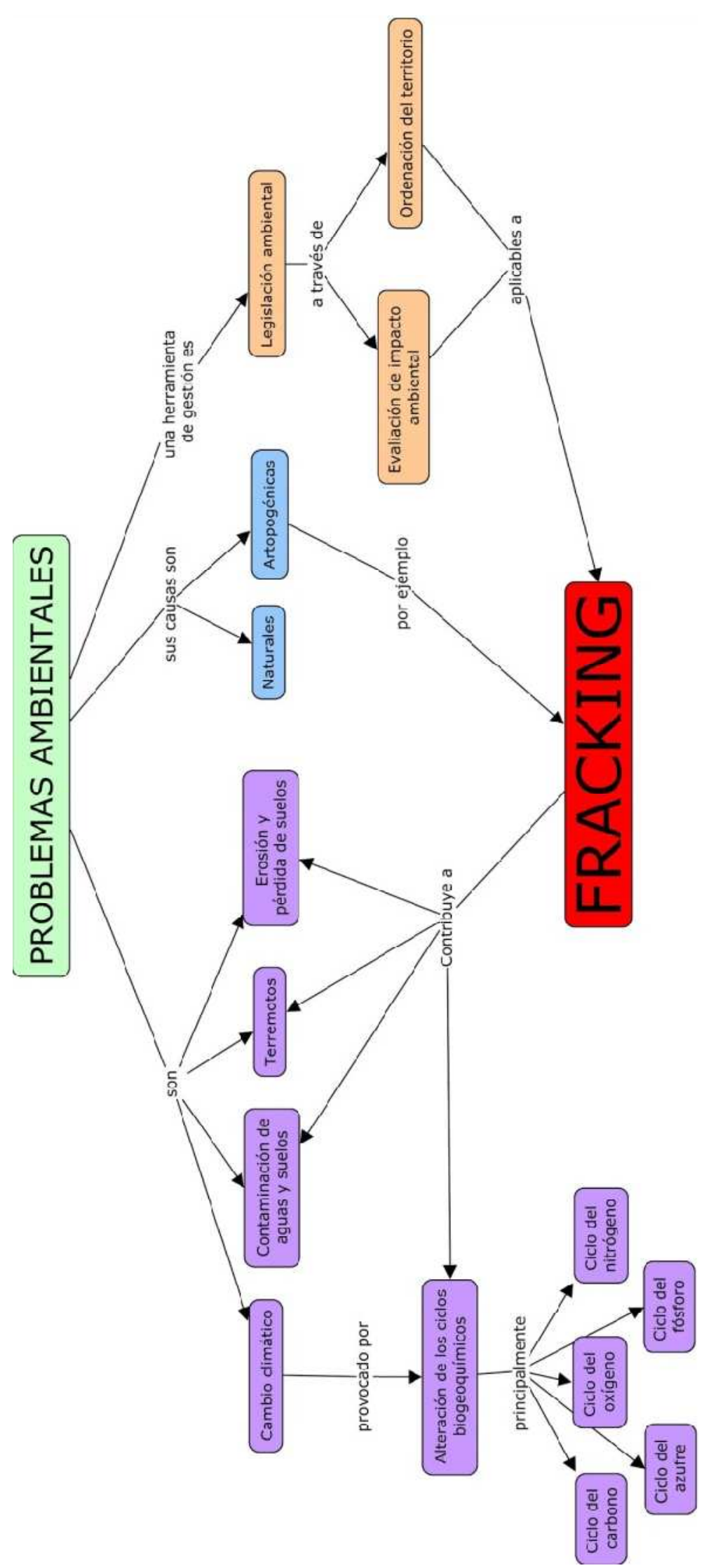




\section{Unidad Didáctica: Who wants fracking in town? 2015}

\section{ANEXO 4. Beneficios de la técnica Jigsaw en alumnos con necesidades especiales.}

Como recoge Elliot Aronson en la página web dedicada a la técnica Jigsaw [16], esta forma de aplicar el aprendizaje cooperativo es beneficioso para alumnos con menos capacidades intelectuales, alumnos con altas capacidades y alumnos disruptivos.

En el caso de alumnos con menores capacidades, el profesor debe asegurarse de que este alumno no presenta un informe de menor calidad que el resto de sus compañeros. La clave para que esto no ocurra reside en el grupo de expertos. Antes de presentar el informe sobre su parte de la actividad a su equipo, cada estudiante forma parte de un grupo de expertos que han estado trabajando el mismo tema, donde tiene la posibilidad de discutir sobre su informe y modificarlo de acuerdo con las sugerencias de sus compañeros del grupo de expertos. Las primeras veces que utilice este método es recomendable que el profesor se asegure de que todos los miembros de cada grupo de expertos realizan un informe correcto, aunque más adelante esta supervisión se vuelve innecesaria.

El problema con los alumnos con altas capacidades suelen centrarse en la pérdida de interés por parte del estudiante al percibir que las actividades planteadas no le suponen un reto. Al tratarse de una técnica basada en el aprendizaje entre iguales, el Jigsaw permite que los alumnos tomen en determinados momentos el papel de profesores, lo cual supone un reto para este tipo de estudiantes. Esto produce beneficios psicológicos y produce un aprendizaje más profundo.

En cuanto a los problemas de alumnos disruptivos, con tendencia a dominar el debate, este método propone la designación por parte del profesor de un moderador de las discusiones. Es tarea del moderador controlar que los miembros del equipo se comporten de manera adecuada y repartir la participación de manera equitativa. De este modo, los alumnos se dan cuenta rápidamente de que el equipo funciona de manera más efectiva si se permite que cada uno presente su material antes de realizar las preguntas y comentarios. Así, es el propio interés del grupo el que reduce los problemas de dominancia. 


\section{Unidad Didáctica: Who wants fracking in town? 2015}

\section{ANEXO 5. Hoja de preguntas para la Actividad 2}

Answer the following questions:

1. How do greenhouse gases affect to global warming? And depletion of the ozone layer?

2. If there were no human being, would there still be global warming? And the greenhouse effect?

3. Can an earthquake have human causes?

4. Which of the following are source of pollution? Chemicals, waste, light, nutrients, magnetic fields, noise and nanoparticles.

5. What happens to $\mathrm{CO}_{2}$ after it is emitted into the atmosphere?

6. What do plants "eat"? Soil, water or air?

7. Where is there more carbon? Atmosphere, hydrosphere, geosphere or biosphere?

8. Are economic growth and care of the environment compatible?

9. Does every human activity have an impact on environment?

10. Which kind of activities should be allowed in protected areas?

Las ideas previas que se pretenden identificar con cada pregunta son las siguientes (esta información no se le dará al alumnado):

1. Identificar el "agujero" de la capa de ozono con el cambio climático.

2. No identificar los cambios climáticos y el efecto invernadero como un proceso natural.

3. Esta pregunta se utilizará posteriormente para introducir el tema del fracking.

4. No considerar el ruido y el exceso lumínico como problemas ambientales.

5. Identificar ideas previas generales acerca del ciclo del carbono 


\section{Unidad Didáctica: Who wants fracking in town? 2015}

6. Creer que las plantas obtienen los nutrientes (incluidos el $\mathrm{CO}_{2}$ ) principalmente del suelo, ignorando la importancia de la fotosíntesis en la nutrición vegetal.

7. Percibir erróneamente el tamaño relativo de los diferentes reservorios de carbono en la tierra.

8. Identificar ideas previas generales e introducir el concepto de desarrollo sostenible.

9. Identificar ideas previas acerca de las evaluaciones de impacto ambiental (EIA).

10. Adoptar posturas de conservacionismo radical, expresadas como intervención cero. Esta pregunta está relacionada con los conceptos de legislación ambiental y ordenación del territorio. 
ANEXO 6. Presentación para la Actividad 3

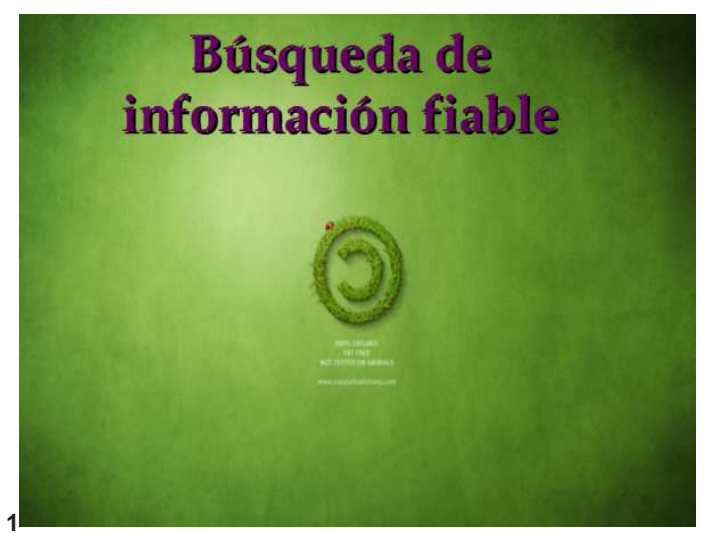

¿Es veraz esta información?

- Autor:

- ¿Es reputado?

- ¿Es una fuente oficial?

- ¿Es un desconocido?

- Veracidad:

- ¿Explica de donde obtiene la información?

- ¿Cita las fuentes?

- Vigencia:

- ¿Está obsoleta?

3

Algunas herramientas

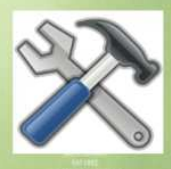

Otra información de interés

- Operadores lógicos:

- Normas de citación APA

http://normasapa.com/

- Más información:

Evaluating information found on the internet.

Johns Hopkins
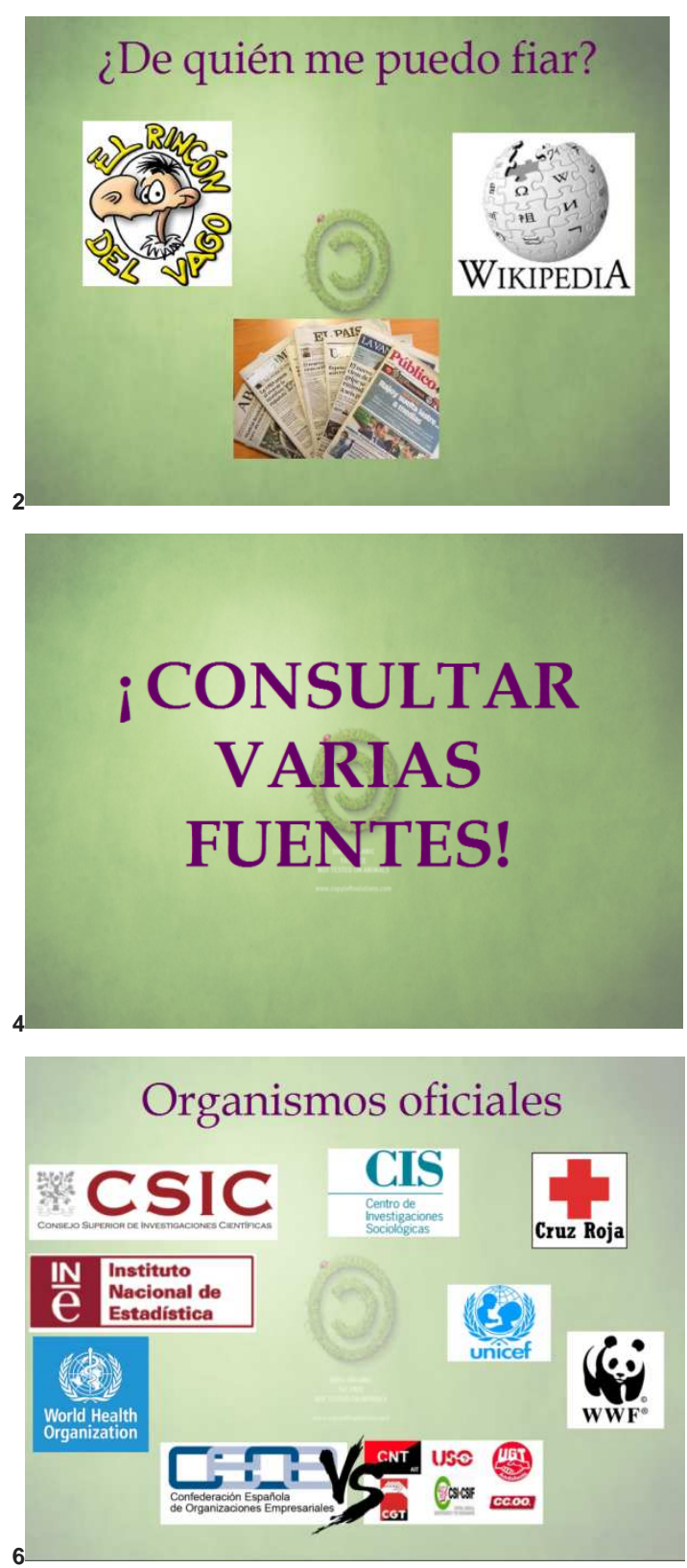
ANEXO 7. Esquemas mudos para la actividad 5
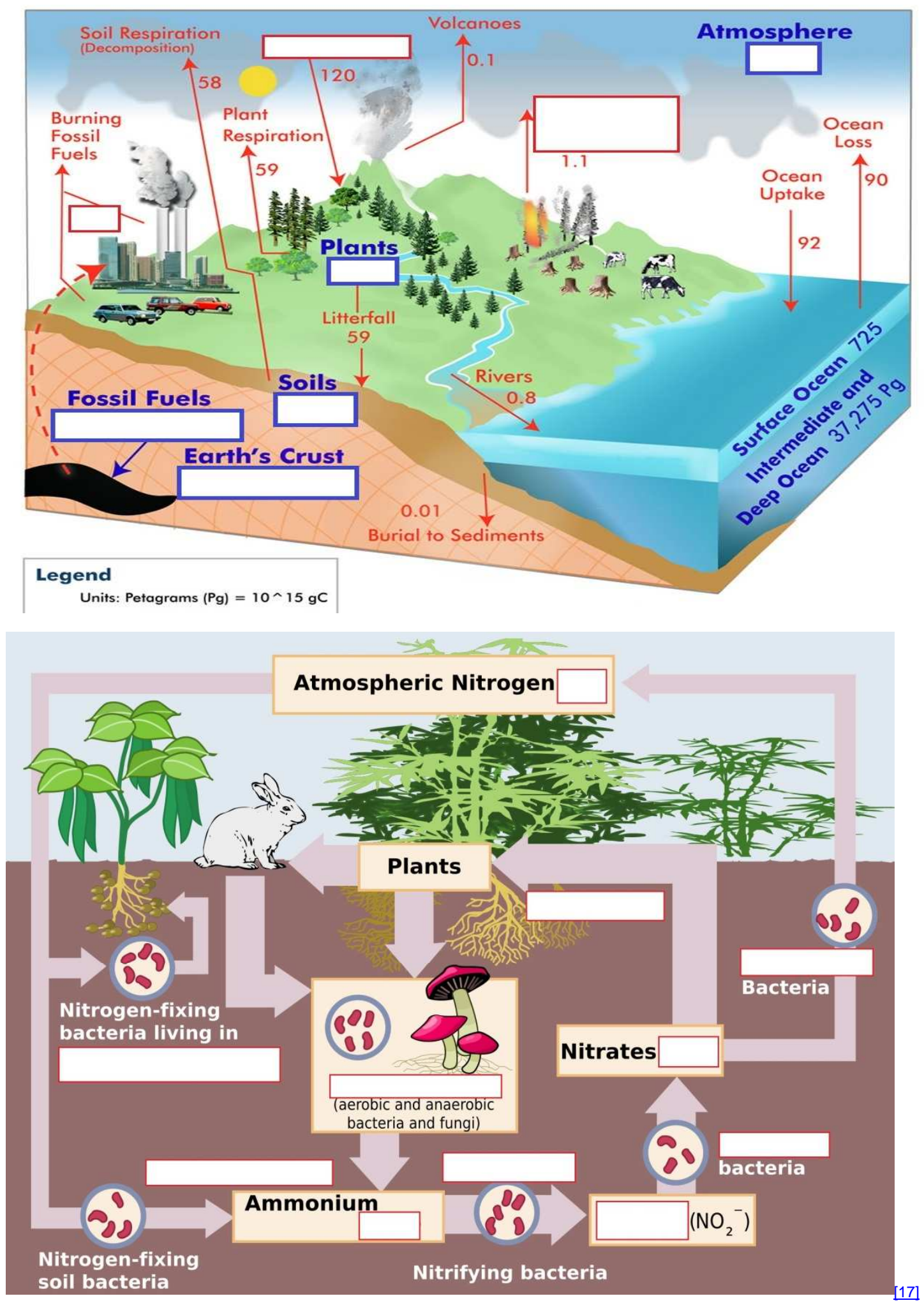

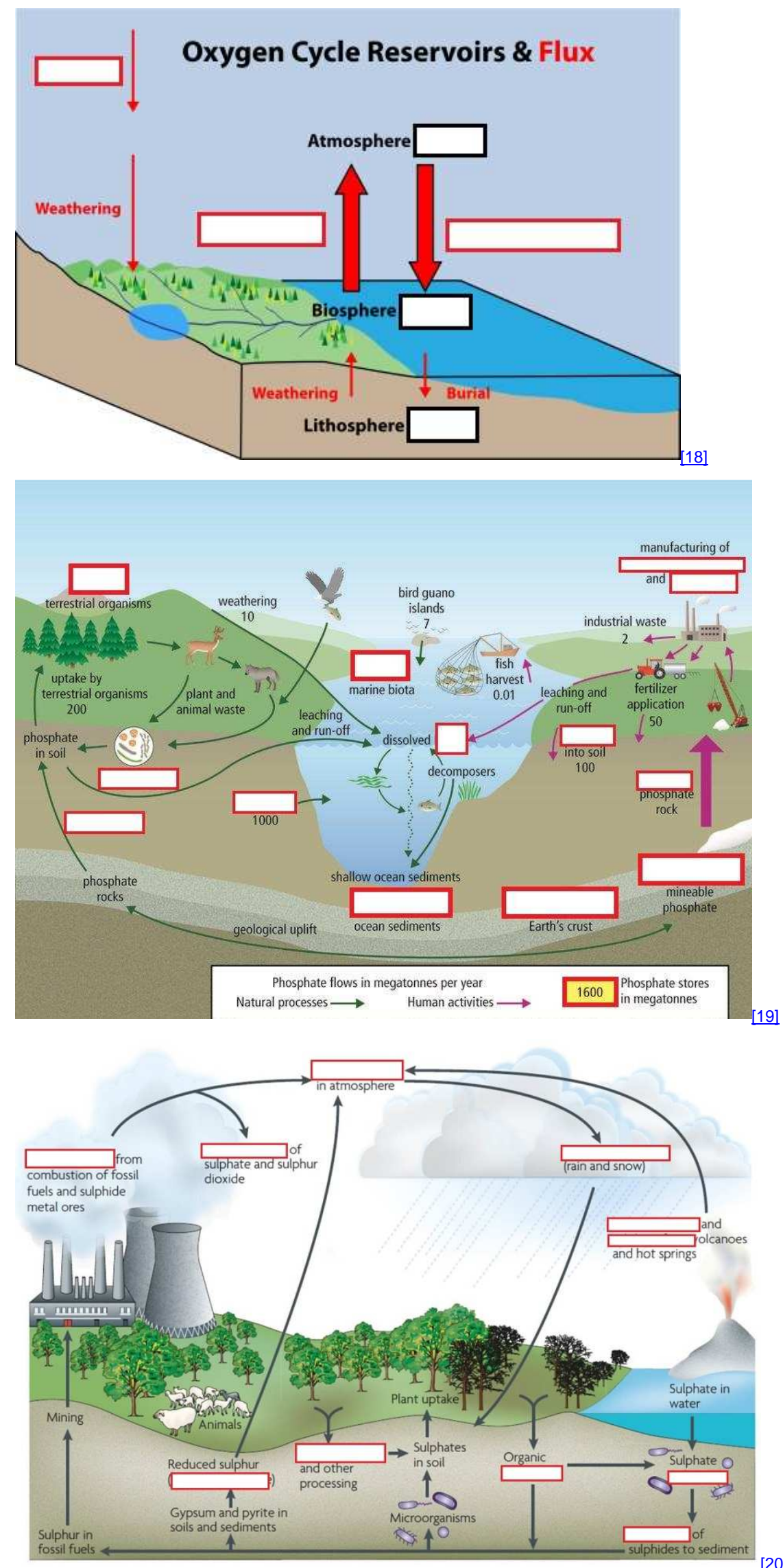


\section{Unidad Didáctica: Who wants fracking in town? 2015}

\section{ANEXO 8. Materiales para la actividad 6}

La información que se entregará a los alumnos para realizar cada uno de los apartados de la actividad 6 son:

Descripción de la técnica de fracturación hidráulica

Extracto de la página web earthworksaction.org [21]:

\section{“Hydraulic Fracturing 101}

\section{Hydraulic fracturing - What it is}

Geologic formations may contain large quantities of oil or gas, but have a poor flow rate due to low permeability, or from damage or clogging of the formation during drilling. This is particularly true for tight sands, shales and coalbed methane formations.

Hydraulic fracturing (aka fracking, which rhymes with cracking) stimulates wells drilled into these formations, making profitable otherwise prohibitively expensive extraction. Within the past decade, the combination of hydraulic fracturing with horizontal drilling has opened up shale deposits across the country and brought large-scale natural

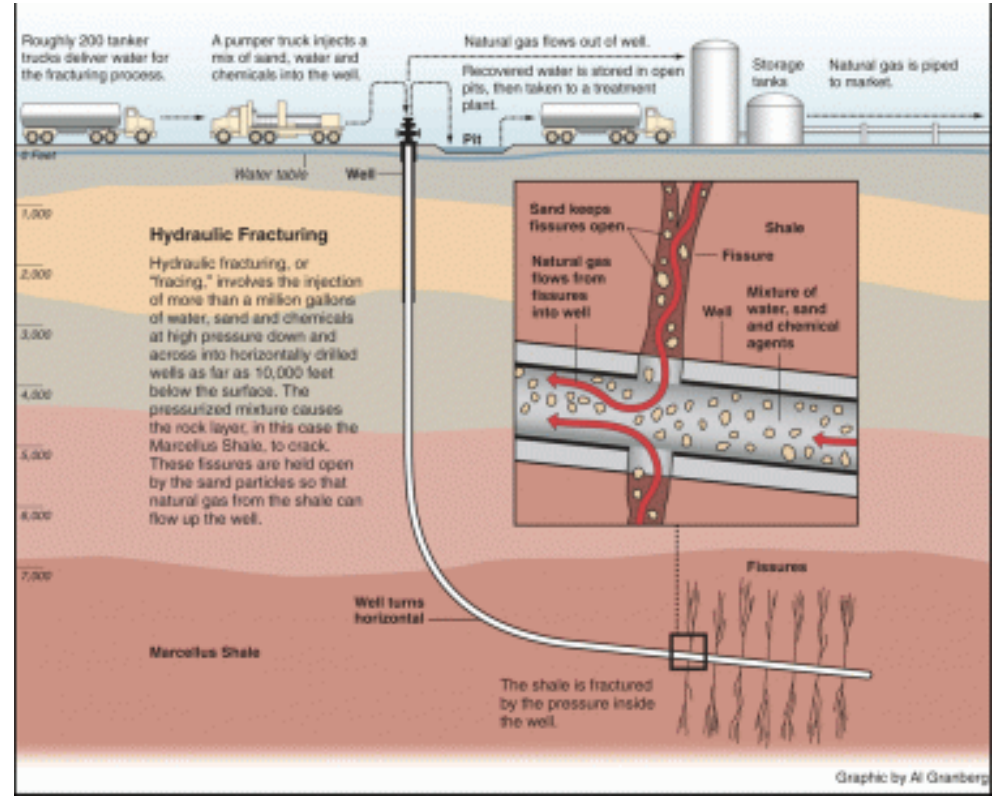
gas drilling to new regions.

The fracking process occurs after a well has been drilled and steel pipe (casing) has been inserted in the well bore. The casing is perforated within the target zones that contain oil or gas, so that when the fracturing fluid is injected into the well it flows through the perforations into the target zones. Eventually, the target formation will not be able to absorb the fluid as quickly as it is being injected. At this point, the pressure created causes the formation to crack or fracture. Once the fractures have been created, injection ceases and the fracturing fluids begin to flow back to the surface. Materials called proppants (e.g., usually sand or ceramic beads), which were injected as part of the frac fluid mixture, remain in the target formation to hold open the fractures.

Typically, a mixture of water, proppants and chemicals is pumped into the rock or coal formation. There are, however, other ways to fracture wells. Sometimes fractures are created by injecting gases such as propane or nitrogen, and sometimes acidizing occurs simultaneously with fracturing. Acidizing involves pumping acid (usually hydrochloric acid), into the formation to dissolve some of the rock material to clean out pores and enable gas and fluid to flows more readily into the well." 


\section{Unidad Didáctica: Who wants fracking in town? 2015}

Legislación

Artículo del diario online Energíadiario.com [22] titulado "El fracking queda regulado por primera vez en España con la Ley de Evaluación Ambiental”, Publicado el 28 de Noviembre de 2013:

"Los proyectos consistentes en la realización de perforaciones para la exploración, investigación o explotación de hidrocarburos que requieran de la técnica de fracking tendrán el visto bueno administrativo en un plazo de cuatro meses, prorrogable a dos más por razones justificadas y debidamente motivadas."

Hasta ahora, el Ministerio de Industria, Energía y Turismo o las comunidades autónomas concedían las autorizaciones a los proyectos estudiando caso por caso, con la Ley del Sector de Hidrocarburos, de 1998, como única norma nacional.

Con la Ley de Evaluación Ambiental, el promotor del proyecto de fracking deberá elaborar previamente un estudio de impacto ambiental y presentar la documentación técnica pertinente. El órgano competente emitirá una declaración de impacto ambiental en el plazo máximo de seis meses, cuando actualmente esta situación puede demorarse varios años.

Durante la tramitación en el Congreso y el Senado, los diferentes partidos de la oposición reiteraron sus quejas por el hecho de que la norma se tramite de forma urgente cuando en la Unión Europea se aprobará próximamente una directiva europea en materia de evaluación ambiental y afirmaron que la norma propiciará que "quien puede pagar, contamina".

El proyecto de Ley de Evaluación Ambiental, que unifica las normas sobre evaluación ambiental estratégica y de evaluación de impacto ambiental, tiene como objetivo "ser un instrumento eficaz para la protección medioambiental" minimizando los impactos que pueden causar al entorno los planes, programas y proyectos que se lleven a cabo en toda España y puedan afectar significativamente al medio ambiente.

Con este Proyecto de Ley se simplifican los procedimientos de evaluación ambiental estratégica y de evaluación de impacto ambiental, al emplear un esquema similar para ambos (procedimiento ordinario y simplificado) y homogeneizar su terminología, de manera que los plazos para los proyectos de evaluación estratégica ordinaria será de 22 meses, prorrogable por dos meses más por razones justificadas debidamente motivadas; los de evaluación ambiental estratégica simplificada, cuatro meses; los de evaluación de impacto 


\section{Unidad Didáctica: Who wants fracking in town? 2015}

ambiental ordinaria, cuatro meses, prorrogable por dos meses más por razones justificadas debidamente motivadas, y los de evaluación de impacto ambiental simplificada, tres meses

Por otro lado, el proyecto de Ley de Evaluación Ambiental recoge que los estudios de impacto ambiental deben incorporar en su descripción técnica "la peligrosidad sísmica natural o la peligrosidad sísmica inducida por el proyecto", para evitar casos como el almacén subterráneo de gas natural Castor, emplazado frente a las costas de Vinaròs (Castellón) y que causó más de 300 temblores en el golfo de Valencia el pasado mes de septiembre."

Comunicado de WWF sobre la legislación del fracking a nivel europeo [23]:

“New EU directive allows for EIA-free fracking

The new Directive 2014/52/EU "of 16 April 2014 amending Directive 2011/92/EU on the assessment of the effects of certain public and private projects on the environment" has been welcomed by many environmental groups as a major step towards strengthening impact assessment legislation. It has however also attracted much criticism as hydraulic fracturing, a relatively new and environmentally detrimental technology for the extraction of shale gas, will eventually not be covered by the new legislation.

Since the 9 October 2013 European Parliament vote adopting amendments to the proposed directive and calling for the inclusion of shale gas operations under mandatory environmental impact assessment, pressing lobbying, mostly behind the scenes, had targeted the Commission. Succumbing to the pressures, the European Commission finally issued a non-binding "Recommendation of 22 January 2014 on minimum principles for the exploration and production of hydrocarbons (such as shale gas) using high-volume hydraulic fracturing". "

$\underline{\text { Impactos sobre el medioambiente y la sociedad }}$

Comunicado de Greenpeace España a cerca de las repercusiones del fracking (Greenpeace, s.f.):

“2. ¿Cuáles son los principales problemas de la fractura hidráulica? Este proceso conlleva una serie de impactos ambientales, algunos de los cuales aún no están plenamente caracterizados o comprendidos, entre ellos contaminación de las aguas subterráneas, contaminación atmosférica, emisión de gases de efecto invernadero (metano), terremotos 


\section{Unidad Didáctica: Who wants fracking in town? 2015}

(sismicidad inducida), contaminación acústica e impactos paisajísticos. Además de estos impactos, también se debe tener en cuenta los relacionados con el tráfico de camiones para transportar el gas extraído, el consumo de agua y la ocupación del territorio.

Agua: - El proceso de fractura hidráulica consume enormes cantidades de agua. Se ha calculado que se requieren entre 9.000 y 29.000 metros cúbicos de agua para las operaciones de un solo pozo. Esto podría causar problemas con la sostenibilidad de los recursos hídricos incluso en países de clima templado, y aumentar la presión del consumo de suministros en las zonas más áridas.

- Se sabe muy poco de los peligros ambientales asociados con los productos químicos que se añaden a los fluidos usados para fracturar la roca, productos que equivalen a un $2 \%$ del volumen de esos fluidos. De hecho, en EE.UU. (el país con más experiencia hasta ahora, aunque muy reciente, con estas técnicas), esos productos están exentos de la regulación federal y/o la información sobre ellos está protegida debido a intereses comerciales. Se sabe que hay al menos 260 sustancias químicas presentes en alrededor de 197 productos, y algunos de ellos se sabe que son tóxicos, cancerígenos o mutagénicos. Estos productos pueden contaminar el agua debido a fallos en la integridad del pozo y a la migración de contaminantes a través del subsuelo.

- Entre un $15 \%$ y un $80 \%$ del fluido que se inyecta para la fractura vuelve a la superficie como agua de retorno, y el resto se queda bajo tierra, conteniendo aditivos de la fractura y sus productos de transformación. Entre las sustancias disueltas a partir de la formación rocosa, donde está el gas durante el proceso de fractura, se encuentran metales pesados, hidrocarburos y elementos naturales radiactivos.

- No se puede descartar una posible contaminación de los acuíferos subterráneos y de las aguas superficiales debido a las operaciones de la fractura hidráulica y a la disposición de las aguas residuales, ya sea a través de una planta de tratamiento de agua o directamente a las aguas superficiales. Estos productos químicos pueden, por lo tanto, ser vertidos en los acuíferos y fuentes de aguas subterráneas que alimentan los suministros públicos de agua potable. Incluso pequeñas cantidades de hidrocarburos cancerígenos son perjudiciales para los seres humanos. En algunos casos, estas aguas residuales son mínimamente procesadas antes de ser vertidas a las aguas que alimentan los suministros públicos, y a veces son retenidas en los estanques que más tarde pueden verter estos productos químicos al medio ambiente.

Contaminación atmosférica: - Se ha registrado benceno, un potente agente cancerígeno, en el vapor que sale de la "pozos de evaporación", donde a menudo se almacenan las aguas residuales del fracking. Las fugas en los pozos de gas y en las tuberías también pueden contribuir a la contaminación del aire y a aumentar las emisiones de gases de efecto 


\section{Unidad Didáctica: Who wants fracking in town? 2015}

invernadero. El gran número de vehículos que se necesitan (cada plataforma de pozos requiere entre 4.300 y 6.600 viajes en camión para el transporte de maquinaria, limpieza, etc.) y las operaciones de la propia planta también pueden causar una contaminación atmosférica significativa si tenemos en cuenta los gases ácidos, hidrocarburos y partículas finas.

Emisiones de gases de efecto invernadero (GEI): • Es crucial conocer y cuantificar las fugas de metano a la atmósfera y cuestiona ya a la industria del fracking que asegura que son inferiores al $2 \%$. Sin embargo, un reciente estudio de la NOAA1 (National Oceanic and Atmospheric Administration) y de la Universidad de Colorado, en Boulder, determina que en el área conocida como la cuenca Denver-Julesburg (EE.UU) las fugas son del 4\%, sin incluir las pérdidas adicionales en el sistema de tuberías y distribución. Esto es más del doble de lo anunciado. Cabe recordar que el metano tiene una capacidad como gas de efecto invernadero 25 veces superior al dióxido de carbono.

- Los promotores del fracking defienden que el uso de este gas permitiría ser más independientes energéticamente y disminuir la quema de carbón. Sin embargo, los expertos determinan que, a menos que las tasas de fuga de metano extraído, por esta técnica, se pueda mantener por debajo del 2\%, la sustitución de este gas por el carbón no es un medio eficaz para reducir la magnitud del cambio climático en el futuro (Según el estudio estadounidense del año 2011, de Tom Wigley, del Centro para la Investigación Atmosférica -NCAR-). Otro motivo más para descartar la explotación este tipo de gas y apostar por las energías renovables.

Contaminación acústica e impactos paisajísticos • Las operaciones de perforación pueden causar una degradación severa del paisaje (intensa ocupación del territorio) y contaminación acústica simplemente como resultado de las operaciones diarias (paso de camiones y transportes). Estas pueden afectar a las poblaciones cercanas y a la fauna local a través de la degradación del hábitat."

Artículo de del think tank Brookings [24] señalando los beneficios del fracking:

"Innovations in drilling and hydraulic fracturing ("fracking") have enabled tremendous amounts of natural gas to be extracted from underground shale formations that were long thought to be uneconomical. But has this shale gas boom translated in an economic boom? According to Catherine Hausman and Ryan Kellogg, who shared the first-ever estimates of broad-scale welfare and distributional implications of fracking as part of the most recent 
conference of the Brookings Papers on Economic Activity (BPEA), the answer is yes. Here's why:

\section{As fracking grows, natural gas prices are dropping}

The U.S. fracking revolution has caused natural gas prices to drop 47 percent compared to what the price would have been prior to the fracking revolution in 2013.
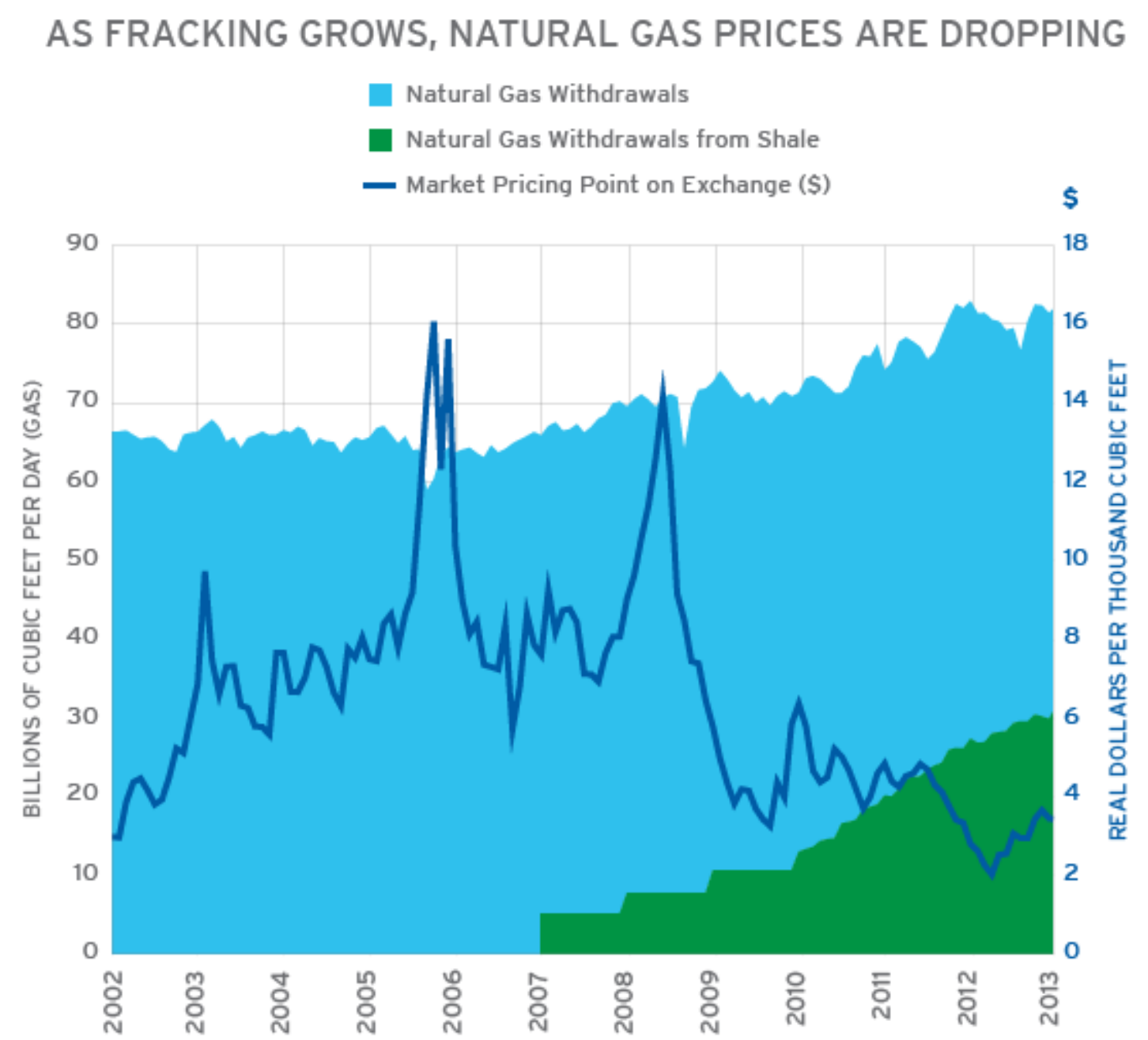

Note: Gross withdrawals include not only marketed production, but also natural gas used to repressure wells, vented and flared gas, and non-hydrocarbon gases removed.

Source: U.S. Energy Information Administration

BROOKINGS

Energy consumers are seeing economic gains 
Gas bills have dropped $\$ 13$ billion per year from 2007 to 2013 as a result of increased fracking, which adds up to $\$ 200$ per year for gas-consuming households. Moreover, all types of energy consumers, including commercial, industrial, and electric power consumers, saw economic gains totaling $\$ 74$ billion per year from increased fracking.

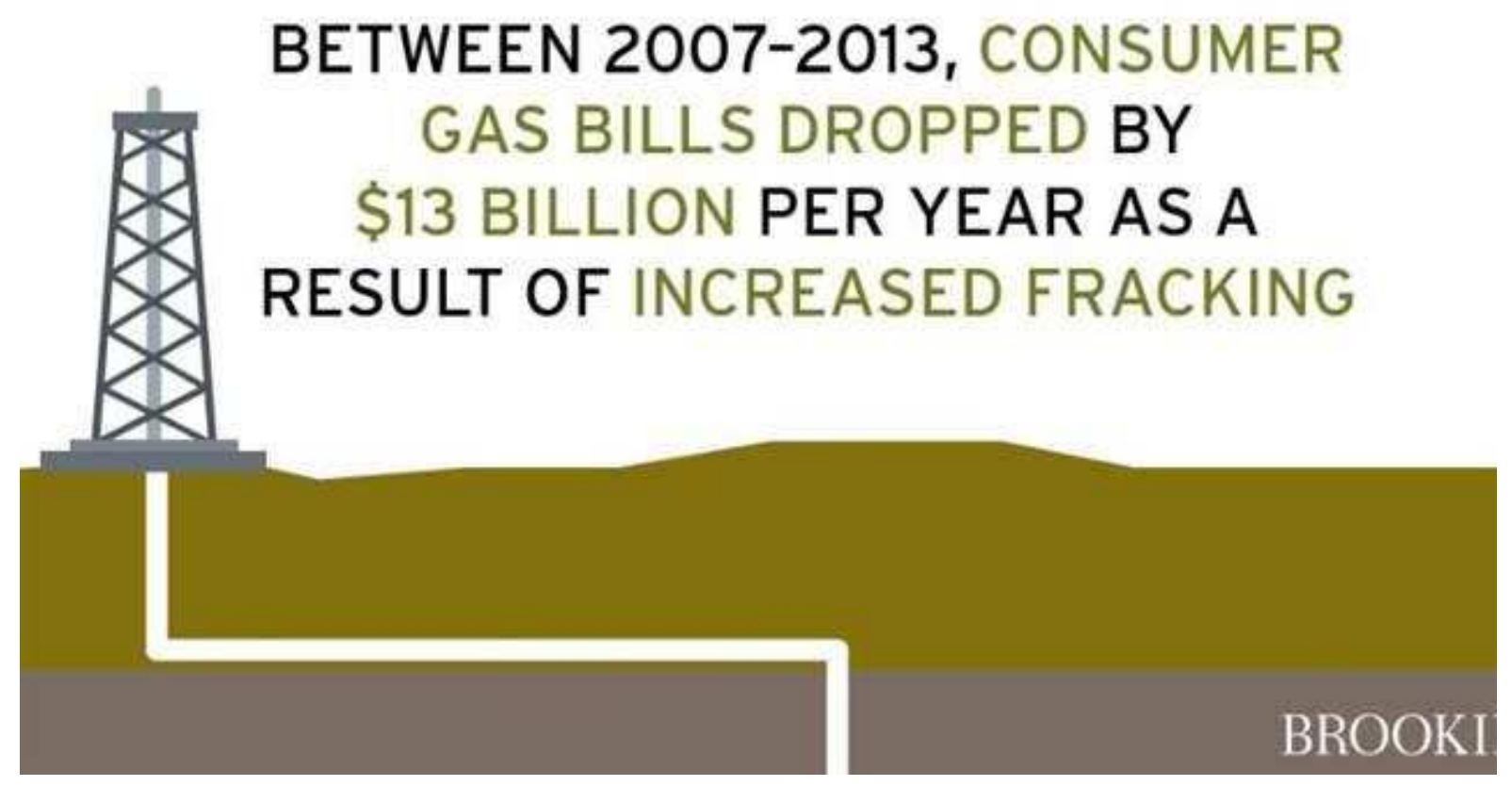

\section{All regions are experiencing economic benefits}

Though one would expect colder states that use natural gas for space heating to benefit most from shale gas, the authors point out that the West South Central region (Arkansas, Louisiana, Oklahoma, and Texas) gained the most at $\$ 432$ per person in consumer benefits, followed by East North Central (Illinois, Indiana, Michigan, Ohio, and Wisconsin) with $\$ 259$ per person in benefits. The area to gain the least is the Pacific (California, Oregon, and Washington), but consumers there still benefited to the tune of $\$ 181$ per year."

\section{Situación actual del fracking en España y el resto del mundo}

Página web del Ministerio de Industria, Energía y Turismo (figura 9), en el que se muestra el estado de las concesiones para iniciar procesos de extracción de gas natural mediante la fractura hidráulica [25]. 


\section{Unidad Didáctica: Who wants fracking in town? 2015}

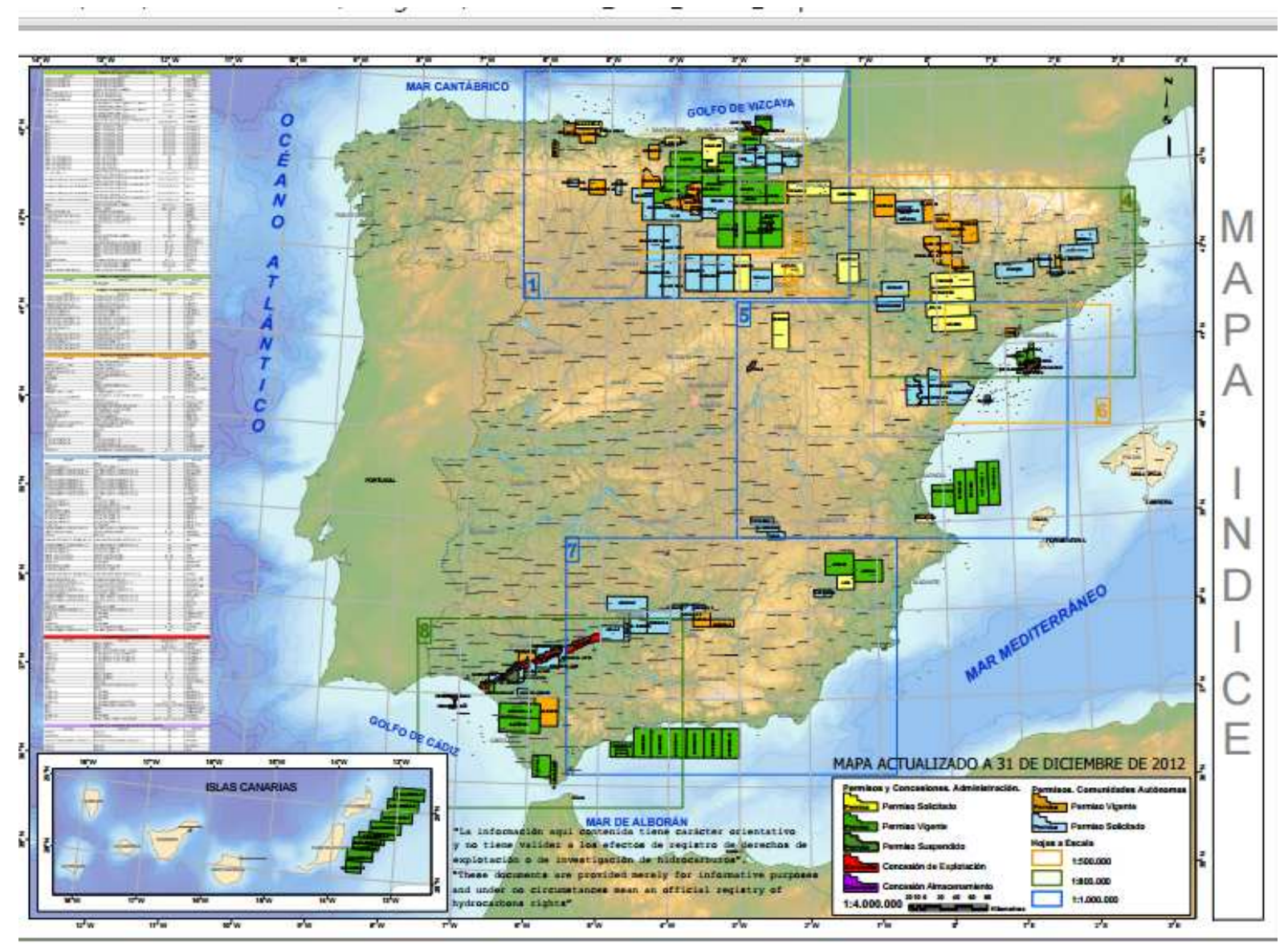

Figura 9. Mapa del ministerio de industria en el que se muestran el estado de los procesos de fracking en España.

Artículo de eldiario.es [26] en el que se muestra el estado del fracking en las distintas comunidades autónomas de España.

"El objetivo del Gobierno por mantener el control sobre la regulación del fracking en España está provocando que ponga su maquinaria legal en funcionamiento para cortar cualquier intento por parte de comunidades autónomas u otro organismo que intente limitar, entorpecer o prohibir la actividad. Este es el panorama en el que se enfrentan parlamentos, gobiernos y tribunales en el intento de controlar la extracción de hidrocarburos mediante la inyección de agua a altísima presión en el subsuelo.

Con la regulación española encauzada por la ley de Evaluación Ambiental y la Comisión Europea dejando en manos de los estados plena autonomía para legislar, al Ejecutivo le 


\section{Unidad Didáctica: Who wants fracking in town? 2015}

surgieron tres CCAA (Cantabria, La Rioja y Navarra) que prohibieron el fracking en su territorio. El Gobierno recurrió rápidamente ante el Tribunal Constitucional el texto cántabro. El TC falló a su favor por invasión de competencias exclusivas del Estado. Le seguirán las otras dos leyes. Otra comunidad más, Cataluña, buscó un giro legal y usó sus competencias en urbanismo para no permitir licencias de este tipo en terrenos no urbanizables.

La pelea legal ofrece episodios contradictorios como el de los parlamentos de Castilla y León o la Comunidad Valenciana - con mayoría del PP- votando en contra de iniciativas antifracking mientras las diputaciones provinciales de Valladolid, Burgos, Castellón o Valencia (todas dominadas por el PP) aprobaron mociones para frenar este método de extracción.

Ante las incertidumbres, cientos de municipios se han declarado libres de fracking, según el registro de Amigos de la Tierra. ¿Hasta dónde llega su capacidad para aplicar normas a las extracciones de gas? Samuel Martín, de Ecologistas en Acción, analiza que " el nivel local puede tener un recorrido mediante los planes generales de urbanismo". Y recuerda que la sentencia del Tribunal Constitucional, que anuló la ley cántabra, "decía que no se puede hacer una prohibición genérica pero sí razonada para determinadas áreas"."

\section{$\underline{\text { Casos de estudio }}$}

Denuncia del grupo Mesa de la Ría sobre el fracking en Doñana [27]

“Mesa de la Ría denuncia que REPSOL realiza fracking en la costa y GAS NATURAL recibe autorización de investigación para la fracturación hidráulica en Doñana.

La Mesa de la Ría considera que REPSOL INVESTIGACIONES PRETOLIFERAS S.A. puede estar realizando fracking en los yacimientos Poseidon en las costas de Doñana (Huelva), cuyo gas se deshidrata en la planta en tierra que linda con el Parque Natural de Doñana.

Repsol carece de la documentación ambiental necesaria con la que acredite estar bajo el control ambiental o supervisión autonómica, estatal y Europea, lo que explicaría la negativa del Ayuntamiento de Huelva o el SEPRONA a facilitar la documentación requerida como, las 


\section{Unidad Didáctica: Who wants fracking in town? 2015}

analíticas o, el convenio suscrito con el Ayuntamiento de Huelva para tratar las aguas contaminadas en la depuradora de la ciudad.

Repsol Investigaciones Petrolíferas SA., no tiene la preceptiva Autorización Ambiental Unificada para llevar a cabo todas esas actividades, hecho que ha sido denunciado por la Mesa de la Ría ante la Junta de Andalucía, la Comisión y el Parlamento Europeos, y finalmente ante la UNESCO, entidades a las que añadirá la posibilidad de que se esté realizando fracking en la costa, además de los permisos concedidos en el interior del mismo Parque Nacional de Doñana.

REPSOL funciona sin la preceptiva Autorización según la Ley 7/2007 de 9 de Julio de Gestión y Calidad Ambiental de la Junta de Andalucía (trasposición de la Directiva Europea IPPC) a la que era obligatorio que se adaptaran todas las industrias existentes con anterioridad a su promulgación, con el límite de fecha el día 30 de abril de 2008, según la disposición final sexta. (Modificación de la Ley 16/2002, de 1 de julio, de prevención y control integrados de la contaminación.) de la ley 42/2007, de 13 de diciembre, del Patrimonio Natural y de la Biodiversidad, con el conocimiento y connivencia de la Junta de Andalucía (PSOE-IU) y el Ayuntamiento de Huelva (PP).

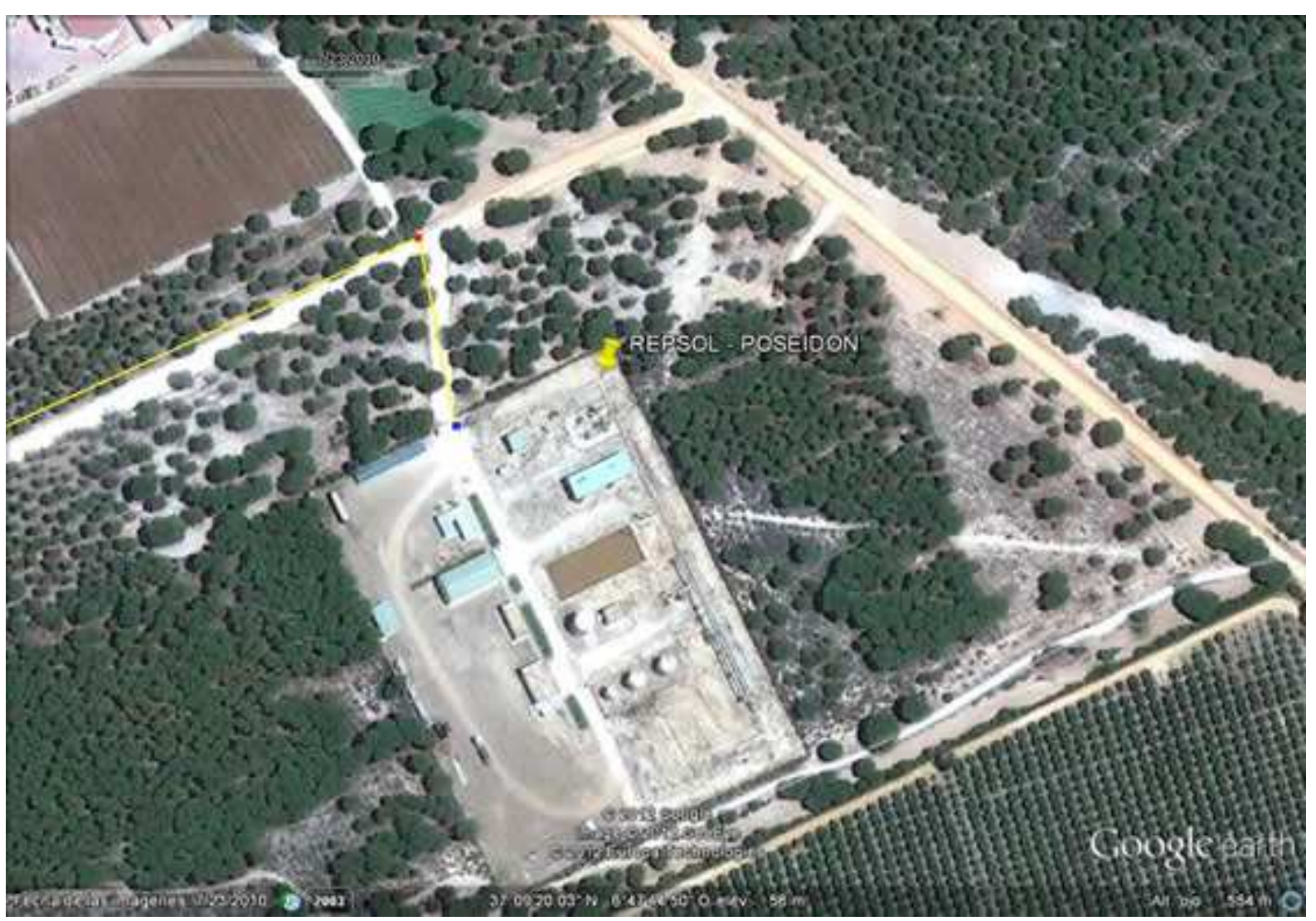




\section{Unidad Didáctica: Who wants fracking in town? 2015}

La enorme caravana de camiones cisterna que REPSOL traslada durante treinta kilómetros a la depuradora de la ciudad de Huelva, se realiza avalado por un Convenio con la empresa semipública Aguas de Huelva, que el Ayuntamiento Onubense oculta a la ciudadanía y a los grupos de oposición, y que tiene todas las papeletas de tratar de esconder la primera realización de fracking en medio marino en España.

\section{AUTORIZACIÓN DE ESTUDIOS PARA FRACKING EN DOñANA.}

El Real Decreto 1495/2010, de 5 de noviembre, por el que se otorga a Petroleum Oil \& Gas España, SA, el permiso de investigación de hidrocarburos denominado Horquilla para realización de fracking, afecta al interior del propio Parque Nacional de Doñana.

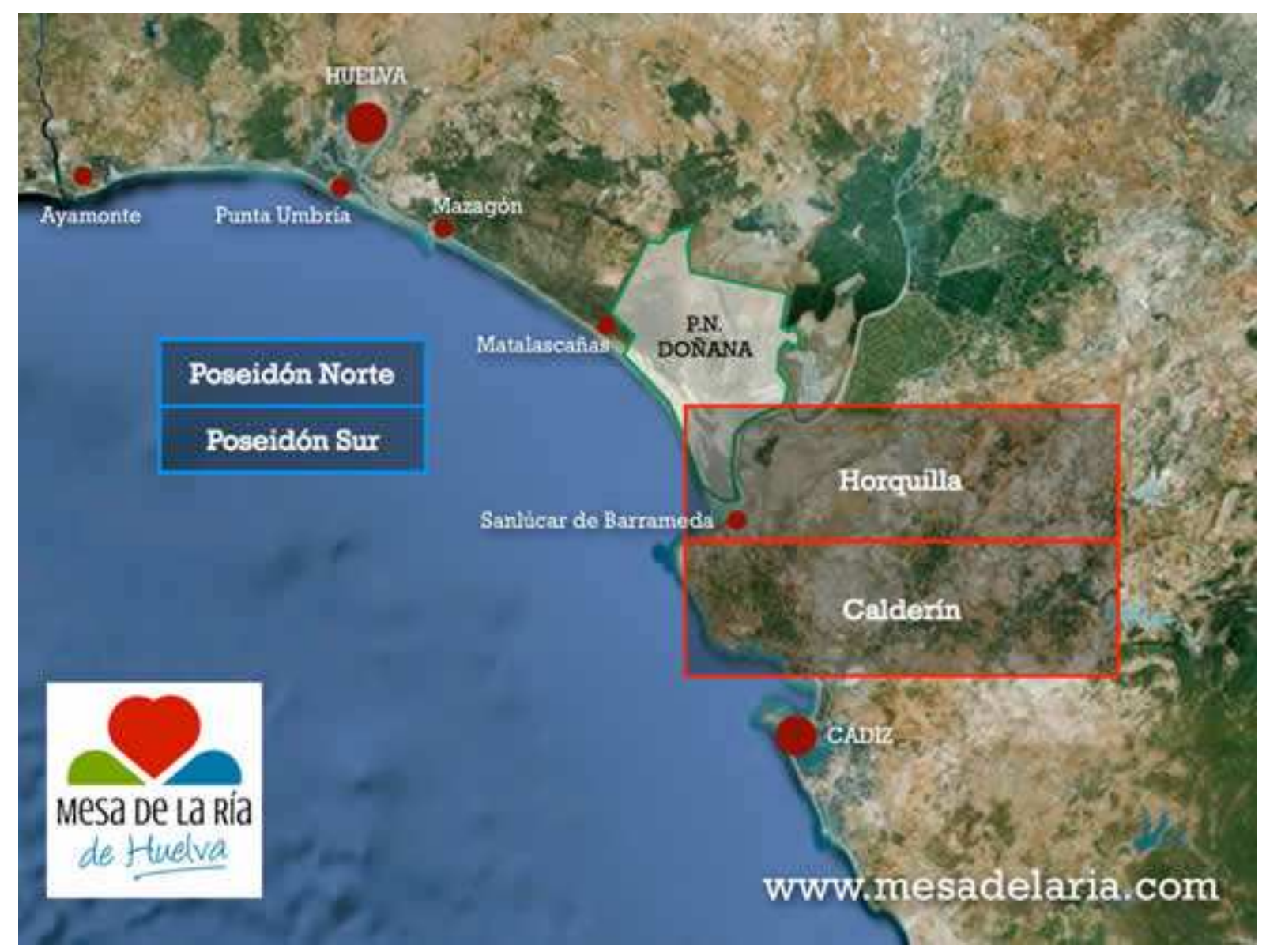

\section{EL TITULO DE PATRIMONIO DE LA HUMANIDAD DE DOÑANA, AMENAZADO.}

Ante los proyectos gasísticos en Doñana que ponen en peligro el Parque Natural, entre los que se encuentra la extracción de gas de REPSOL, la Mesa de la Ría solicitó a la UNESCO se revise el expediente de Doñana, a la que añadirá éstas autorizaciones para 


\section{Unidad Didáctica: Who wants fracking in town? 2015}

perforaciones para fracking y la posibilidad de que REPSOL ya esté utilizando está técnica tan dañina para el medio ambiente.

La Mesa de la Ría entiende que estos proyectos y realidades industriales ponen en peligro el futuro del Parque Nacional, y espera que, esta denuncia, sirva de toque de atención al Gobierno de España y a la Junta de Andalucía para que paralicen trasformación del parque Natural de Doñana en Parque Gasístico.

La UNESCO informó a la Mesa de la Ría fue inmediata, en un escrito fechado 5 de abril indicó que se pondrán en contacto con el Gobierno de España para que les informe sobre estos proyectos y que, en una reunión de la UNESCO que tendrá lugar los días 16 al 27 de junio en Nom Pen (capital de Camboya), trataran la preocupación que tienen sobre el futuro del Parque de Doñana y de su condición de Patrimonio de la Humanidad.

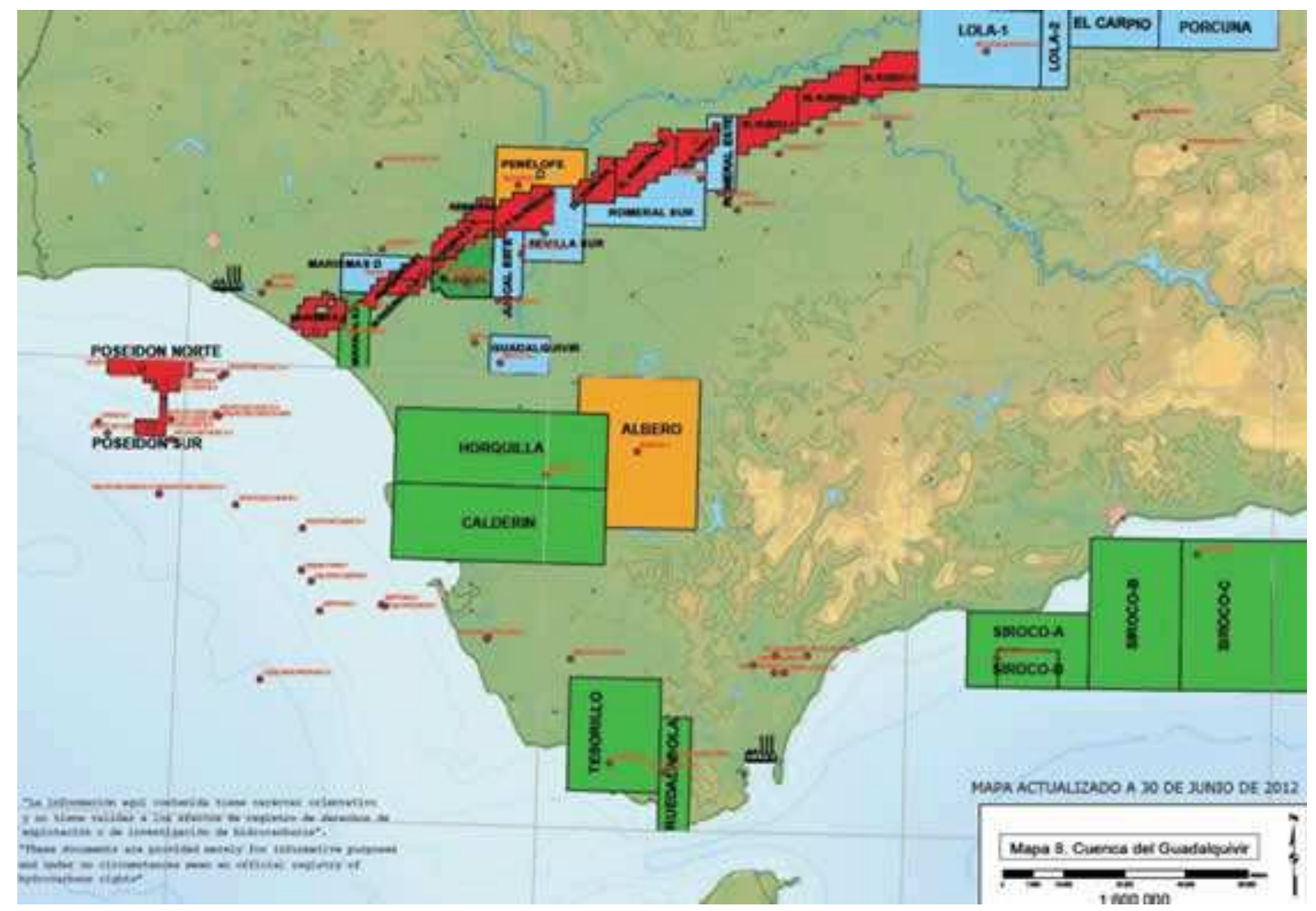

\section{MESA DE LA RIA EN CONTRA DEL FRACKING}

El colectivo ciudadano con representación municipal solicitará en el próximo Pleno del Ayuntamiento de Huelva que el municipio se posicione en contra del Fracking e inste a la junta de Andalucía a hacer lo mismo. 


\section{Unidad Didáctica: Who wants fracking in town? 2015}

Huelva es una zona sísmica y con riesgo de terremotos y tsunamis, con graves riesgos antropológicos entre los que se encuentra una refinería, regasificadoras y un Polo Químico, y se trata de una zona en donde, además de éstos, no tardará mucho en llegar el aluvión de tales permisos como ha ocurrido en la Provincia de Cádiz, por lo que el colectivo ciudadano pide al Ayuntamiento y Junta de Andalucía que se opongan a ésta técnica tan contaminante y con tantos riesgos"

Artículo de la BBC Fracking tests near Blackpool 'likely cause' of tremors [28]:

"It is "highly probable" that shale gas test drilling triggered earth tremors in Lancashire, a study has found.

But the report, commissioned by energy firm Cuadrilla, also said the quakes were due to an "unusual combination of geology at the well site".

It said conditions which caused the minor earthquakes were "unlikely to occur again".

Protesters opposed to fracking, a gas extraction method, said the report "did not inspire confidence".

Six protesters from campaign group Frack Off climbed a drilling rig at one of Cuadrilla's test drilling sites in Hesketh Bank, near Southport, ahead of the report.

They oppose the controversial extraction method which pumps water and chemicals underground at high pressure to shatter rock formations and release gas, claiming it can be unsafe.

\section{Safety concerns}

A spokeswoman for Lancashire Police said the protest came to an end at about 16:00 GMT. Three people were arrested on suspicion of aggravated trespass. Three others were reported for summons, on the same allegation.

Cuadrilla suspended its shale gas test drilling in June, over fears of links to the earthquakes.

One tremor of magnitude 2.3 hit the Fylde coast on 1 April, followed by a second of magnitude 1.4 on 27 May.

A study by The British Geological Survey placed the epicentre for each quake about $500 \mathrm{~m}$ away from the Preese Hall-1 well, at Weeton, near Blackpool. 


\section{Unidad Didáctica: Who wants fracking in town? 2015}

The Geo-mechanical Study Of Bowland Shale Seismicity report, carried out by independent experts, said the combination of geological factors that caused the quakes was rare, and would be unlikely to occur together again at future well sites.

It said: "If these factors were to combine again in the future local geology limits seismic events to around magnitude 3 on the Richter scale as a worst-case scenario."

However, it said that "even the maximum seismic event is not expected to present a risk".

Mark Miller, chief executive officer of Cuadrilla Resources, said: "We unequivocally accept the findings of the independent report and we are pleased that there is no threat to people or property in the local area from our operations.

"We are ready to put in place the early detection system that has been proposed in the report so that we can provide additional confidence and security to the local community.

"Cuadrilla is working with the local and national authorities to implement the report's recommendations so we may resume our operations."

A spokesman for Frack Off said: "This report does not inspire confidence, they should have done their research before drilling began."

He added: "Can we believe anything else the industry says when it talks about the safety of fracking?"

Protesters have called for an end to fracking. There have been concerns that potentially carcinogenic chemicals could escape during the process and find their way into drinking water sources.

\section{'Hopelessly naive'}

"The contamination of irrigation water means that everyone's food supplies could potentially be affected," the Frack Off spokesman added.

Friends of the Earth's senior climate campaigner Tony Bosworth said: "This report shows fracking for shale gas caused earth tremors in Lancashire - experience in the US shows it could also pollute air and water supplies.

"Extracting shale gas would suck vital funding away from clean and safe energy alternatives that could create thousands more UK jobs. 


\section{Unidad Didáctica: Who wants fracking in town? 2015}

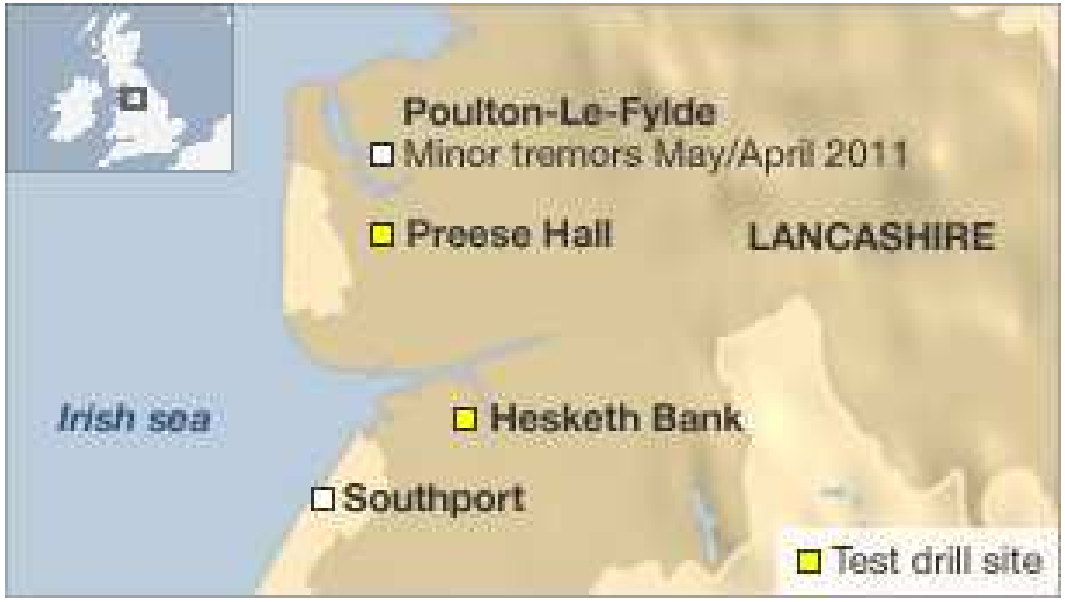

"An early seismic detection system won't be enough to make local people feel safe - there should be no more fracking in Britain until the health and environmental impacts are fully understood."

Doug Parr, chief scientist at Greenpeace, added: "Anyone who believes shale gas is the solution to our energy needs is being hopelessly naive.

"There are significant unknowns about the local and global impacts of fracking, illustrated by the conclusion by seismologists that recent fracking in the North West was responsible for a minor earthquake."

He said fracking was a "distraction from the real challenges" and that "real energy solutions" would be found in using renewable sources.

Nick Molho, head of energy policy at World Wildlife Fund UK, reiterated a call for a moratorium on fracking in the UK.

"These findings are worrying, and are likely to add to the very real concerns that people have about fracking and shale gas," he said.

The industry denies that shale gas is unsafe and a government committee has recommended that fracking should be allowed to go ahead.

The Department of Energy and Climate Change (DECC) said: "The implications of this report will be reviewed very carefully - in consultation with the British Geological Survey, independent experts, and the other key regulators, HSE and the Environment Agency before any decision on the resumption of these hydraulic fracture operations is made."' 


\section{Unidad Didáctica: Who wants fracking in town? 2015}

\section{ANEXO 9. Bases del juego de roles}

The international company Brent Petroleum is interested in doing a preliminary study near a small village in la Vega de Granada. It is believed to be a natural gas field there, suitable for exploitation by hydraulic fracturing, a.k.a. fracking.

The Ministry of Industry has given its approval to this preliminary study (without any formal commitment that the operation should be allowed in case to be viable). However, local media have echoed the news and environmental groups have quickly expressed their disagreement.

The Mayor of the town, who says he has never heard about fracking, has finally taken actions on the matter. In order to form an opinion about this conflict, he has brought together in a meeting all parties involved in the discussion. They are:

- Technicians and shareholder from Brent Petroleum

- Local ecologist group "Granada Verde"

- Civil servants from the Ministry of Industry

- Local neighborhood association

- Union members of local farmers

- The town Mayor (teacher)

After the meeting, the Mayor shall make a decision which, no doubt, will not make everybody happy. By the way, people from Brent Petroleum come from different countries and can not understand Spanish so...let's talk in English. 


\section{Unidad Didáctica: Who wants fracking in town? 2015}

\section{ANEXO 10. Roles de cada grupo}

\section{Technicians and shareholder from Brent Petroleum.}

This international company has wide experience in fossil energy field. They have performed this this very method in many countries around the world. The rise in oil prices makes now profitable exploitation of this kind of field. Shareholders can not lose the opportunity to be the pioneer in the extraction of shale gas in Spain, which would mean huge profits for them.

Key words:

- Experience

- Safe technology

- Earthquakes are few and soft

- Job creation

Documentation:

- Eleconomista.es. El fracking en España podría ser una realidad en 2016: habría gas para 70 años de consumo [29].

- Vídeo de BNK Petroleum Inc. Vídeo fracturación hidráulica [30].

- Local ecologist group "Granada Verde”.

Although they have no resources to make their own studies, mates from other NGOs and against-fracking movements have been providing evidences of the negative consequences of fracking for years. Stopping this act would mean to earn great prestige among international NGOs.

Key words:

- Environmental impacts

- Sustainability

- Environmental Impact Assessment

- Environmental legislation

Documentation:

- Greenpeace. Fractura hidráulica para extraer gas natural (fracking) (Greenpeace, s.f.)

- Vídeo: No al fracking en Europa [14] 


\section{Civil servants from the Ministry of Industry}

The Ministry gives priority to this project for two main reasons: In one hand, it would mean lower energy prices and, therefore, greater competitiveness of domestic enterprises. On the other hand, it would create jobs, which is accorded with their job creation policy. However it is mandatory to respect environmental legislation.

Key words:

- Energetic competitiveness

- Employment

- Environmental law

Documentation:

- Bloomberg Business. Fracking Will Support 1.7 Million Jobs, Study Shows [31]

- Vídeo: What is Hydraulic Fracturing? [32]

\section{Local neighborhood association.}

They see economic recovery as a necessary thing, since there is many unemployed people in this town. However, actions taken by environmental groups make them suspicious of this activity: They do not want to drink contaminated water or suffer earthquakes. It may be another way to create job in the area.

Key words:

- Employment

- Pollution

- Earthquakes

Documentation:

- National Journal. How many jobs does fracking really creates? [33]

- Vídeo: Fracking explained: Opportunity or danger? [34] 


\section{Unidad Didáctica: Who wants fracking in town? 2015}

\section{Union members of local farmers.}

They are afraid of the expropriation of the land the work and pollution of the water they use for watering. They demand to the government to invest in more sustainable patterns of development such as organic farming.

Key Words:

- Land management

- Pollution

- Environmental development

Documentation:

- Elpaís.es. Revés a las prohibiciones regionales del 'fracking' [35]

- Vídeo: Benzene diet? No, thanks. California farmers angry at fracking wastewater use amidst record drought [36] 


\section{Unidad Didáctica: Who wants fracking in town? 2015}

\section{ANEXO 11. Materiales para la actividad 8}

Qué es una evaluación de impacto ambiental [37]

"- Las directrices europeas definen impacto ambiental como la diferencia entre el medio ambiente modificado por la intervención del ser humano y la situación del medio ambiente futuro tal y como habría evolucionado, normalmente, sin la modificación.

- El impacto puede ser negativo para el entorno natural y, a la vez, positivo para la calidad de vida del ser humano. Es necesario llevar a cabo una evaluación de los impactos ambientales positivos y negativos de los distintos proyectos o acciones.

- La evaluación es un proceso administrativo en el que la admi-nistración ambiental competente podrá emitir un dictamen favorable o no del proyecto.

- Se entiende por evaluación del impac-to ambiental el conjunto de estudios y sistemas técnicos que permiten estimar los efectos que la ejecución de un determinado proyecto, obra o actividad causa sobre el medio ambiente.

Según la legislación española, existe una serie de proyectos que requieren una EIA de obligado cumplimiento:

1. Refinerías de petróleo bruto.

2. Centrales térmicas.

3. Centrales nucleares.

4. Instalaciones de almacenamiento o eliminación de residuos radiactivos.

5. Plantas siderúrgicas integrales.

6. Instalaciones de extracción, tratamiento o transformación de amianto o de productos derivados.

7. Instalaciones químicas integradas.

8. Construcción de autopistas, autovías, líneas de tren, aeropuertos, etc.

9. Puertos comerciales, puertos deportivos y vías navegables.

10. Instalaciones especializadas en la eliminación de residuos tóxicos o peligrosos.

11. Construcción de presas.

12. Primeras repoblaciones forestales cuando entrañen graves trans-formaciones ecológicas."

Metodología de una EIA [37]

"La evaluación del impacto ambiental (EIA) es un proceso cuyo objetivo fundamental es facilitar la toma de decisiones respecto a algún proyecto que afecta al medio ambiente $y$, a su vez, a diversos colectivos. A partir de esta evaluación se emite la llamada 
declaración del impac-to ambiental (DIA), que es el dictamen final que permitirá o impedirá llevar a cabo dicho proyecto.

Una EIA debe identificar los elementos de riesgo de un proyecto para eliminarlos, corregirlos, minimizarlos o aconsejar la nulidad de la intervención sobre el medio. La evaluación de impactos debe tener en cuen-ta, básicamente, los siguientes puntos:

. El análisis en profundidad de todos los aspectos del proyecto, que será llevado a cabo por expertos.

. El estudio del medio que puede verse afectado por el proyecto, con-siderando todos sus componentes, tanto naturales como humanos.

- La identificación y predicción de las alteraciones o impactos ambientales que puede ocasionar el proyecto, la estimación de la probabilidad de que éstos ocurran y la proposición de alternativas viables.

- La valoración global de la incidencia del proyecto sobre todos los aspectos, tanto ambientales, como sociales, económicos, etc. que pueden verse afectados, así como de la capacidad de asimilación de los impactos por parte del entorno. Esta valoración se refleja en un infor-me final que será estudiado por el organismo ambiental competente.

Las formas de llevar a efecto una EIA son:

a) Matrices causa- efecto.

- La más conocida es la matriz de Leopold se trata de una tabla de doble entra-da donde se relacionan las acciones humanas, en las columnas, con factores o indicadores de impacto situados en las filas.

- Acciones (columnas): se consideran las acciones previas, las de la fase de construcción, explotación y abandono, cambios en el uso del territorio, destino de residuos, ruidos, olores...

- Factores (filas): se valoran los componentes de medio físico (calidad del aire, contaminación atmosférica, clima, suelo, geomorfología, hidrología), medio biológico (flora, fauna, paisaje) y medio socioeconómico (población, patrimonio histórico, productividad primaria)

- Es cuantitativa permite valorar los impactos de los distintos aspectos del proyecto. Cada impacto se valora mediante la magnitud $(M)$ del posible impacto y la importancia (I) relativa del impac-to en el conjunto del proyecto. M e I se valoran en una escala del 1 a 10. Para la magnitud se añade el signo '+' si el impacto es beneficio-so y el signo '-' si es perjudicial.

En la parte superior de cada casilla se sitúa el valor de $M$, magnitud del impacto, con valo-res que van de -10 (impacto negativo) $a+10$ (impacto positivo). Y en la parte inferior de la casilla, los valores de la, importancia ambiental, que a su vez también puede tomar valores entre $-10 y+10$. 


\section{Unidad Didáctica: Who wants fracking in town? 2015}

Una vez se ha completado la matriz, se puede realizar una valoración comparando los resultados obtenidos en ambos grupos de valores.

\section{b) Matrices acción/impacto.}

Son matrices en las que las acciones se sitúan de la misma forma que en las de causa efecto. Sin embargo, en lugar de situar los factores, se colocan directamente los impactos producidos por éstos.

- La valoración suele ser cualitativa, por lo que resultan más fáciles de elaborar para los no expertos. Los impactos se señalan en las cuadrículas con los signos: si, + ,0."

\section{Ordenación del territorio [38]}

“- Ordenar el territorio supone usarlo racionalmente, dedicando a la actividad más adecuada cada zona del mismo, es decir, destinando cada lugar para lo que es más apto. Mediante la Ordenación del Territorio se podrá seña-lar el lugar idóneo para trazar carreteras, organizar cultivos, construir viviendas o determinar aquellos lugares que sea necesario con-servar. Además sirve para elaborar mapas de riesgo.

- Su misión es de compatibilizar su uso con su conservación y mantenimiento- a largo plazo (desarrollo sostenible), evitando los posibles impactos y riesgos.

Ej: Una correcta Ordenación del Territorio ha de prohibir, por ejemplo, la edificación en zonas de riesgo de inundaciones o la tala de un bosque autóctono.

La ordenación territorial puede realizarse valorando su capacidad de acogida (capacidad de asimilación de los impactos por parte del entorno).

$1^{\circ}$ Se clasifican las zonas integrantes en unidades ambientales homogéneas con unas características unifor-mes (geológicas, topográficas, botánicas, de uso humano, referidas al paisaje, o especialmente vulnerables a determinados impactos) que la hagan más o menos apta para un determinado proyecto, o más o menos frágil ante un posible impacto.

2 - Una vez determinadas las unidades ambientales, se enfrentan, mediante una matriz de capacidad de acogida, a las actividades humanas previstas y se señala en cada cuadrícula el grado de acogida (vocacional, aceptable sin limitaciones, aceptable con autorización, aceptada tras una EIA y prohibida) de cada unidad del territorio para cada uno de sus distintos usos."

\section{Legislación ambiental internacional [39]}

"Su finalidad es plantear los principios generales que deben inspirar la actuaciones de los Estados y de la sociedad para lograr una mejor protección del ambiente. Destaca por su especial interés la Declaración de Río sobre el Medio Ambiente y el Desarrollo, aprobada por la Conferencia de las NNUU reunida en Río de Janeiro en 1992. En esta 


\section{Unidad Didáctica: Who wants fracking in town? 2015}

conferencia se consolida y se proclama a nivel internacional la idea de "desarrollo sostenible" y se aprobaron cuatro documentos:

- Declaración de Río sobre el Medio Ambiente y el Desarrollo

- Convención marco de las NNUU sobre el Cambio Climático

- Convenio sobre la Diversidad Biológica

- Agenda 21

\section{Convenios internacionales}

Los convenios internacionales tratan temas concretos que afectan a todos o a varios países. Hay muchísimos dedicados a temas medioambientales como:

- Convenio de Ramsar. Protege los humedales por su gran importancia como hábitats para las aves acuáticas.

- Convenio de Berna. Sobre la conservación de la fauna y de la flora salvajes y de sus hábitats naturales en Europa.

- Convenio de Bonn. Sobre la conservación de especies migratorias.

- Convenio de Washington (CITES). Sobre el comercio internacional de especies amenazadas de la flora y la fauna silvestres.

- Convenio de Ginebra. Sobre la contaminación atmosférica transfronteriza a gran distancia.

- Convenio de Viena. Sobre la protección de la capa de ozono.

- Convenio de Basilea. Sobre el control de los movimientos transfronterizos de los desechos peligrosos y su eliminación.

- Convenio de Río. Sobre la diversidad biológica

- Convención de NNUU contra la Desertificación (París, 1994)

- Convenio Marco de las NNUU sobre el Cambio Climático, Nueva York (1992); Cumbre de Kyoto, 1997,...

- Cumbre de Johannesburgo, 2002 Legislación de la Unión Europea

Los tres tipos más importantes de disposiciones comunitarias son los Reglamentos, las Decisiones y las Directivas.

Los Reglamentos y las Decisiones se aplican directamente en todos los países miembros, mientras que las Directivas son de obligado cumplimiento pero es cada uno de los países el que tiene que hacer sus leyes concretas para aplicarlas en su propio territorio. Las Directivas son el instrumento normativo más utilizado.

Hay varios cientos de normativas europeas sobre impacto ambiental, protección de la atmósfera, calidad de las aguas, regulación de vertidos, conservación de la naturaleza, gestión de residuos, etc. 


\section{Unidad Didáctica: Who wants fracking in town? 2015}

Programas Marco.- La forma en la que se ha organizado la política ambiental en Europa ha sido a través de Programas de cinco años de duración. El Primer Programa de Acción abarcó de 1973 a 1977 y se dedicó especialmente a la contaminación atmosférica y a la gestión de los recursos y del medio."

\section{Legislación ambiental en España [39]}

"Dentro de las normas y leyes españolas de interés ambiental destaca lo que se establece en el artículo 45 de la Constitución Española de 1978, que dice:

1‥ Todos tienen derecho a disfrutar de un medio ambiente adecuado para el desarrollo de la persona, así como el deber de conservarlo.

$2^{a}$. Los poderes públicos velarán por la utilización racional de todos los recursos naturales, con el fin de proteger y mejorar la calidad de vida y defender el medio ambiente, apoyándose en la indispensable solidaridad colectiva.

3a . Para quienes violen lo dispuesto en el apartado anterior, en los términos que la Ley fije, se establecen sanciones penales o, en su caso, administrativas, así como la obligación de reparar el daño causado.

El estado tiene competencia exclusiva en legislación básica sobre medio ambiente, pero se han ido concediendo competencias a las Comunidades Autónomas en muy diferentes materias. La finalidad de la normativa estatal es fijar un marco legal común para todas las Comunidades Autónomas que garantice el principio de igualdad entre los ciudadanos españoles.

Son muy numerosas las Leyes, Reglamentos y Órdenes ministeriales que regulan aspectos ambientales. De especial interés es la figura del "delito ecológico" introducida en el Código Penal por vez primera en 1983 para castigar con penas de arresto y multas a las personas responsable de daños ambientales. Competencias de las Comunidades

\section{Autónomas y los municipios}

Las Autonomías y los municipios son competentes en muchas cuestiones ambientales. Las Comunidades Autónomas dictan Leyes y Decretos Autonómicos y los municipios Ordenanzas Municipales que regulan cuestiones muy diversas en este campo." 


\section{Unidad Didáctica: Who wants fracking in town? 2015}

\section{ANEXO 12. Batería de preguntas}

\section{Environmental problems}

* What is climate change?

* How do greenhouse gases affect to global warming? and depletion of the ozone layer?

* Does climate change affect every country in the same way? Explain the differences between them.

* What is the main cause of climate change?

* If there were no human being, would there still be climate change? and the greenhouse effect?

* How does climate change affect the environment?

* How can climate change affect our everyday life?

* List and explain 5 consequences of climate change in human lives

* Can climate change be beneficial for some people groups?

* Which human activities are changing the climate?

* Is it possible to stop climate change?

* What does it means that "there is a depletion in the ozone layer"?

* Where is the depletion of the ozone layer? Can it affect people around the world?

* What are CFCs? Why are they banned in most developed countries?

* Is the depletion of the ozone layer problem already solved?

* How can we prevent ozone layer to deplete?

* Is depletion of the ozone layer related with some other environmental issue? How?

- Why is biodiversity important?

* What does it means that we are living the Sixth Extinction?

* Is global warming related with reduction of biodiversity? How?

- List 5 consequences of reduction of biodiversity for human beings

* How is the human being causing a reduction in biodiversity? 


\section{Unidad Didáctica: Who wants fracking in town? 2015}

Which are the main air pollutants?

Where does air pollutants come from?

What are the consequences of air pollution in human health?

How does air pollution affect the economy?

* Which of the following are source of pollution? Chemicals, waste, light, nutrients, magnetic fields, noise and nanoparticles.

* Is air pollution related with other environmental issues? Explain with which one a how.

* What is weathering?

Why might weathering be a problem?

List 3 process that pollute soils and underground water

* Explain how weathering and soil and underground water pollution affects human societies

- Is it safe to farm near an oil refinery, why?

* How does changes in the use of lands affects weathering?

How long can soil contamination last on time?

Can an earthquake have human causes?

- How can we prevent volcano and earthquake risk?

What are the natural cases of earthquakes and volcanos?

What kind of effect can volcanos have on other environmental issues?

\section{Cycle of matter}

What happens to $\mathrm{CO}_{2}$ after it is emitted into the atmosphere?

* What do plants eat? soil, water or air?

* Where is there more carbon? atmosphere, hydrosphere, geosphere or biosphere?

- What are the two main anthropogenic process that release carbon dioxide to the atmosphere? 


\section{Unidad Didáctica: Who wants fracking in town? 2015}

What is the main natural process that release carbon dioxide into the atmosphere?

Where is more oxygen in nature, atmosphere, biosphere or lithosphere?

* Describe the process of photolysis. How important is it in the whole oxygen cycle?

* In which way is photosynthesis the opposite to respiration on oxygen cycle?

* How do we name the process that makes oxygen come out from lithosphere? And the opposite one? Describe them.

* Is there a risk for living being to run out of oxygen? Why?

* What are the three main states of nitrogen in soil?

* Name the arrows: $\mathrm{N}_{2} \rightarrow \mathrm{NH}_{2}{ }^{+} \rightarrow \mathrm{NO}_{2}^{-} \rightarrow \mathrm{NO}_{3}^{-}$

What is the role of legumes in nitrogen cycle?

* There are few species of microorganisms able to fix atmospheric nitrogen into a more usable form such as ammonia. What would happen if they would become extinct?

* Name the main organic and inorganic forms of nitrogen in nature

How does the human being alter the nitrogen cycle?

* What is the main pool of phosphate in nature?

List three human based and two natural activities in the cycle of phosphate

Why is mining important in the phosphate cycle?

* Name and describe the two ways of deposition of sulphur and sulphate from atmosphere

- What is the role of microorganisms in sulfur cycle?

* What is acid precipitation? How does it affect to forest?

How do humans act on the sulfur cycle?

\section{Fracking}

* Describe the process of hydraulic fracturing

- What are the two process involved in fracking?

* Is fracking legal in Spain? And in Europe? 


\section{Unidad Didáctica: Who wants fracking in town? 2015}

* Is it allowed to do fracking in a National Park? Should it be?

* List and explain impacts of fracking on nature

* How good or bad is fracking for society?

- Where is it planned to be fracking in Spain?

* Tell what you know about the history of fracking

* How is fracking related to earthquakes?

* How does fracking affect to the global cycle of carbon?

* Who in Spain is FOR and AGAINST fracking?

\section{Sustainability}

* What is sustainability?

* Are economic growth and care of the environment compatible?

* How can sustainability help us to develop?

- What is the alternative to sustainable development?

- Who promotes sustainable development in theory and in facts?

\section{Environmental legislation, EIA and land management}

* What is an Environmental Impact Assessment?

* Are impacts on the environment always negative?

* List 5 projects which need an EIA to be taken

* Does every human activity have an impact on environment?

* Name and explain the different phases of an EIA

* Explain two different methods to develop an EIA

* What are the differences between an Leopold matrix and a action/impact matrix?

* What kind of activities should be allowed in protected areas?

- What is land management?

* How can we prevent an environmental risk by using a control risk map? 


\section{Unidad Didáctica: Who wants fracking in town? 2015}

* Can you name 3 main international environmental agreement?

* What is an Agenda 21?

* What does "polluter pays" (quien contamina paga) means?

* Explain the hierarchy between European and Spanish environmental legislation 
Unidad Didáctica: Who wants fracking in town? 2015

ANEXO 13. Matriz de evaluación del debate

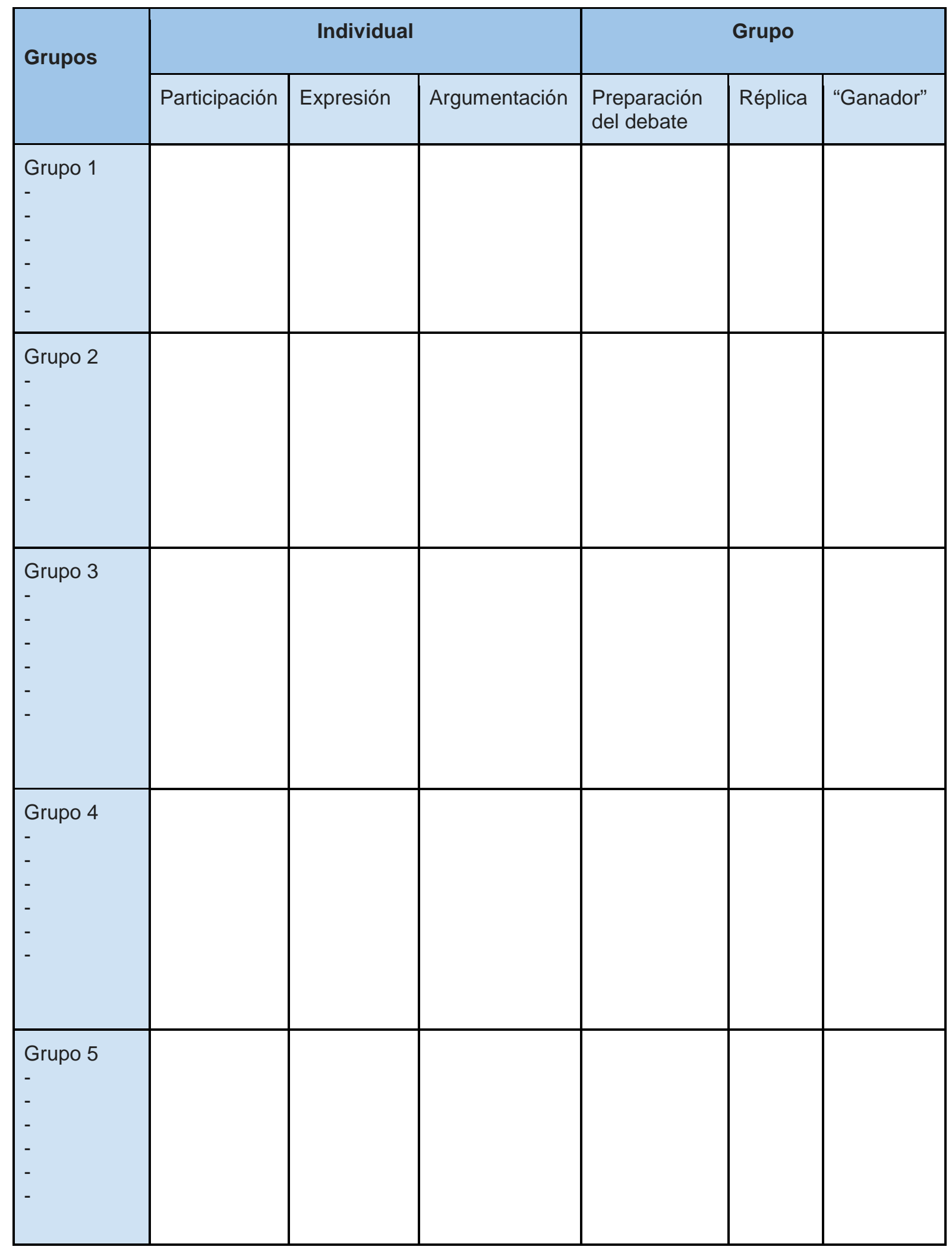

